\title{
A Versatile Method for the Preparation of Ferroelectric Supramolecular Materials via Radical End-Functionalization of Vinylidene Fluoride Oligomers
}

\author{
Miguel Garcia-Iglesias, Bas F. M. de Waal, Andrey V. Gorbunov, Anja R. A. Palmans, \\ Martijn Kemerink and E. W. Meijer
}

\section{Linköping University Post Print}

\section{Tweet}

N.B.: When citing this work, cite the original article.

Original Publication:

Miguel Garcia-Iglesias, Bas F. M. de Waal, Andrey V. Gorbunov, Anja R. A. Palmans, Martijn Kemerink and E. W. Meijer, A Versatile Method for the Preparation of Ferroelectric Supramolecular Materials via Radical End-Functionalization of Vinylidene Fluoride Oligomers, 2016, Journal of the American Chemical Society, (138), 19, 6217-6223.

http://dx.doi.org/10.1021/jacs.6b01908

Copyright: American Chemical Society

http://pubs.acs.org/

Postprint available at: Linköping University Electronic Press

http://urn.kb.se/resolve?urn=urn:nbn:se:liu:diva-129159 


\title{
A Versatile Method for the Preparation of Ferroelectric Supramolecu- lar Materials via Radical End-functionalization of Vinylidene Fluoride Oligomers
}

Miguel García-Iglesias, ${ }^{\dagger}$ Bas F. M. de Waal, ${ }^{\dagger}$ Andrey. V. Gorbunov, ${ }^{\S}$ Anja R. A. Palmans, ${ }^{\dagger}$ Martijn Kemerink, ${ }^{\S}$, and E. W. Meijer ${ }^{*, \dagger}$

${ }^{\dagger}$ Institute of Complex Molecular Systems, Laboratory of Macromolecular and Organic Chemistry, Eindhoven University of Technology, P.O. Box 513, 5600 MB, Eindhoven, The Netherlands.

$\S$ Department of Applied Physics, Eindhoven University of Technology, PO Box 513, 560o MB Eindhoven, The Netherlands.

${ }^{\ddagger}$ Complex Materials and Devices, Department of Physics, Chemistry and Biology (IFM), Linköping University, 58183 Linköping, Sweden.

KEYWORDS. Supramolecular ferroelectrics, Semiconductors, oVDF, radical reaction, semiconducting molecules.

\begin{abstract}
A synthetic method for the end-functionalization of vinylidene fluoride oligomers (OVDF) via a radical reaction between terminal olefins and OVDF-I is described. The method shows a wide substrate scope and excellent conversions, and permits the preparation of different disc-shaped cores such as benzene-1,3,5-tricarboxamides (BTAs), perylenes bisimide (PBI) and phthalocyanines $(\mathrm{Pc})$ bearing three to eight ferroelectric oligomers at their periphery. The formation, purity, OVDF conformation, and morphology of the final adducts has been assessed by a combination of techniques, such as NMR, size exclusion chromatography, (SEC), differential scanning calorimetry (DSC), polarized optical microscopy (POM) and atomic force microscopy (AFM). Finally, PBI-OVDF and Pc-OVDF materials show ferroelectric hysteresis behavior together with high remnant polarizations, with values of as high as $P_{r} \sim 37 \mathrm{mC} / \mathrm{m}^{2}$ for Pc-OVDF. This work demonstrates the potential of preparing a new set of ferroelectric materials by simply attaching OVDF oligomers to different small molecules. The use of carefully chosen small molecules paves the way to new functional materials in which ferroelectricity and electrical conductivity or light-harvesting properties coexist in a single compound.
\end{abstract}

\section{INTRODUCTION}

Ferroelectric and piezoelectric materials play a vital role in modern technologies ranging from capacitors, hydrophones and actuators to frequency-controlled devices. ${ }^{1}$ To further advance these technologies, access to cheaper and readily processable materials that show large ferroelectric and piezoelectric responses is highly desired. Organic materials are currently explored as they are potentially cheap, easily processable, biocompatible, and can be endowed with diverse and tunable functions. In addition, their mechanical flexibility is crucial for piezoelectric applications.

Since the discovery of the first organic ferroelectric material in $192 \mathrm{O}^{2}$ the observation of ferroelectric properties in organic materials has not been profuse. ${ }^{3}$ In fact, most of the organic ferroelectric research is focused on polyvinylidene fluoride (PVDF). 4 PVDF displays a large remnant polarization, a short switching time, and an excellent thermal sta- bility which makes it suitable for the fabrication of piezoelectric films. 5 The ferro- and piezoelectric properties of PVDF originate from the antiparallel intrachain arrangement of the alternated $\mathrm{CH}_{2}$ and $\mathrm{CF}_{2}$ segments in the zigzag all-anti conformation, the so-called $\beta$-form. ${ }^{6}$ However, untreated PVDF thin films processed from the melt or from solution are not ferroelectric. ${ }^{6 b}$ They possess a mixture of $\alpha, \beta$, and $\gamma$ conformations ${ }^{4}$ and additional steps, such as mechanical stretching,,$^{\mathrm{bb}}$ thermal annealing ${ }^{7}$ and electrical poling ${ }^{8}$ have to be performed in order to achieved the $\beta$ phase necessary to display ferro- and piezoelectric properties.

More recently, vinylidene fluoride oligomers (OVDF) and poly(vinylidene fluoride-trifluoroethylene $\mathrm{P}\left(\mathrm{VDF}-\mathrm{co}^{-}\right.$ TrFE), a copolymer based on PVDF, have been evaluated to enhance the formation of the $\beta$-phase. In OVDFs with a degree of polymerization (DP) smaller then 10, the ferroelectric $\beta$-form is spontaneously formed when processing the film from a solution of polar solvents. 9 
Scheme 1. Structure of the discotic molecules BTA-OVDF, PBI-OVDF and Pc-OVDF.
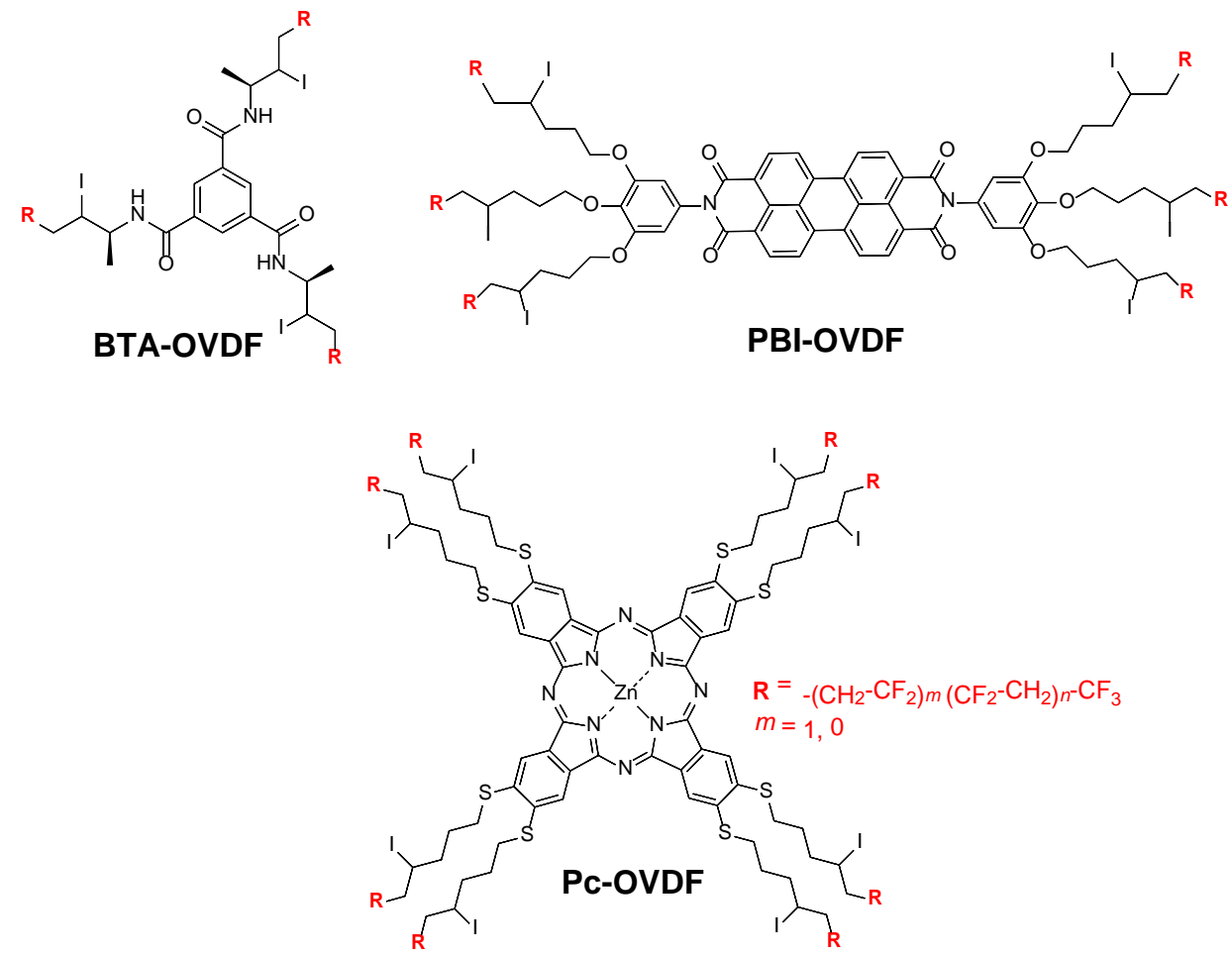

In contrast to polymers, OVDFs can be readily vapor deposited without decomposition of the material. ${ }^{10}$ In addition the ferroelectric properties are better than those reported for the polymers." Also in $\mathrm{P}(\mathrm{VDF}-\mathrm{co}-\mathrm{TrFE})$, the $\beta$-form arises spontaneously from solution. The presence of the PTrFE block induces an all-trans stereochemical conformation due to the steric hindrance from the additional fluorine atoms. ${ }^{6 a, 12}$

Due to the interesting properties of OVDF, inclusion complexes of OVDF with zeolites and cyclodextrins have been studied. ${ }^{13}$ However, to date the covalent coupling of OVDF with organic molecules has not been reported. Therefore, attaching oligomers of VDF covalently to small and well-defined molecules opens up many possibilities to induce ferroelectric and piezoelectric properties in different materials. In addition, the beneficial OVDF processing properties could be synthetically tuned with careful design of the small molecules. Moreover, the combination of ferroelectric properties with other properties such as semiconducting or light harvesting properties by blending the different components becomes accessible, which would represent a significant advantage in the field of non-volatile memory devices ${ }^{14}$ and solar cells. ${ }^{15}$ Recent progress combining semiconducting core molecules substituted at the periphery with appropriately flexible alkyl chains have resulted in unprecedented physical properties due to the rational design of the side chains which control the packing of the columnar aggregates and therefore the chargecarrier mobilities along them. ${ }^{16}$ Thus, the union of small light harvesting or semiconducting molecules with covalently attached OVDF could give rise to materials with improved optoelectronic properties due to the higher interfacial area and the absence of phase separation issues that are inherent to conventional blended systems where ferroelectric and semiconducting functionalities are introduced by different compounds.

Herein, we show the synthesis and characterization of covalently coupled OVDF to a variety of organic scaffolds; scaffolds that can order themselves into supramolecular morphologies. In order to achieve this, a radical addition of $\mathrm{CF}_{3}\left(\mathrm{CH}_{2} \mathrm{CF}_{2}\right)_{\mathrm{n}}\left(\mathrm{CF}_{2} \mathrm{CH}_{2}\right)_{\mathrm{m}} \mathrm{I}(\mathrm{m}=\mathrm{o}, 1$ and $\mathrm{n} \approx 6)$ I-OVDF to terminal olefins is introduced. This radical reaction allows the synthesis of three different central cores bearing three to eight OVDF oligomers at their periphery (Scheme 1). The central cores were selected to fulfill different aims. Benzene-1,3,5-tricarboxamides (BTAs) are known to exhibit ferroelectric properties due to the possibility to orient the amides forming a macrodipole. ${ }^{17}$ On the other hand, perylene bisimides (PBI) and phthalocyanines (Pc) were selected because they display high extinction coefficients ${ }^{18}$ and semiconducting properties. ${ }^{19}$ These characteristics, in combination with the ferroelectric properties arising from the OVDF side chains, can be used in the fabrication of future optoelectronic devices. A full characterization of the bulk and ferroelectric properties of these novel materials is presented.

\section{RESULTS AND DISCUSSION}

Synthesis and characterization. In order to circumvent the troublesome synthesis of the vinylidene fluoride oligomers, we selected $\mathrm{CF}_{3}\left(\mathrm{CH}_{2} \mathrm{CF}_{2}\right)_{\mathrm{n}}\left(\mathrm{CF}_{2} \mathrm{CH}_{2}\right)_{\mathrm{m}} \mathrm{I}(\mathrm{m}$ $=0,1$ and $n \approx 6)(I-O V D F)^{18 b}$, kindly provided by DAIKIN, and developed a method to couple these OVDF precursor to the scaffold selected (Scheme 1 ). The ${ }^{1} \mathrm{H}-\mathrm{NMR}$ spectrum of I-OVDF in deuterated acetone showed two 
Scheme 2. Synthetic method for the end-functionalization of oligo(vinylidene fluoride).

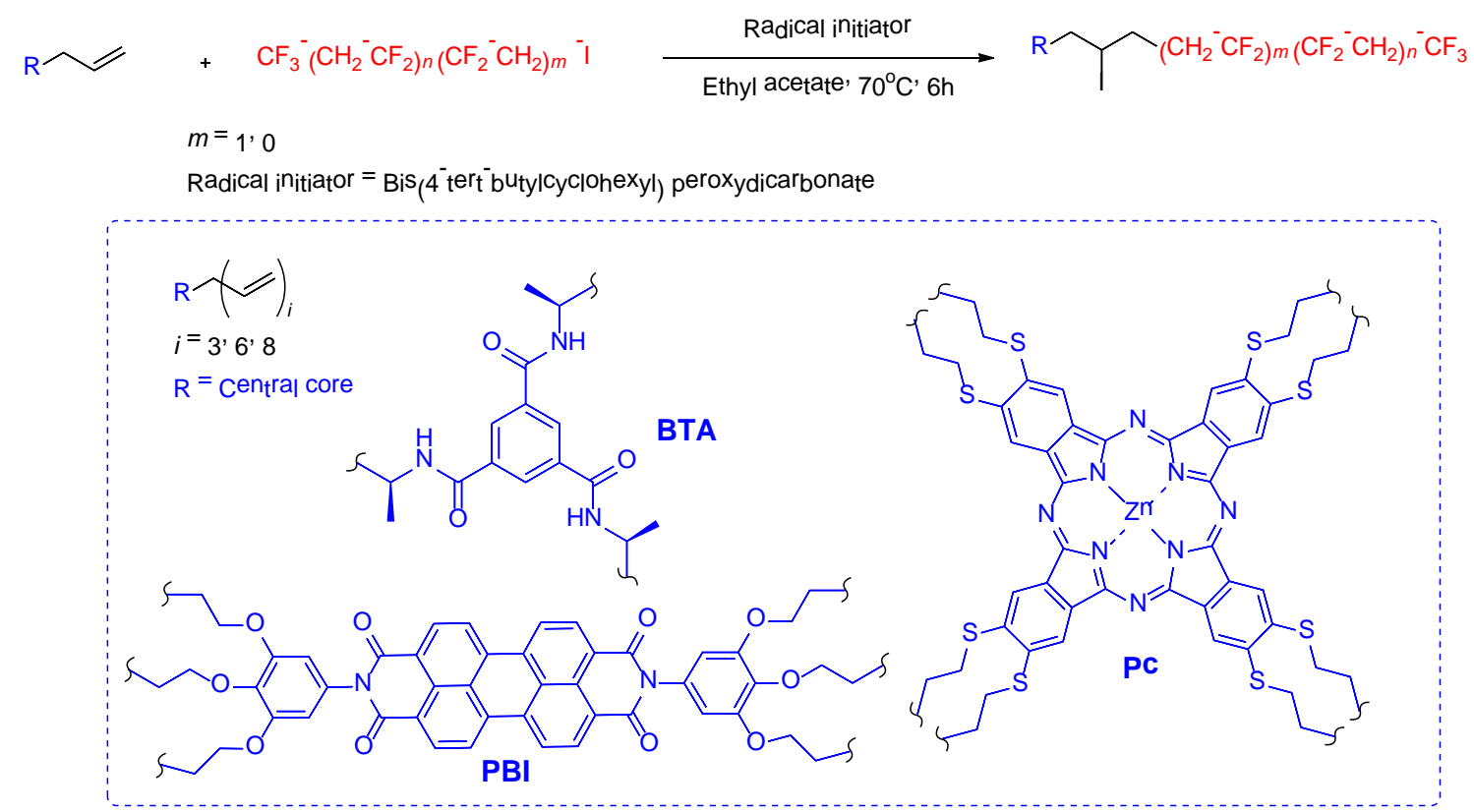

signals centered at 3.61 and $3.86 \mathrm{ppm}$ with a ratio of the signal intensities of 3:1. Those peaks were assigned to methylene protons of the terminal VDF unit carrying an iodine atom as end group attached to $-\mathrm{CH}_{2} \mathrm{CF}_{2} \mathrm{I}$ or to $\mathrm{CF}_{2} \mathrm{CH}_{2} \mathrm{I}$, respectively. In addition, the ${ }^{19} \mathrm{~F}-\mathrm{NMR}$ spectrum of I-OVDF showed a peak at $-38 \mathrm{ppm}$ corresponding to $\mathrm{CH}_{2} \mathrm{CF}_{2} \mathrm{I}$ and at -110 and $-115 \mathrm{ppm}$ corresponding to $-\mathrm{CF}_{2}-$ $\mathrm{CH}_{2} \mathrm{I}$ (see Figures $\mathrm{S}_{14}$ and $\mathrm{S}_{15}$ ). Hence, I-OVDF is a mixture of oligomers, in which the iodine is either coupled to a $\mathrm{CH}_{2}$ or a $\mathrm{CF}_{2}$ group. For reasons of clarity we depict it as $\mathbf{I}-$ OVDF.

A number of synthetic coupling strategies were evaluated. The nucleophilic substitution of the iodide for azides, previously described in the literature, ${ }^{20}$ was successful and proved to be specific for those oligomers with the iodine coupled to $\mathrm{CF}_{2}$ groups. However, the subsequent 1-3 dipolar addition of the azido-OVDF to alkynes failed. Alternatively, the procedure developed by Kitagawa ${ }^{21}$ to obtain terminal olefins from I-OVDF failed in the absence of zeolites. Other reactions such as fluoroalkylations of arylboronic acids with fluoroalkyl iodides were tested ${ }^{22}$ but only afforded undesired products.

After a full year of trying to use standard organic coupling strategies with a large variety of catalysts, we turned our attention to radical reactions. Radical iodine transfer polymerizations have been successfully used for the synthesis of I-OVDF and copolymers of PVDF. ${ }^{23}$ Therefore, we proceeded to couple I-OVDF to terminal olefins via a radical reaction. For this purpose, different radical initiators were tested using BTA as a model substrate. Applying bis (4-(tert-butyl)cyclohexyl) peroxydicarbonate as the radical source and ethyl acetate as the solvent afforded the desired product whereas other radical initiators did not result in coupling products (Scheme 2). This radical coupling proceeded in mild conditions; heating the mixture at $7 \mathrm{O}^{\circ} \mathrm{C}$ for $6 \mathrm{~h}$ sufficed to get full conversion.
After establishing the optimal conditions for the coupling reactions, I-OVDF was reacted with three desired central cores, BTA, PBI and Pc, substituted with three, six, and eight terminal olefins, respectively. In all cases, inspection of the ${ }^{1} \mathrm{H}$ - and ${ }^{19} \mathrm{~F}-\mathrm{NMR}$ spectra of the crude samples showed that the peaks corresponding to $\mathrm{CH}_{2} \mathrm{CF}_{2} \mathrm{I}$ and $\mathrm{CF}_{2} \mathrm{CH}_{2} \mathrm{I}$ disappeared after $6 \mathrm{~h}$ of radical addition. Moreover, the ${ }^{1} \mathrm{H}-\mathrm{NMR}$ spectra of the crudes also lacked the peaks corresponding to the terminal olefines, indicating their quantitative conversion. After purification by size exclusion chromatography (SEC), BTA-OVDF, PBI-OVDF and Pc-OVDF were obtained and fully characterized by ${ }^{1} \mathrm{H}-$ NMR, ${ }^{19}$ F-NMR, SEC, matrix-assisted laser desorption/ionization) (MALDI-ToF-MS) and UV-spectroscopy.

The ${ }^{1} \mathrm{H}-\mathrm{NMR}$ spectrum of purified BTA-OVDF showed Ar- $\mathrm{H}$ and $\mathrm{NH}$ resonances at different positions, indicating a loss of symmetry due to the presence of differently terminated chains coupled to the aromatic core. Additionally, the spectra also showed different peaks between 5.2 and 4.5 ppm corresponding to the protons next to the iodide (see Figure $\mathrm{S}_{17}$ ). The ${ }^{1} \mathrm{H}-\mathrm{NMR}$ spectra of PBI-OVDF and PcOVDF showed broader signals, indicative for a high degree of aggregation, which is most likely caused by interactions between aromatic cores (see Figures S2O and S24).

SEC traces measured in THF of both the starting material (I-OVDF) and the final products confirmed the findings of NMR. The starting material showed a number-averaged molecular weight $\left(M_{\mathrm{n}}\right)$ of $522 \mathrm{~g} / \mathrm{mol}$, in line with that expected for $\mathrm{CF}_{3}\left(\mathrm{CH}_{2} \mathrm{CF}_{2}\right)_{\mathrm{n}} \mathrm{I}(\mathrm{n} \approx 6)$, and a molar-mass dispersity $(\nexists)$ of 1.37. The SEC traces of the final products, BTA-OVDF, PBI-OVDF, showed significantly lower retention times indicating higher molecular weights, and no peak at the retention time corresponding to I-OVDF. The values for $M_{\mathrm{n}}$ are all in the expected range, between 2.4 $\mathrm{kDa}$ and $7.5 \mathrm{kDa}$ for 3 to 8 times substituted cores, and the molar-mass dispersities are even lower than the dispersity 
shown by the starting oligomer mixture, see Figure 1 and Table 1.

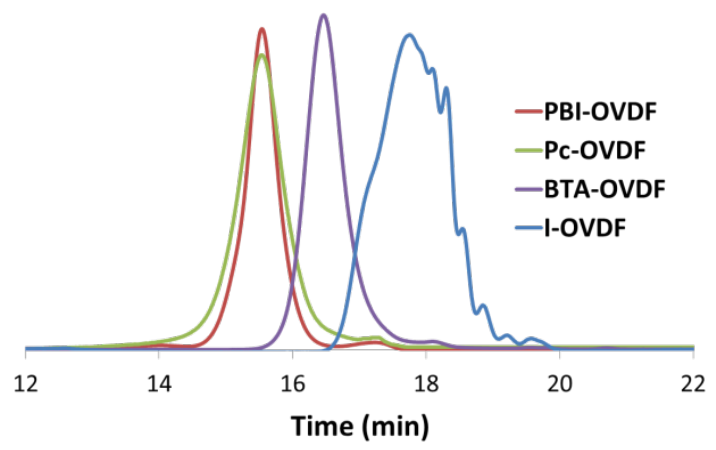

Figure 1. Size-exclusion chromatogram equipped with a PDA detector for OVDF-I, BTA-OVDF, PBI-OVDF and Pc-OVDF using THF as eluent.

Table 1. Molecular weight and dispersity for OVDF-I, BTA-OVDF, PBI-OVDF and Pc-OVDF determined by GPC using THF as eluent. SEC calibrated with narrow dispersity polystyrene standards\#.

\begin{tabular}{|c|c|c|c|}
\hline Product & $\boldsymbol{M}_{\mathbf{n}}$ & $\boldsymbol{M}_{\mathbf{w}}$ & $\boldsymbol{Ð}$ \\
& {$[\mathbf{g} / \mathbf{m o l}]$} & {$[\mathbf{g} / \mathbf{m o l}]$} & {$[-]$} \\
\hline I-OVDF & 522 & 718 & 1.37 \\
\hline BTA-OVDF & 2412 & 2876 & 1.19 \\
\hline PBI-OVDF & 6525 & 7097 & 1.09 \\
\hline Pc-OVDF & 7557 & 9253 & 1.18 \\
\hline
\end{tabular}

Whereas SEC and NMR confirmed the attachment of the OVDF chains to the different scaffolds, it remained unclear if the iodine was still present after work-up. Thus, all final products were analyzed by MALDI-TOF-MS. BTA-OVDF showed a relatively broad molecular weight distribution corresponding to the molecular weight distribution expected for the final compound due to the use of an oligomer mixture $(Ð=1.37)$. Next to the $[\mathrm{M}]^{+}$peaks within the spectrum, a second distribution was observed corresponding to $\left[\mathrm{M}-\mathrm{NH}_{4}\right]^{+}$peaks, see Figure 2 . Analysis of the masses showed that the molecular weights observed for BTAOVDF correspond with the final molecule bearing 3 iodine atoms.

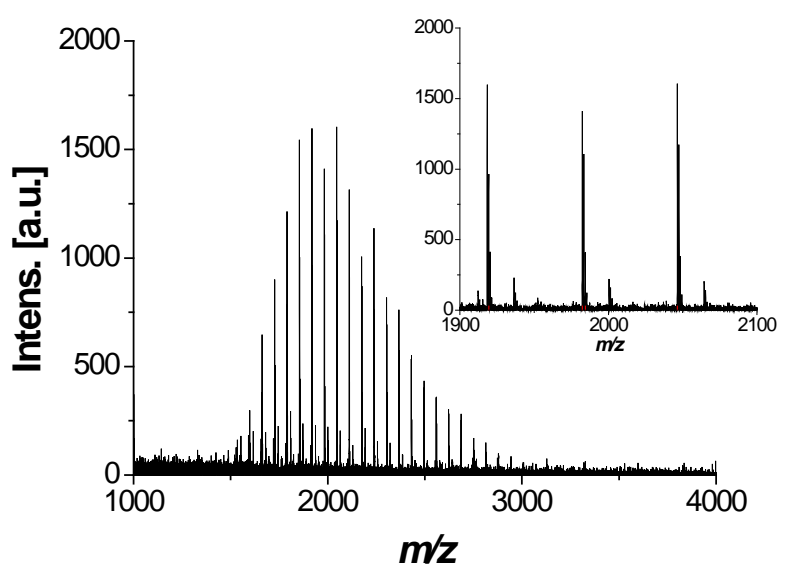

Figure 2. MALDI-TOF-MS spectrum of BTA-OVDF.

The MALDI-TOF spectra of PBI-OVDF and Pc-OVDF showed broader and less defined distributions, caused by the higher number of OVDF chains located at the periphery of the molecules. However, the molecular weight distribution in both cases was consistent with the results found by SEC (see Figures S22 and S26).

Finally, the characteristic absorption of the PBI and Pc chromophores, located around 485 and $520 \mathrm{~nm}$, and 470 and $700 \mathrm{~nm}$, respectively, were observed by UVspectroscopy for the final compounds PBI-OVDF and PcOVDF. Both compounds showed hypsochromic shifts when compared with their precursors, indicative for the formation of $\mathrm{H}$-aggregates in THF. Additionally, compounds PBI-OVDF and Pc-OVDF showed a strong absorbance at shorter wavelengths due to the presence of the OVDF tails, which confirmed the covalent attachment of the OVDF side chains. (see S28 and S29). In summary, by a combination of different analytical techniques, we demonstrate that the radical coupling between terminal olefins and OVDF-I is an effective synthetic tool and results in three new star-shaped molecules that are designed to have morphologies for potential ferroelectric properties.

Thermal behavior, OVDF conformation and morphology of the materials. The thermal behavior and the different conformations of the OVDF of the starting material and the final products were evaluated by differential scanning calorimetry (DSC), polarized optical microscopy (POM) and infrared (IR) spectroscopy. Moreover, the morphology of the drop-casted materials has been studied by atomic force microscopy (AFM).

The starting material I-OVDF showed a melting peak around $120^{\circ} \mathrm{C}$ with a shoulder at $102{ }^{\circ} \mathrm{C}$, probably the result of lower molecular weight fractions. ${ }^{9}$ During cooling, a crystallization peak appeared at $74^{\circ} \mathrm{C}$. The BTAOVDF, PBI-OVDF and Pc-OVDF DSC traces did not show shoulders in the melting peaks. They all showed transitions at higher temperatures in the heating and cooling run compared to I-OVDF, although there is not a clear trend upon increasing the number of OVDF chains per molecule (see Table 2 and Figures S16, S19, S23 and S27). 
Table 2 Transition temperatures $\left[{ }^{\circ} \mathrm{C}\right]$ and corresponding enthalpies $(\mathrm{J} / \mathrm{g})$ of I-OVDF, BTA-OVDF, PBI-OVDF and Pc-OVDF obtained by DSC measurements. ${ }^{[a]}$

\begin{tabular}{|c|c|c|}
\hline Product & $T_{\mathbf{1}}\left(\Delta H_{1}\right)^{[\mathbf{b}]}$ & $T_{\mathbf{2}}\left(\Delta H_{2}\right)$ \\
\hline I-OVDF & $102.0(5)$ & $74.5(37)$ \\
& $122.2(23)$ & \\
\hline BTA-OVDF & $124.2(27)$ & $92.7(35)$ \\
\hline PBI-OVDF & $126.4(18)$ & $112(20)$ \\
\hline Pc-OVDF & $129(25)$ & $110(26)$ \\
\hline
\end{tabular}

[a] All the DSC data were collected during the second heating and cooling run. $[\mathrm{b}] \mathrm{T}_{1}$ is the transition temperature measured during heating; [c] T2 is the transition temperature measured during cooling. The cooling and heating rate was $2 \mathrm{~K} \mathrm{~min}^{-1}$.

The thermal behavior of the I-OVDF, BTA-OVDF, PBIOVDF and Pc-OVDF was further investigated using Polarizing Optical Microscope. Under crossed polarizers OVDFI, BTA-OVDF and PBI-OVDF showed birefringent textures after slow cooling from the isotropic melt at a rate of $2^{\circ} \mathrm{C} / \mathrm{min}$. Slow cooling induced the growth of a pseudo-focal conic texture, typical for a columnar mesophase, for BTA-OVDF and PBI-OVDF indicating long range order, while I-OVDF showed a less ordered texture (see Figure S30). Pc-OVDF did not show any birefringence under cross polarizers upon cooling, indicating the formation of an amorphous material.

IR spectroscopy is a sensitive technique to assess the presence the different conformations of PVDF in the solid state. PVDF films show strong absorption bands at 1290, 1190,880 , and $84 \mathrm{o} \mathrm{cm}^{-1}$ when the ferroelectric $\beta$-phase is present. ${ }^{6,24}$ I-OVDF, BTA-OVDF, PBI-OVDF and PcOVDF were analyzed by IR in order to elucidate the conformation of the OVDF within the materials. Drop-casted samples from a solution of THF of I-OVDF and BTAOVDF showed the characteristic vibrations of the all-trans conformation $\left(1270,1190,880\right.$ and $\left.840 \mathrm{~cm}^{-1}\right)$ at room temperature. When cooling slowly from the isotropic melt, IOVDF retains mostly the $\beta$-conformation together with the $\gamma$ conformation $\left(1230 \mathrm{~cm}^{-1}\right)$. In contrast, BTA-OVDF evolves to the formation of the non-ferroelectric $\alpha$ form $\left(1403,1204,1183,975,874,794,760\right.$ and $614 \mathrm{~cm}^{-1}$ ) (see $S_{32}$ ). However, the formation of the, presumably aligned, $\beta$-form could be achieved by slow cooling in the presence of an electrical field (8o $\mathrm{V} / \mu \mathrm{m}$, Figure 3$)$. For this purpose, we used commercial glass LC cells with a constant cell spacing of $5 \mu \mathrm{m}$ between ITO (indium tin oxide) transparent electrodes. Changes within the morphology of the BTA-OVDF liquid crystal were observed by POM by comparing the regions in which the electric field was applied with regions in which it was not (see $\mathrm{S}_{31}$ ). Such changes are presumably deriving from the evolution from the non-ferroelectric $\alpha$ form to the $\beta$-conformation and the alignment of the last one when applying an electrical field, which is in good agreement with the IR experiments.

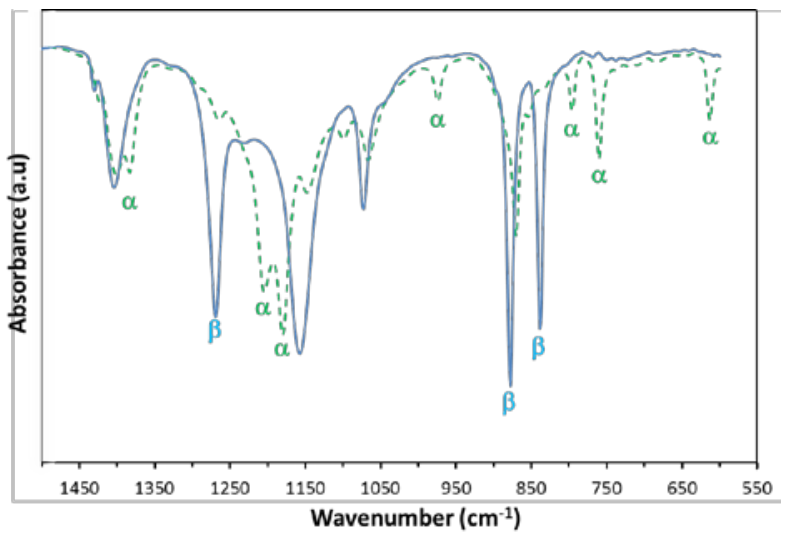

Figure 3. IR spectra of BTA-OVDF before (dashed line) and after (solid line) applying an electrical field of $(8 \mathrm{o} / \mu \mathrm{m})$ in a liquid crystal cell.

The conformation of PBI-OVDF and Pc-OVDF sidechains was also analyzed by IR. In both cases, the presence of the $\pi$-extended cores gave rise to a more amorphous conformation of the OVDF chains, observing overlapping of the OVDF peaks with the core-derived peaks as concluded from the comparison of individual IR spectra. A small increase of the $\beta$-form was observed when cooling slowly from the isotropic melt, obtaining the highest $\beta$ conformation ratio for PBI-OVDF and Pc-OVDF when applying an electrical field $(8 \mathrm{o} \mathrm{V} / \mu \mathrm{m})$ while heating the materials to $90^{\circ} \mathrm{C}$ (see $\mathrm{S}_{33}$ and $\mathrm{S}_{34}$ ). X-ray Diffraction (XRD) experiments have been carried out on unpoled samples given the difficulties on analyzing the samples after poling them between gold electrodes to achieve the highest ordered morphology. However undefined morphology of the compounds Pc-OVDF and Pc-PDI were achieved (see S35). The conformation of the OVDF was observed for BTA-OVDF, changing from $\alpha$ to $\beta$ after applying an electrical field of $1 \mathrm{KV}$ for $2 \mathrm{~h}$ using a corona poling device(see $S_{3} 6$ ).

(a)
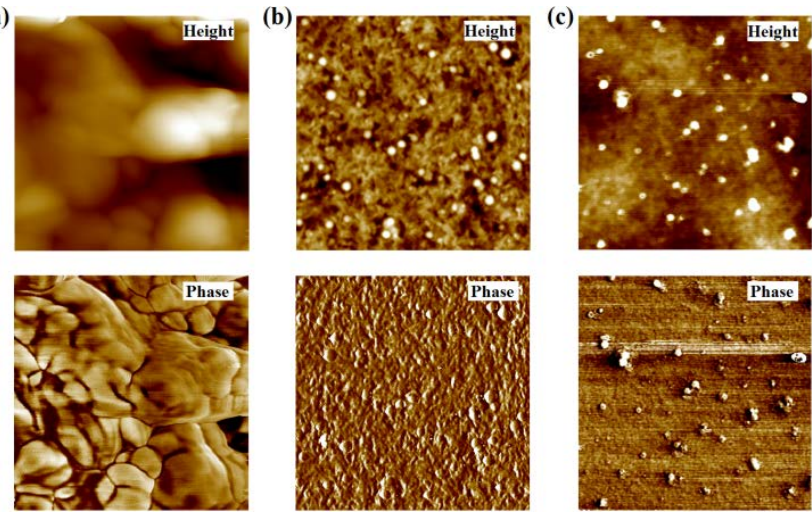

Figure 4. Atomic force microscopy (AFM) topographical images (height and phase) of drop-casted samples (20 $\mathrm{mg} / \mathrm{ml}$ in $\mathrm{CHCl}_{3}$ ) on a glass substrate after annealing at $70^{\circ} \mathrm{C}$ for complete solvent evaporation: a) BTA-OVDF $\left(0.385 \times 0.385 \mu^{2}\right)$, Total vertical scales $-150 \mathrm{~nm}$ and $47^{\circ}$ phase degrees. b) PBI-OVDF $(5 \times$ 
$\left.5 \mu^{2}\right)$, Total vertical scales $-50 \mathrm{~nm}$ and $44^{\circ}$ phase degrees. c) Pc-OVDF $\left(5 \times 5 \mu^{2}\right)$, Total vertical scales $-25 \mathrm{~nm}$ and $10^{\circ}$ phase degrees

Finally, morphological studies of the drop-casted materials were performed by AFM (Figure 4). BTA-OVDF showed a very rough surface topology consisting of large domains. In contrast, PBI-OVDF and Pc-OVDF films displayed completely different morphologies. Both materials produced rather smooth films, on top of which domainlike structures with sizes in the range of hundreds of $\mathrm{nm}$ can be observed. These domains are probably due to the formation of aggregates by $\pi-\pi$ stacking of the aromatic perylene and phthalocyanine cores in the presence of the OVDF matrix. ${ }^{25}$ and to their low solubility at relatively high concentrations. ${ }^{26}$ Due to the extreme roughness and the sticky nature of the BTA-OVDF material it was technically not feasible to reliably scan larger areas than few hundred $\mathrm{nm}$. However, even on small areas we observed a very high surface roughness in comparison to the other materials. In summary, the morphology of the materials and the conformation of the OVDF of BTA-OVDF, PBI-OVDF and PcOVDF within the materials has been analyzed by different techniques. The formation of the highest fraction of $\beta$-conformation has been observed after applying an electrical field at elevated temperatures, followed by slow cooling. Moreover, PBI-OVDF and Pc-OVDF show a tendency to form aggregates in the solid state which is in agreement with the ${ }^{1} \mathrm{H}$-NMR and UV-spectroscopy data obtained in solution as described above.

Electrical switching properties. The ferroelectric switching properties of our systems were assessed on metal-ferroelectric-metal (M-F-M) capacitor structures using gold electrodes on a glass substrate. The functional organic films were prepared by drop-casting from a chloroform solution. The active layer thickness ranged from 1 to $4 \mu \mathrm{m}$. All materials were first heated while applying an external electric field $(25 \mathrm{~V} / \mu \mathrm{m})$. Slow modulation of the electric field was found to improve the uniform alignment of the macro-dipoles perpendicular to the gold electrodes. ${ }^{27}$

The actual ferroelectric switching experiments were performed on pre-aligned devices. Polarization vs. applied field (P-E) hysteresis loops were obtained by the doublewave method (DWM, see SI), ${ }^{28}$ which allows to suppress the effects of (non-hysteretic) conduction currents from the (hysteretic) displacement current. The latter is integrated vs. applied field to obtain the quasi-static polarization shown in Figure 5. (a)

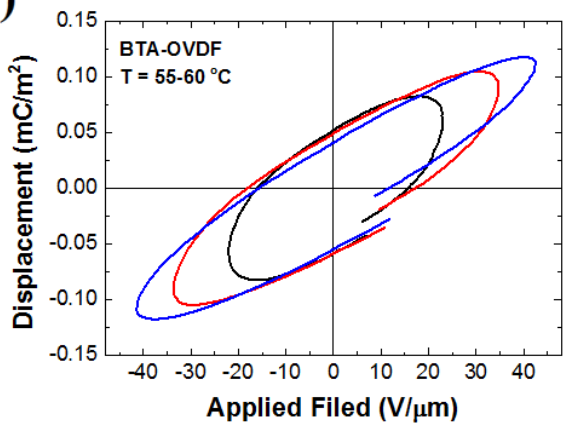

(b)

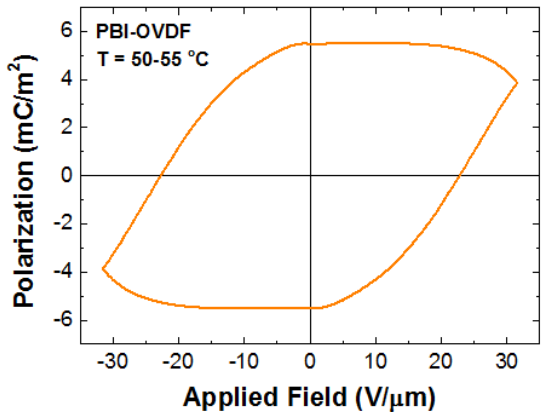

(c)

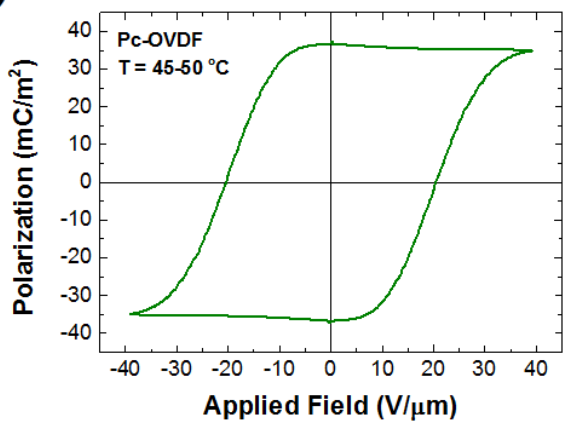

Figure 5. Electrical switching behavior in of OVDF-based supramolecular systems: a) Typical series of displacement vs. field $(D-E)$ loops obtained on BTA-OVDF at 50-60 ${ }^{\circ} \mathrm{C}$; Saturated ferroelectric polarization vs. field (P-E) loops obtained at $f=1 \mathrm{~Hz}$ on b) PBI-OVDF at $50-55^{\circ} \mathrm{C}$ and c) Pc-OVDF at $45-50^{\circ} \mathrm{C}$.

Despite showing the highest degree of ferroelectric $\beta$ conformation of all materials investigated here, BTAOVDF only showed paraelectric properties (Fig. 5a). The absence of ferroelectric switching may be related to steric hindrance in the densely packed aggregates of BTA-OVDF or to the rough morphology that may suppress effective switching. ${ }^{29}$ This lack of ferroelectric behavior is the more surprising, since both a BTA with alkyl sidechains and the I-ODVF itself show ferroelectricity, but the combination of both is a highly dielectric material.

Ferroelectric hysteresis behavior has been found for PBIOVDF and Pc-OVDF devices, which showed concave P-E curves, indicative of polar switching (Figures $5 \mathrm{~b}, \mathrm{c}$ ). The coercive field $\left(E_{C}\right)$ and remnant polarization $\left(P_{r}\right)$ for saturated polarization of PBI-OVDF and Pc-OVDF were obtained from the quasi-static ferroelectric hysteresis behavior at 50-55 ${ }^{\circ} \mathrm{C} .3^{\circ} \mathrm{PBI}-\mathrm{OVDF}$ displayed $E_{C} \sim 23 \mathrm{~V} / \mu \mathrm{m}$ and $P_{r}$ $\sim 4 \mathrm{mC} / \mathrm{m}^{2}$, which are respectable values for a supramolecular organic ferroelectric. ${ }^{3 \mathrm{~d}}$ Nevertheless, the hysteresis 
loops show convex regions which is typical for a lossy dielectric and composite ferroelectric materials exhibiting conductance. ${ }^{31}$ This current leakage is likely to result from Ohmic conduction through the semiconducting perylene cores. At the same time, the low crystallinity of the polar units might affect the shape of the hysteresis loop. ${ }^{32}$ In addition, slowly responding ionic species can contribute to the non-ideal shape of the P-E curves. Finally, Pc-OVDFbased devices show nearly ideal hysteresis behavior, exhibiting a remarkably high remnant polarization $\left(P_{r} \sim 37\right.$ $\left.\mathrm{mC} / \mathrm{m}^{2}\right)$ at a similar coercive field $\left(E_{C} \sim 20.5 \mathrm{~V} / \mu \mathrm{m}\right)$. For comparison, properly treated pure OVDF films give $P_{r} \sim 90$ $\mathrm{mC} / \mathrm{m}^{2} 33$ but at a more than two times higher coercive field $E_{C}$. These differences might be a logical consequence of weaker dipole-dipole interaction in the present "diluted" OVDF-containing materials. The significant difference in remnant polarization between Pc-OVDF and PBI-OVDF can tentatively be explained by differences in the OVDF weight percentage per molecule and the amount of $\beta$ phase conformation. Therefore, we can tentatively conclude that the percentage of $\beta$-phase achieved, the crystallinity and the dipole density are affecting the ferroelectric response of the materials. These influences were investigated in detail on PVDF, ${ }^{34}$ for which also a reduction of the ferroelectric response as a result of adding a non-ferroelectric phase to the ferroelectric matrix has been observed. 35

\section{CONCLUSIONS}

A synthetic method for the end-functionalization of OVDF has been developed, allowing the synthesis of three disc-shaped molecules substituted at the periphery with three, six and eight oligomers of the well-known ferroelectric oligomer. The desired compounds were obtained in good yields via a radical reaction between terminal olefins and OVDF-I. The formation and purity of the final adducts has been confirmed by a combination of analytical techniques. The thermal behavior and the morphology of the materials have been also assessed. The conformation of the OVDF sidechains of BTA-OVDF, PBI-OVDF and PcOVDF within the materials has been analyzed by IR, observing, in all cases, the highest fraction of $\beta$-conformation after applying an electrical field at elevated temperatures, followed by slow cooling. For both PBI-OVDF and PcOVDF ferroelectric hysteresis behavior was observed, with appreciable remnant polarization, especially for Pc-OVDF. Despite the formation of a dominant $\beta$-phase, BTA-OVDF did not show any ferroelectric behavior.

The reported examples demonstrate the possibility to prepare a new class of ferroelectric materials by attaching OVDF oligomers to different small semiconducting molecules. Combining two orthogonal properties, such as ferroelectricity and electrical conductivity, in a single compound can give rise to new and unprecedented functional materials. Studies using these materials into non-volatile memory devices are published elsewhere. ${ }^{6}$

\section{ASSOCIATED CONTENT}

Supporting Information.
The supporting information contains all of the synthetic details and molecular characterization as well as the device manufacturing and the details of the ferroelectric measurements. It is available free of charge on the ACS Publication website at DOI:

\section{AUTHOR INFORMATION}

\section{Corresponding Author}

E.W.Meijer@tue.nl

\section{ACKNOWLEDGMENT}

We like to thank Thomas Gonzalez (MRL-UCSB) for synthetic support and Stefan Meskers for stimulating discussions. The work was financed by the Dutch Polymer Institute (DPI \# 765), the Dutch Ministry of Education, Culture and Science (Gravity program 024.001.035), the European Research Council (FP7/2007-2013, ERC Grant Agreement 246829).

\section{REFERENCES}

(1) Scott, J. F. Sci. 2007, 315, 954-959.

(2) Valasek, J. Phys. Rev. 1921, 17, 475-481.

(3) (a) Horiuchi, S.; Tokura, Y. Nat Mater 2008, 7, 357-366. (b) Horiuchi, S.; Tokunaga, Y.; Giovannetti, G.; Picozzi, S.; Itoh, H.; Shimano, R.; Kumai, R.; Tokura, Y. Nature 2o10, 463, 789-792. (c) Tayi, A. S.; Shveyd, A. K.; Sue, A. C.-H.; Szarko, J. M.; Rolczynski, B. S.; Cao, D.; Kennedy, T. J.; Sarjeant, A. A.; Stern, C. L.; Paxton, W. F.; Wu, W.; Dey, S. K.; Fahrenbach, A. C.; Guest, J. R.; Mohseni, H.; Chen, L. X.; Wang, K. L.; Stoddart, J. F.; Stupp, S. I. Nature 2012, 488, 485-489.(d) Tayi, A. S.; Kaeser, A.; Matsumoto, M.; Aida, T.; Stupp, S. I. Nat. Chem 2015, 7, 281-294.

(4) Lovinger, A. J. Sci. 1983, 220 , 1115-1121.

(5) (a) Kawai, H. Jpn. J. Appl. Phys. 1969, 8, 975-976. (b) Calvert, P. Nature 1975, 256, 694.

(6) (a) Furukawa, T. Phase Transitions 1989, 18, 143-211. (b) Kepler, R. G.; Anderson, R. A. Adv. Phys. 1992, 41, 1-57. (c) Dubois, J.-C. Adv. Mater. 1996, 8, 542.

(7) El Mohajir, B.-E.; Heymans, N. Polymer 20o1, 42, 56615667 .

(8) (a) Wegener, M.; Gerhard-Multhaupt, R. IEEE Trans. 2oo3, 50, 921-931. (b) Arlt, K.; Wegener, M. IEEE Trans. 2010, 17, $1178-1184$.

(9) (b)Umemoto, S.; Kikutani, T.; Okui, N. Polym. J. 1998, зо, 659-663. (b) Herman; Uno, T.; Kubono, A.; Umemoto, S.; Kikutani, T.; Okui, N. Polymer 1997, 38, 1677-1683.

(10) Noda, K.; Ishida, K.; Kubono, A.; Horiuchi, T.; Yamada, H.; Matsushige, K. J. Appl. Phys. 2003, 93, 2866-2870.

(11) (a) Noda, K.; Ishida, K.; Kubono, A.; Horiuchi, T.; Yamada, H.; Matsushige, K. Japanese J. Appl. Physics, Part 1 200o, 39, 6358-6363. (b)Matsumoto, A.; Horie, S.; Yamada, H.; Matsushige, K.; Kuwajima, S.; Ishida, K. Appl. Phys. Lett. 2007, 90, 202906-202909.

(12) Kodama, H.; Takahashi, Y.; Furukawa, T. Ferroelectrics 1997, 203, 433-455.

(13) (a) Yanai, N.; Uemura, T.; Kosaka, W.; Matsuda, R.; Kodani, T.; Koh, M.; Kanemura, T.; Kitagawa, S. Dalton Trans. 2012, 41, 4195-4198. (b) Boschin, F.; Blanchemain, N.; Bria, M.; Delcourt-Debruyne, E.; Morcellet, M.; Hildebrand, H. F.; Martel, B. J. Biomed. Mater. Res. A 2006 , $79 A, 78-85$.

(14) (a) Asadi, K.; de Leeuw, D. M.; de Boer, B.; Blom, P. W. M. Nat. Mater. 20o8, 7, 547-550. (b) Naber, R. C. G.; Asadi, K.; 
Blom, P. W. M.; de Leeuw, D. M.; de Boer, B. Adv. Mater. 2010, 22, 933-945. (c) Fabiano, S.; Usta, H.; Forchheimer, R.; Crispin, X.; Facchetti, A.; Berggren, M. Adv. Mater. 2014, 26, 74387443 .

(15) (a) Choi, T.; Lee, S.; Choi, Y. J.; Kiryukhin, V.; Cheong, S.W. Sci. 2009, 324, 63-66. (b) Yuan, Y.; Reece, T. J.; Sharma, P.; Poddar, S.; Ducharme, S.; Gruverman, A.; Yang, Y.; Huang, J. Nat Mater 2011, 10, 296-302. (c) Yuan, Y.; Reece, T. J.; Sharma, P.; Poddar, S.; Ducharme, S.; Gruverman, A.; Yang, Y.; Huang, J. Nat. Mater. 2011, 10, 296-302. (d) Yuan, Y.; Xiao, Z.; Yang, B.; Huang, J. J. Mater. Chem. A 2014, 2, 6027-6041.

(16) (a) Feng, X.; Marcon, V.; Pisula, W.; Hansen, M. R.; Kirkpatrick, J.; Grozema, F.; Andrienko, D.; Kremer, K.; Müllen, K. Nat Mater 2009, 8, 421-426. (b) Pisula, W.; Feng, X.; Müllen, K. Adv. Mater. 2010, 22, 3634-3649.

(17) (a) Sugita, A.; Suzuki, K.; Tasaka, S. Chem. Phys. Lett. 2004, 396, 131-135. (b) Fitié, C. F. C.; Roelofs, W. S. C.; Kemerink, M.; Sijbesma, R. P. J. Am. Chem. Soc. 2010, 132, 6892-6893. (c) Fitié, C. F. C.; Roelofs, W. S. C.; Magusin, P. C. M. M.; Wübbenhorst, M.; Kemerink, M.; Sijbesma, R. P. J. Phys. Chem. B 2012, 116, 3928-3937.

(18) (a) Gsänger, M.; Oh, J. H.; Könemann, M.; Höffken, H. W.; Krause, A.-M.; Bao, Z.; Würthner, F. Angew. Chem. Int. Ed. 2010, 122, 752-755. (b) Chen, Z.; Baumeister, U.; Tschierske, C.; Würthner, F. Chem. - A Eur. J. 2007, 13, 450-465. (c) Claessens, C.; Blau, W.; Cook, M.; Hanack, M.; Nolte, R. M.; Torres, T.; Wöhrle, D. In Molecular Materials and Functional Polymers SE - 1; Blau, W.; Lianos, P.; Schubert, U., Eds.; Springer Vienna, 2001; pp. 3-11.

(19) Elemans, J. A. A. W.; van Hameren, R.; Nolte, R. J. M.; Rowan, A. E. Adv. Mater. 20o6, 18, 1251-1266. Semiconducting properties of perylenes bisimides: (a) Zhang, M.-X.; Zhao, G.-J. ChemSusChem 2o12, 5, 879-887. (b) Jones, B. A.; Ahrens, M. J.; Yoon, M.-H.; Facchetti, A.; Marks, T. J.; Wasielewski, M. R. Angew. Chemie Int. Ed. 2004, 43, 63636366. (c) Malenfant, P. R. L.; Dimitrakopoulos, C. D.; Gelorme, J. D.; Kosbar, L. L.; Graham, T. O.; Curioni, A.; Andreoni, W. Appl. Phys. Lett. 2002, 8o, 2517-2519. Semiconducting properties of phthalocyanines: (a) Eley. D. D. Nature 1948, 162, 819. (b) Claessens, C. G.; Hahn, U.; Torres, T. Chem. Rec. 20o8, 8, 75-97.

(20) Vukićević, R.; Hierzenberger, P.; Hild, S.; Beuermann, S. J. Polym. Sci. Part A Polym. Chem. 2010, 48, 4847-4854.

(21) Yanai, N.; Uemura, T.; Uchida, N.; Bracco, S.; Comotti, A.; Sozzani, P.; Kodani, T.; Koh, M.; Kanemura, T.; Kitagawa, S. J. Mater. Chem. 2011, 21, 8021-8025.

(22) Qi, Q.; Shen, Q.; Lu, L. J. Am. Chem. Soc. 2012, 134, 65486551.

(23) (a) Boyer, C.; Valade, D.; Sauguet, L.; Ameduri, B.; Boutevin, B. Macromolecules 2005, 38, 10353-10362. (b) Araki, T.; Kodani, T. Method of forming thin film. WO Patent 2004085498, October 7, 2004. (c) Voet, V. S. D.; ten Brinke, G.; Loos, K. J. Polym. Sci. Part A Polym. Chem. 2014, 52, 2861-2877.
(24) (a)Lopes, A. C.; Costa, C. M.; Tavares, C. J.; Neves, I. C.; Lanceros-Mendez, S. J. Phys. Chem. C 2o11, 115, 1807618082. (b) Li, M.; Wondergem, H. J.; Spijkman, M.-J.; Asadi, K.; Katsouras, I.; Blom, P. W. M.; de Leeuw, D. M. Nat. Mater. 2013, 12, 433-438.

(25) Chellappan, K. V; Kandappa, S. K.; Rajaram, S.; Narayan, K. S. J. Phys. Chem. Lett. 2015, 6, 224-229.

(26) Mangialardo, S.; Larciprete, M. C.; Belardini, a.; Sibilia, C.; Bertolotti, M. Laser Phys. 2008, 18, 1371-1377.

(27) Nalwa H.S. (ed) Ferroelectric Polymers: Chemistry, Physics, and Applications (New York: Dekker, 1995)

(28) (a) Fukunaga, M.; Noda, Y. J. Phys. Soc. Japan 20o8, 77, 64706. (b) Khikhlovskyi, V.; Gorbunov, A. V; van Breemen, A. J. J. M.; Janssen, R. A. J.; Gelinck, G. H.; Kemerink, M. Org. Electron. 2013, 14, 3399-3405.

(29) Lenz, T.; Zhao, D.; Richardson, G.; Katsouras, I.; Asadi, K.; Glaßer, G.; Zimmermann, S. T.; Stingelin, N.; Roelofs, W. S. C.; Kemerink, M.; Blom, P. W. M.; de Leeuw, D. M. Phys. status solidi 2015, 212, 2124-2132.

(30) For both materials no ferroelectric switching has been observed for temperatures below those mentioned in the text, nor above the temperature of the isotropic phase transition.

(31) (a) Dias, C. J.; Inácio, P.; Marat-Mendes, J. N.; Das-Gupta, D. K. Ferroelectrics 1997, 198, 121-130. (b) Wenger, M. P.; Almeida, P. L.; Das-Gupta, D. K.; Blanas, P.; Shuford, R. J. Polym. Eng. Sci. 1999, 39, 483-492. (c) Xin, C.; Shifeng, H.; Jun, C.; Zongjin, L. J. Appl. Phys. 2007, 101, 094110-094110.

(32) Bharti, V.; Kaura, T.; Nath, R. IEEE Trans. Dielectr. Electr. Insul. 1997, 4, 738-741.

(33) Chen, S.; Yao, K.; Hock Tay, F. E. Polym. Int. 2o12, 61, 169173 .

(34) Gomes, J.; Nunes, J. S.; Sencadas, V.; Lanceros-Mendez, S. Smart Mater. Struct. 2010, 19, 65010-65017.

(35) (a) Khan, M. A.; Bhansali, U. S.; Almadhoun, M. N.; Odeh, I. N.; Cha, D.; Alshareef, H. N. Adv. Funct. Mater. 2014, 24, 1372-1381. (b) Soulestin, T.; Ladmiral, V.; Lannuzel, T.; Santos, F. D. Dos; Ameduri, B. Macromolecules 2015, 48, 78617871.

(36) Gorbunov, A. V.; Garcia Iglesias, M.; Guilleme,J.; Roelofs, W. S. C.; Torres, T.; D. González-Rodríguez, D.; Meijer E. W.; Kemerink M. (Manuscript submitted).

(Word Style "TF_References_Section"). References are placed at the end of the manuscript. Authors are responsible for the accuracy and completeness of all references. Examples of the recommended formats for the various reference types can be found at http://pubs.acs.org/page/4authors/index.html. Detailed information on reference style can be found in The ACS Style Guide, available from Oxford Press. 
Authors are required to submit a graphic entry for the Table of Contents (TOC) that, in conjunction with the manuscript title, should give the reader a representative idea of one of the following: A key structure, reaction, equation, concept, or theorem, etc., that is discussed in the manuscript. Consult the journal's Instructions for Authors for TOC graphic specifications.

Insert Table of Contents artwork here

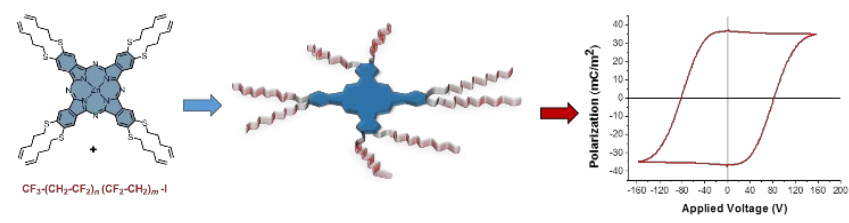




\section{Supporting Online Material for}

\section{A Versatile Method for the Preparation of Ferroelectric Supramolecular Materials via Radical End-functionalization of Vinylidene Fluoride Oligomers}

Miguel García-Iglesias, ${ }^{\dagger}$ Bas F. M. de Waal, ${ }^{\dagger}$ Andrey. V. Gorbunov, ${ }^{\S}$ Anja R. A. Palmans, ${ }^{\dagger}$ Martijn. Kemerink, ${ }^{\S, \ddagger}$ E. W. Meijer*, ${ }^{\dagger}$

† Institute of Complex Molecular Systems, Laboratory of Macromolecular and Organic Chemistry, Eindhoven University of Technology, P.O. Box 513, 5600 MB, Eindhoven, The Netherlands.

$\S$ Department of Applied Physics, Eindhoven University of Technology, PO Box 513, 5600 MB Eindhoven, The Netherlands.

${ }^{\ddagger}$ Complex Materials and Devices, Department of Physics, Chemistry and Biology (IFM), Linköping University, 58183

Linköping, Sweden.

\section{Contents}

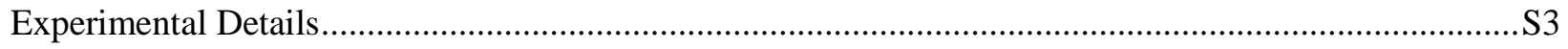

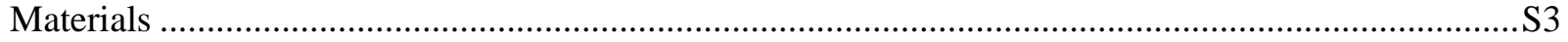

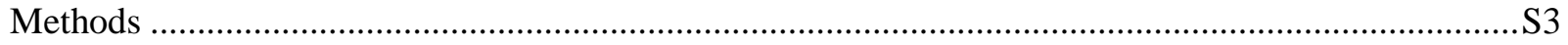

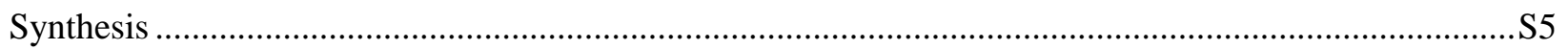

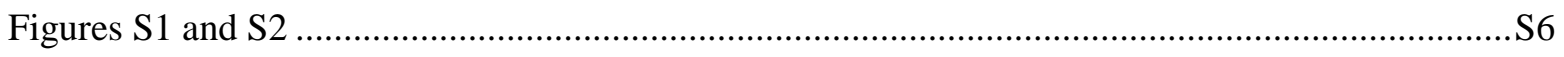

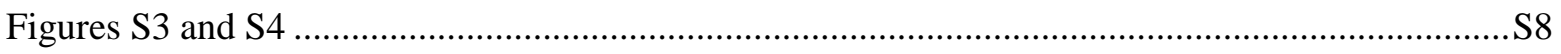

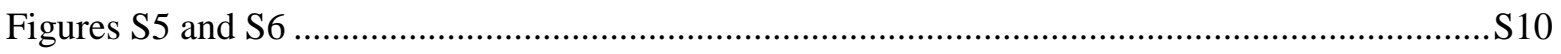

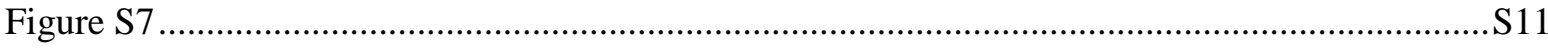

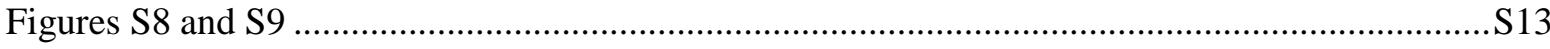

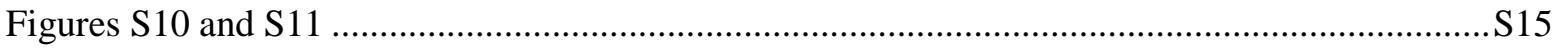

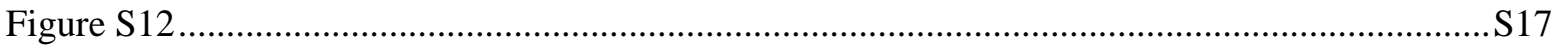

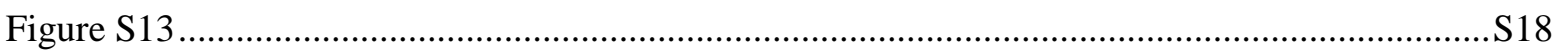

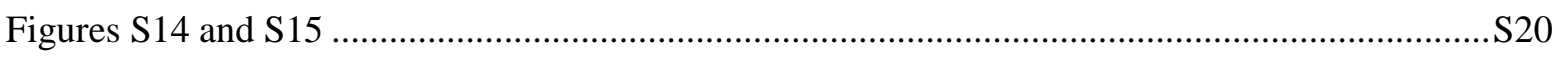

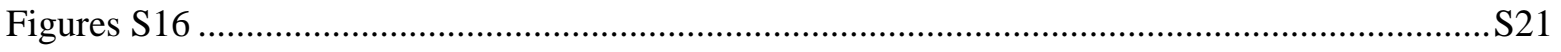

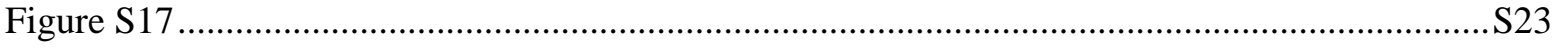

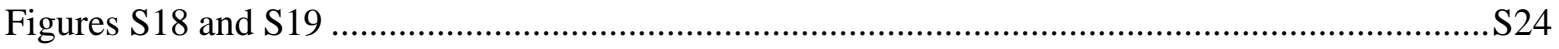

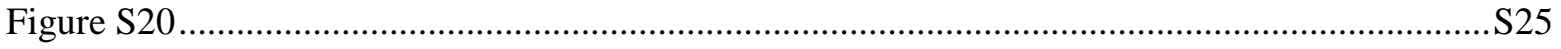

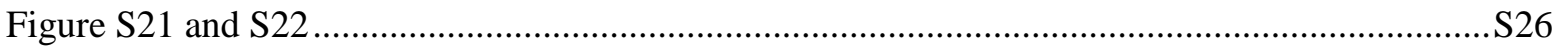

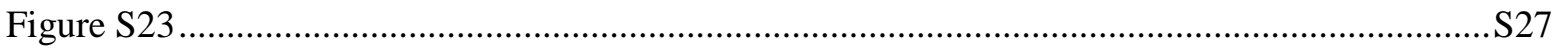

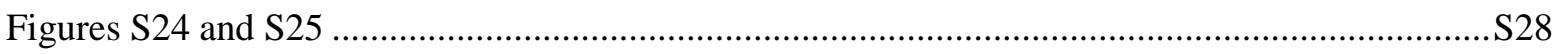




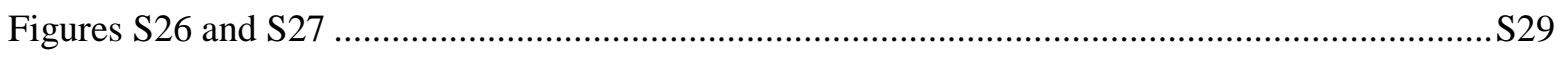

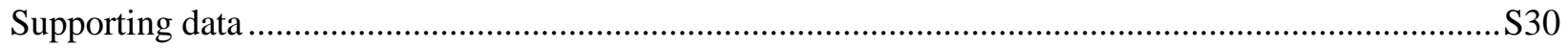

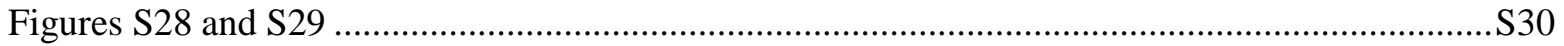

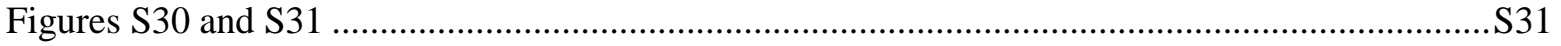

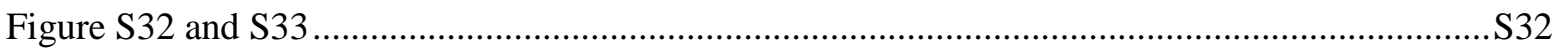

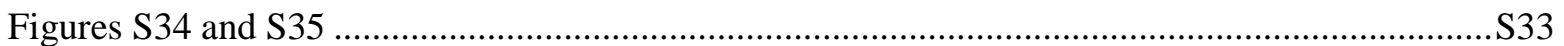

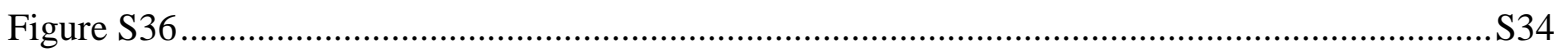

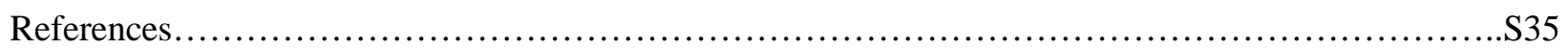




\section{Experimental Details}

\section{Materials}

OVDF-I $\left(\mathrm{CF}_{3}-\left(\mathrm{CH}_{2}-\mathrm{CF}_{2}\right)_{\mathrm{n}}\left(\mathrm{CF}_{2}-\mathrm{CH}_{2}\right)_{\mathrm{m}}-\mathrm{I}, \mathrm{n} \approx 6, \mathrm{~m}=1,0\right)$ was kindly provided by Daikin industries, LTD. Chemical Research \& Development Center, Nishi Hitotsuya, Settsu, Osaka 566-8585, Japan. All other chemicals were obtained from either Acros or Aldrich at the highest purity available and used without further purification. All solvents were of AR quality and purchased from Biosolve. Flash chromatography was performed on a Biotage flash chromatography system using 200-425 mesh silica gel (Type 60A Grade 633) or common column chromatography carried out on silica gel Merck-60 (230-400 mesh, $60 \AA$ ). Sizeexclusion chromatography (SEC) was performed using as stationary phase Bio-beads S-X1. Water was purified on an EMD Milipore Mili-Q Integral Water Purification System. Reactions were followed by thinlayer chromatography (precoated 0.25 mm, 60-F254 silica gel plates from Merck).

\section{Methods}

${ }^{1} \mathrm{H}-\mathrm{NMR}$ and ${ }^{13} \mathrm{C}-\mathrm{NMR}$ spectra were recorded on a Varian Mercury Vx $400 \mathrm{MHz}\left(100 \mathrm{MHz}\right.$ for $\left.{ }^{13} \mathrm{C}\right) \mathrm{NMR}$ spectrometer. Chemical shifts are given in ppm $(\delta)$ values relative to residual solvent or tetramethylsilane (TMS). Splitting patterns are labelled as s, singlet; d, doublet; dd, double doublet; $t$, triplet; q, quartet; quin, quintet; $\mathrm{m}$, multiplet and b stands for broad.

Matrix assisted laser desorption/ionisation mass spectra were obtained on a PerSeptive Biosystems Voyager DE-PRO spectrometer or a Bruker autoflex speed spectrometer using $\alpha$-cyano-4-hydroxycinnamic acid (CHCA) and 2-[(2E)-3-(4-tert-butylphenyl)-2-methylprop-2-enylidene]malononitrile (DCTB) as matrices. Ammonium chloride (5\%) was added to the samples when measuring OVDF derivatives.

Ultraviolet-visible (UV-vis) absorbance spectra were recorded on and a Jasco V-650 UV-vis spectrometer with a Jasco ETCT-762 temperature controller. Solutions were prepared by weighing in the necessary amount of compound for a given concentration, where after this amount was transferred to a volumetric flask (flasks of 10, 25 and $50 \mathrm{~mL}$ were employed). UV-Vis measurements were performed using quartz cuvettes $(1 \mathrm{~mm})$. IR Infrared spectra were recorded on a Bruker Optics Tensor 27 FT-IR spectrometer, equipped with a temperature controller Pike GladiATR EZ-ZONE PM.

Polarization optical microscopy (POM) measurements were done using a Jenaval polarization microscope equipped with a Linkam THMS 600 heating device, with crossed polarizers. The thermal transitions were determined with DSC using a Perkin-Elmer Pyris 1 DSC under a nitrogen atmosphere with heating and cooling rates of $10 \mathrm{~K} \mathrm{~min}^{-1}$.

SEC-measurements were performed on a Shimadzu-system with two PolymerLabs columns in serie (PLgel $5 \mu \mathrm{m}$ mixed C [200 - $2000000 \mathrm{Da}$ ] and PLgel 5 $\mu \mathrm{m}$ mixed D [200-40000 Da]) and equipped with a RI (Shimadzu RID-10A) and a PDA detector (Shimadzu SPD-M10A), with THF as eluent at a constant flow rate of $1.0 \mathrm{~mL} / \mathrm{min}$. Number averaged molecular weights and molecular weight distribution (Mw/Mn) were obtained relative to polystyrene standards (Polymer Laboratories, molecular weight range: 580 - $100000 \mathrm{~g}$ mol-1). The mobile phase was THF at a constant flow rate of $1.0 \mathrm{~mL} / \mathrm{min}$. Number averaged molecular weights $\left(M_{\mathrm{n}}\right)$ and molar mass dispersity $\left(\bigoplus=M_{\mathrm{w}} / M_{\mathrm{n}}\right)$ were obtained relative to polystyrene standards (Polymer Laboratories, molecular weight range: 580 - 377400 g/mol).

LC cells coated with indium tin oxide (electrode area $5.0 \mathrm{~mm}^{2}$, cell spacing $5 \mu \mathrm{m}$ ) used during the electrooptical experiments were purchased from INSTEC. The LC cells were filled above the melting point of the 
products by capillarity. After applying the electrical field the cells were opened in order to analyze the samples by IR spectroscopy.

\section{Device fabrication procedure:}

Experimental metal/functional material/metal (M-F-M) capacitor devices were fabricated in a typical crossbar geometry on a glass substrate. All substrates were chemically cleaned (30 min in acetone, and $30 \mathrm{~min}$ in isopropanol) in ultrasonic bath and deionized. Top and bottom contacts were defined by high vacuum ( $2 \times 10^{-7}$ mbar) evaporation of $70 \mathrm{~nm}$ gold through a shadow mask; for a good adhesion $5 \mathrm{~nm}$ of Cr was evaporated before deposition of the bottom electrode. The functional organic films were prepared by dropcasting from a solution of $20 \mathrm{mg}$ dry materials dissolved per $1 \mathrm{~mL}$ of chloroform, and annealed at 65-70 ${ }^{\circ} \mathrm{C}$ for 1 hour at atmospheric conditions before deposition of top contact, leading to a device area between 0.25 and $0.5 \mathrm{~mm}^{2}$.

In order to achieve as much as possible of the polar $\beta$-conformation and to pole the materials an external field was applied to the devices for 20-30 minutes. We use a low frequency (500 mHz) triangular wave with an amplitude of $25 \mathrm{~V} / \mu \mathrm{m}$. Conditioning was done at an elevated temperature of $\sim 60-65{ }^{\circ} \mathrm{C}$. This procedure is known to promote the alignment of dipolar moieties with the electric field, i.e. out of the electrode plane. Unfortunately, the presence of metallic electrodes prevents us from quantitatively probing any changes in the molecular orientation and $\pi$-stacking.

\section{Electrical switching measurement set-up:}

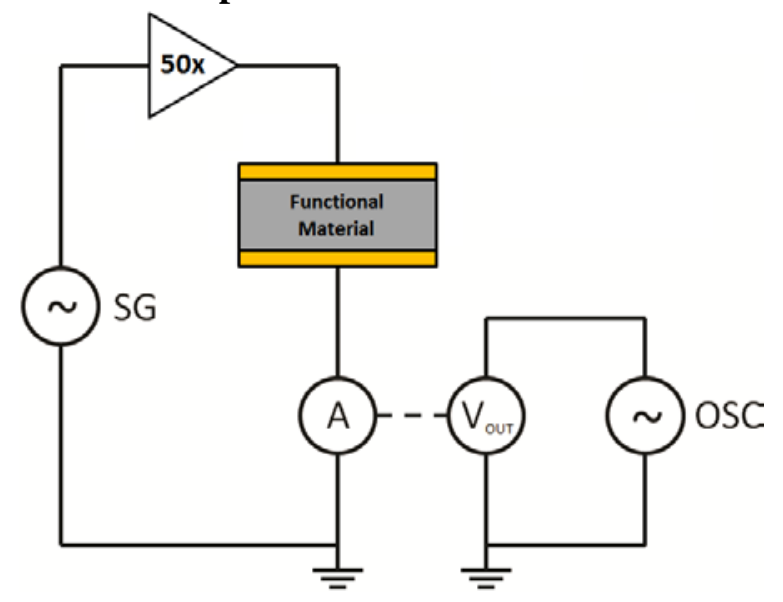

A home-made ferroelectric measurement set-up has been used for electrical hysteresis measurements. Switching signal waveforms were applied by an Agilent 33120a arbitrary waveform generator (SG) after amplication by a Falco WMA-300 high voltage amplifier. The actual circuit current was measured by highspeed Keithley 6485 picoampmeter (A) which was visualized and stored on an Agilent DSO7104A digital oscilloscope (OSC) for further analysis. The signal generator (SG), the picoammeter (A) and the examined sample are connected in series whereas an oscilloscope (OSC) is connected in parallel with the analog output of the picoammeter $\left(\mathrm{V}_{\text {out }}\right)$. To reduce electrical noise the devices were characterized inside the grounded chamber of a Janus probe station at atmospheric pressure. 


\section{Synthetic procedures}
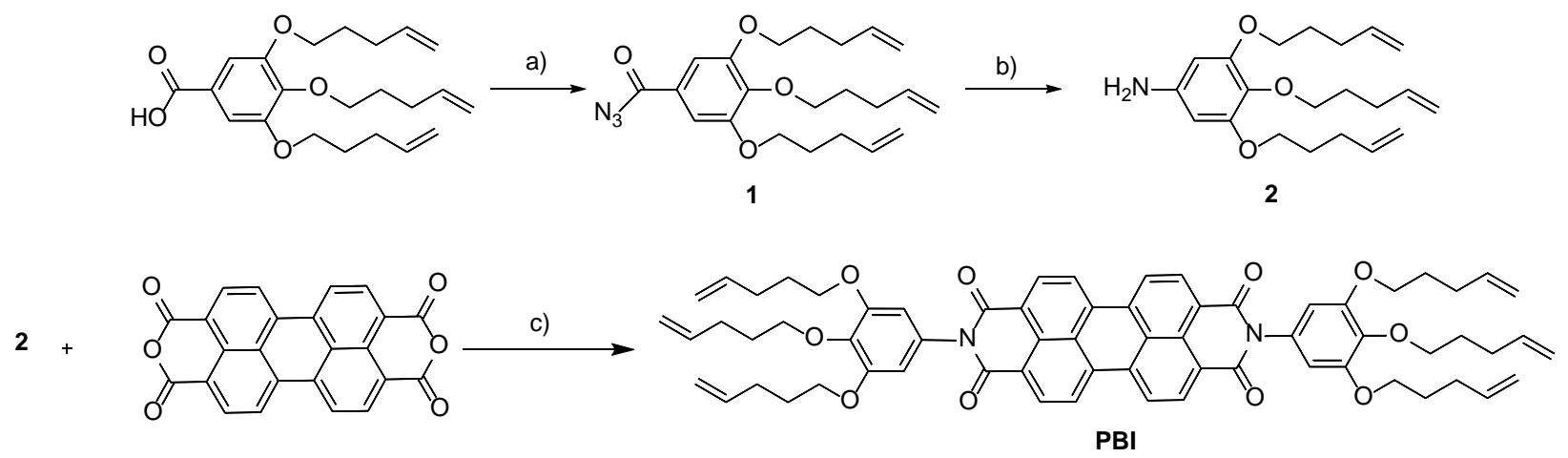

Scheme 1: a) $i \mathrm{Et}_{3} \mathrm{~N}$, ethyl chloroformate, THF, $0{ }^{\circ} \mathrm{C}, 80 \mathrm{~min}$; $i$, $\mathrm{NaN}_{3}$, THF, r.t, 2h, $85.5 \%$. b) i 1,4dioxane, $95^{\circ} \mathrm{C}, 2 \mathrm{~h}$; ii tetrabutylammonium hydroxide, $75^{\circ} \mathrm{C}, 30 \mathrm{~min}, 61.1 \%$. c) Zinc acetate, quinoline, $180{ }^{\circ} \mathrm{C}, 2 \mathrm{~h}, 59 \%$.

\section{3,4,5-Tris(pent-4-en-1-yloxy)benzoyl azide (1)}

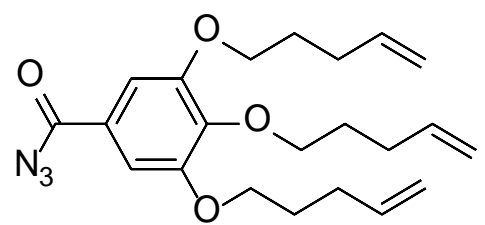

3,4,5-Tris(pent-4-en-1-yloxy)benzoic acid (3.4 g; $9.08 \mathrm{mmol}$ ) was dissolved in $70 \mathrm{~mL}$ dry THF, and 2.4 $\mathrm{mL}$ trietylamine was added. The reaction mixture was stirred and externally cooled with an ice/water bath. Ethyl chloroformate ( $1.75 \mathrm{~mL}$ in $30 \mathrm{ml}$ THF) was added dropwise during 40 minutes. A solution of $5.9 \mathrm{~g}$ (9.08 mmol) of sodium azide in $20 \mathrm{~mL}$ water was added. After stirring for another 40 minutes, the icebath was removed and stirring continued for 2 hours at room temperature. The reaction mixture was extracted 2 times with $100 \mathrm{~mL}$ ether and $200 \mathrm{~mL}$ of water, and the combined organic layers were washed with brine. After drying the ether phase with magnesium sulfate, the ether was removed on a rotary evaporator. The product was purified by column chromatography on silica (Biotage $100 \mathrm{~g}$ KP-Sil column on a Biotage Isolera 1 system, with a gradient $n$-heptane : chloroform from 2:3 v/v to to 1:3 v/v). Yield: $3.1 \mathrm{~g}(7.76$ mmol; 85.5\%).

${ }^{1} \mathrm{H}$ NMR (400 MHz, $\mathrm{CDCl}_{3}$ ) $\delta$ (ppm): 7.24 (s, 2H, Ar), 5.86 (ddtd, $J=16.9,10.2,6.6,1.5 \mathrm{~Hz}, 3 \mathrm{H}$, $\mathrm{CH}_{2}-\underline{\mathrm{CH}}=\mathrm{CH}_{2}$ ), $5.28-4.83\left(\mathrm{~m}, 6 \mathrm{H}, \mathrm{CH}=\underline{\mathrm{CH}_{2}}\right.$ ), 4.05 (dt, $\left.J=18.5,6.4 \mathrm{~Hz}, 6 \mathrm{H},-\mathrm{O}-\underline{\mathrm{CH}_{2}} \underline{2}^{-}\right), 2.36-2.07$ (m, $\left.6 \mathrm{H},-\underline{\mathrm{CH}}_{2}-\mathrm{CH}=\mathrm{CH}_{2}\right), 2.02-1.74\left(\mathrm{~m}, 6 \mathrm{H},-\mathrm{O}-\mathrm{CH}_{2}-\underline{\mathrm{CH}}_{2}-\right) .{ }^{13} \mathrm{C} \mathrm{NMR}\left(100 \mathrm{MHz}, \mathrm{CDCl}_{3}\right) \delta(\mathrm{ppm}): 172.04$, 152.96, 143.73, 138.31, 137.77, 125.37, 115.50, 115.01, 107.96, 73.03, 68.54, 30.27, 29.67, 28.58. FT-IR $(\mathrm{ATR}) \vee\left(\mathrm{cm}^{-1}\right): 3412,3332,2981,2940,2881,2850,2140,1682,1590,1514,1475,1455,1394,1349$, 1242, 1160, 990, 813, 756, 623, 512. 
Figure S1. ${ }^{1} \mathrm{H}$ NMR of $1\left(\mathrm{CDCl}_{3}\right)$

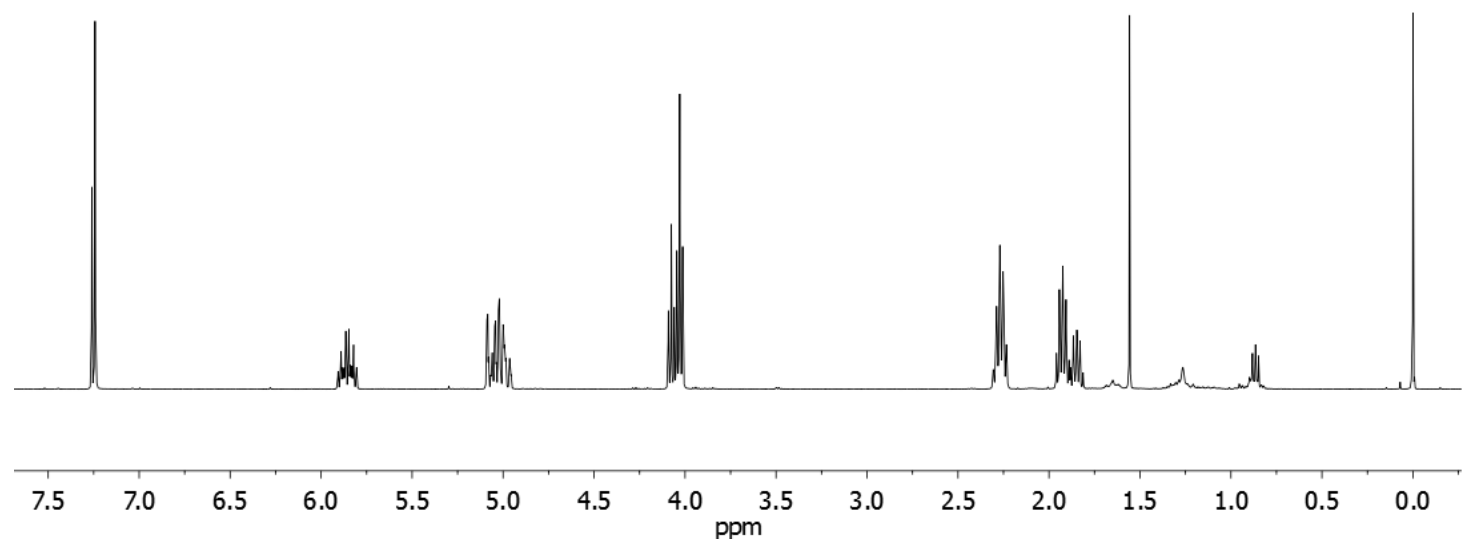

Figure S2. ${ }^{13} \mathrm{C}$ NMR of $1\left(\mathrm{CDCl}_{3}\right)$

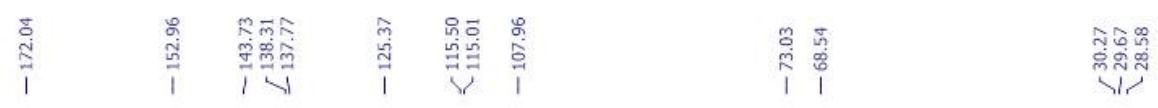

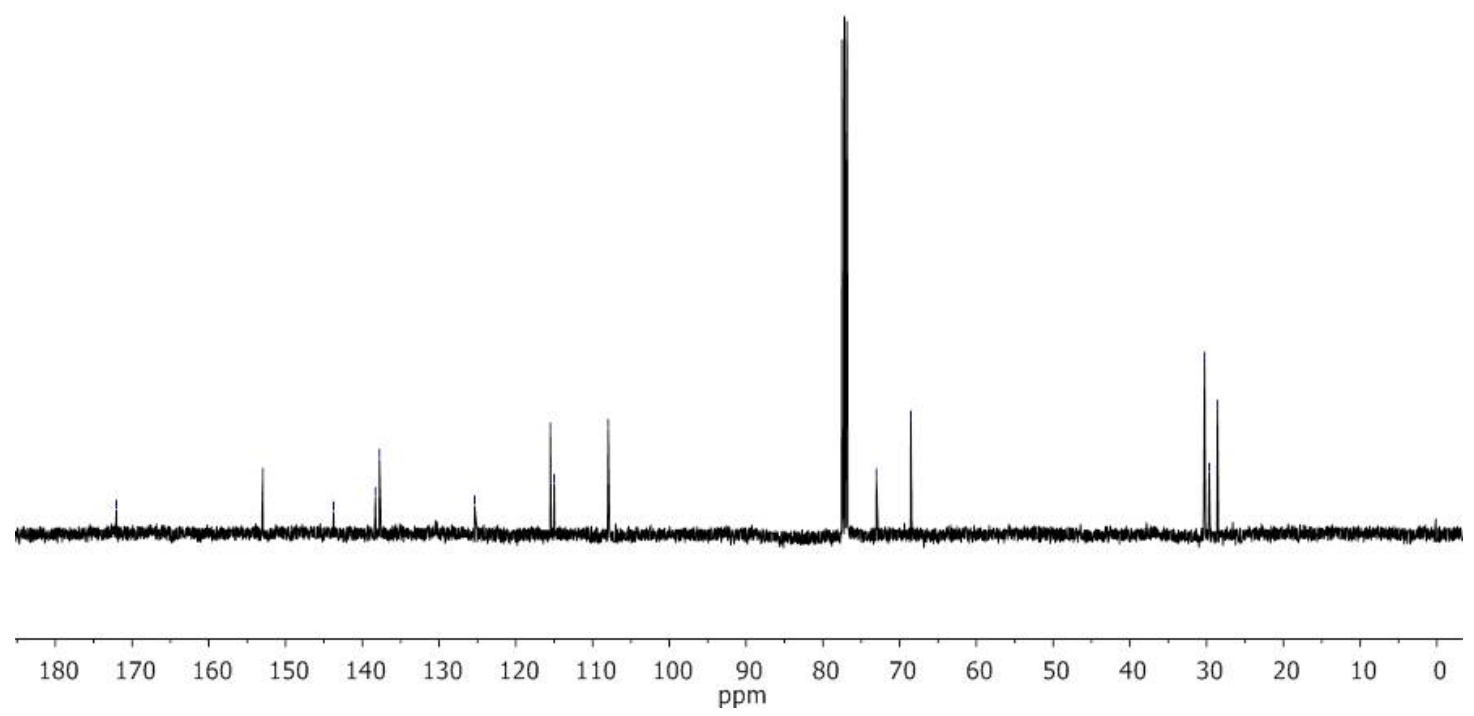




\section{3,4,5-Tris(pent-4-en-1-yloxy)aniline (2).}

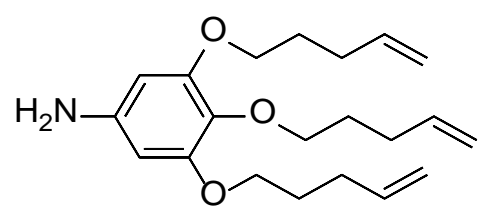

Acylazide 1 ( $3.1 \mathrm{~g} ; 7.76 \mathrm{mmol}$; IR: $2140 \mathrm{~cm}^{-1}$ ) was dissolved in $60 \mathrm{~mL}$ dry 1,4-dioxane and heated to 95 ${ }^{\circ} \mathrm{C}$ for 2 hours until complete conversion to the isocyanate as observed by IR $\left(2260 \mathrm{~cm}^{-1}\right)$. The mixture was cooled down to $70{ }^{\circ} \mathrm{C}$ and the contents were transferred during 20 minutes by a canula to a well stirred solution of tetrabutylammonium hydroxide $(10 \mathrm{~mL}$ of $40 \%$ in water) in dioxane (250 mL) preheated at 70 ${ }^{\circ} \mathrm{C}$. After 30 minutes, the reaction mixture was cooled down to room temperature and concentrated on a rotary evaporator. The crude was extracted with diethylether $(200 \mathrm{~mL})$ and washed with $200 \mathrm{~mL}$ water. The organic phases were combined and washed wit $200 \mathrm{~mL}$ of brine, dried on sodium sulfate and concentrated. The product was purified by column chromatography on Silica (Biotage $50 \mathrm{~g}$ KP-Sil column) by using a Biotage Isolera 1 machine, eluting with chloroform/ethyl acetate (8:2 v/v). Yield: $1.60 \mathrm{~g}$ ( $4.71 \mathrm{mmol} ; 61$ $\%$ ) of a white solid.

${ }^{1} \mathrm{H}$ NMR (400 MHz, $\left.\mathrm{CDCl}_{3}\right) \delta(\mathrm{ppm}): 6.01-5.72\left(\mathrm{~m}, 5 \mathrm{H},-\underline{\mathrm{CH}}=\mathrm{CH}_{2}, \mathrm{Ar}\right), 5.19-4.80\left(\mathrm{~m}, 6 \mathrm{H},-\mathrm{CH}=\underline{\mathrm{CH}_{2}}\right)$ ), 3.90 (dt, $J=19.5,6.4 \mathrm{~Hz}, 6 \mathrm{H},-\mathrm{O}-\mathrm{CH}_{2}-$ ), 3.47 (s, 2H, $-\underline{\mathrm{NH}}_{2}$ ), 2.25 (dddt, $J=14.5,9.3,6.6,1.4 \mathrm{~Hz}, 6 \mathrm{H}$, $\left.-\underline{\mathrm{CH}}_{2}-\mathrm{CH}=\mathrm{CH}_{2}\right), 1.97-1.70\left(\mathrm{~m}, 6 \mathrm{H},-\mathrm{O}-\mathrm{CH}_{2}-\underline{\mathrm{CH}}_{2}-\right) .{ }^{13} \mathrm{C} \mathrm{NMR}\left(100 \mathrm{MHz}, \mathrm{CDCl}_{3}\right) \delta(\mathrm{ppm}): 153.75$, 142.57, 138.81, 138.09, 115.23, 114.60, 94.58, 73.05, 68.29, 30.51, 30.35, 29.67, 28.75. MALDI-TOF-MS: calculated for $\mathrm{C}_{21} \mathrm{H}_{31} \mathrm{NO}_{3} \mathrm{MW}=346.23 \mathrm{~g} / \mathrm{mol}[\mathrm{M}+\mathrm{H}]$, observed $\mathrm{m} / \mathrm{z}=346.24$. FT-IR (ATR) $v\left(\mathrm{~cm}^{-1}\right)$ : 3412, 3332, 3209, 3080, 2978, 2937, 2881, 2848, 1642, 1597, 1504, 1471, 1455, 1394, 1352, 1232, 1160, 990, 813, 756, 623, 583, 554, 527. 
Figure S3. ${ }^{1} \mathrm{H}$ NMR of $2\left(\mathrm{CDCl}_{3}\right)$

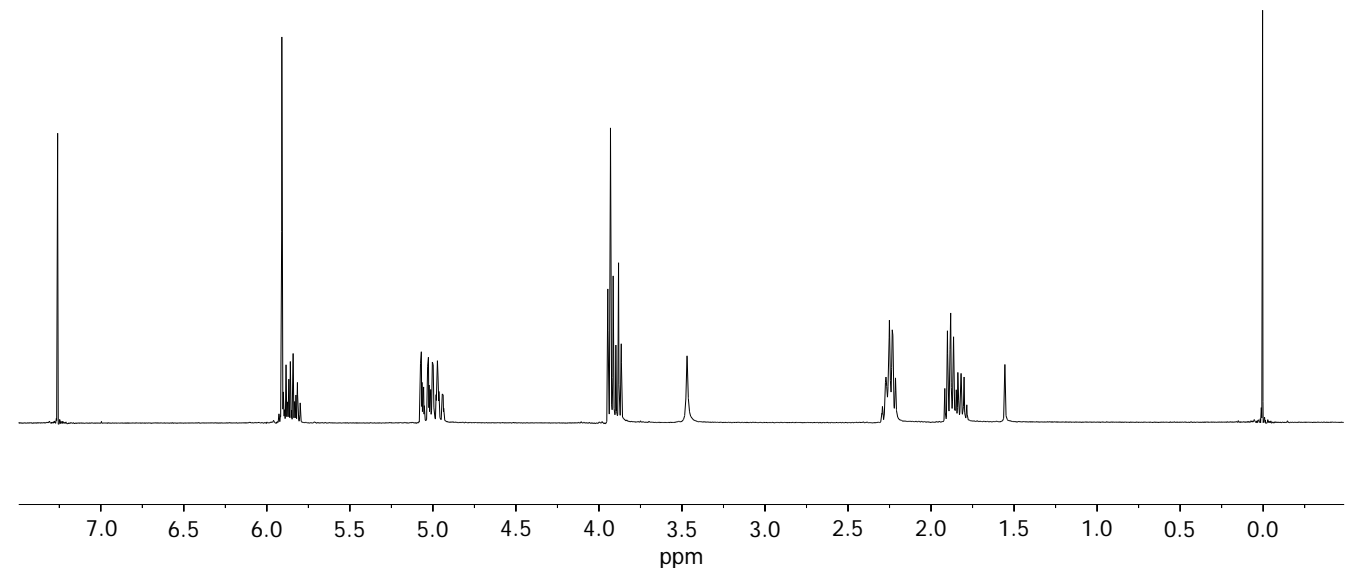

Figure S4. ${ }^{13} \mathrm{C}$ NMR of $2\left(\mathrm{CDCl}_{3}\right)$

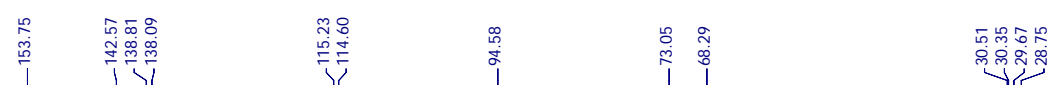

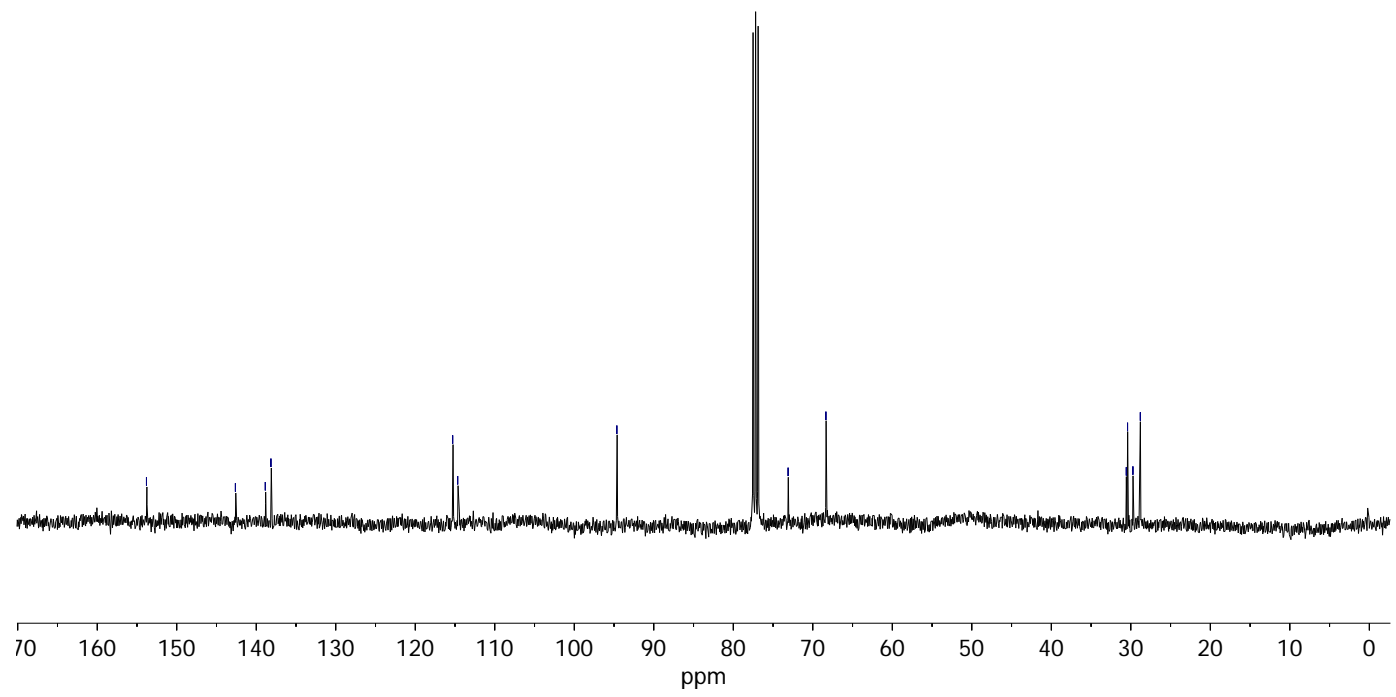




\section{$N, N^{\prime}$-Di(3,4,5-tris(pent-4-en-1-yloxy)phenyl)-perylene-3,4:9,10-tetracarboxylic acid bisimide (PBI):}

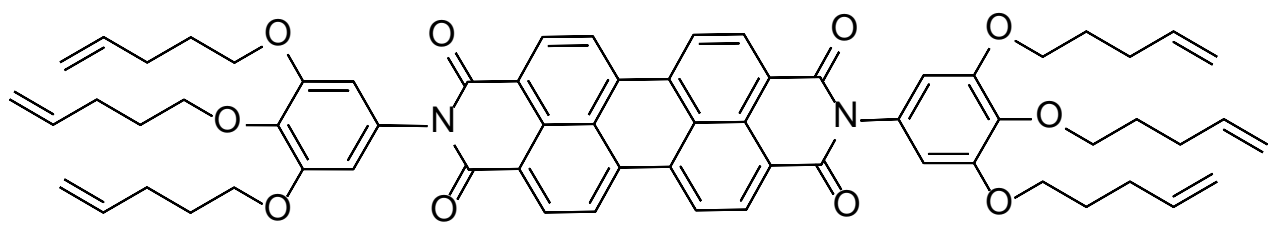

A mixture of perylene-3,4:9,10-tetracarboxylic acid bisanhydride (0.13 g, $0.33 \mathrm{mmol})$, aniline 2 (0.23 g, $0.67 \mathrm{mmol})$ and zinc acetate $(0.073 \mathrm{~g}, 0.33 \mathrm{mmol})$ were mixed in quinoline $(15 \mathrm{~mL})$ in a two-neck roundbottom flask $(25 \mathrm{~mL})$. The reaction mixture was stirred at $180^{\circ} \mathrm{C}$ for $3 \mathrm{~h}$. After cooling to room temperature, the mixture was poured into $\mathrm{MeOH}(30 \mathrm{~mL})$. The precipitate was collected by filtration, washed with methanol (1000 mL), and then dried in vacuum. The crude product was further purified by silica gel column chromatography $\left(\mathrm{CH}_{2} \mathrm{Cl}_{2}\right)$ and then slowly precipitated from $\mathrm{CH}_{2} \mathrm{Cl}_{2} /$ methanol 1:1 (10 $\left.\mathrm{mL}\right)$ to give a red powder. Yield: $203 \mathrm{mg}$ (1.94 mmol; 59\%).

${ }^{1} \mathrm{H}$ NMR (400 MHz, $\mathrm{CDCl}_{3}$ ) $\delta(\mathrm{ppm}): 8.51$ (d, $\left.J=7.9 \mathrm{~Hz}, 4 \mathrm{H}, \mathrm{Ar}\right), 8.15$ (d, $J=8.1 \mathrm{~Hz}, 4 \mathrm{H}, \mathrm{Ar}$ ), 6.66 (s, $4 \mathrm{H}, \mathrm{Ar}), 5.88\left(\mathrm{~m}, 6 \mathrm{H},-\underline{\mathrm{CH}}=\mathrm{CH}_{2}\right), 5.19-4.84\left(\mathrm{~m}, 12 \mathrm{H},-\mathrm{CH}=\underline{\mathrm{CH}_{2}}\right), 4.07$ (t, $\left.J=6.4 \mathrm{~Hz}, 4 \mathrm{H},-\mathrm{O}-\underline{\mathrm{CH}_{2}} \underline{2}^{-}\right)$, 3.88 (t, $\left.J=6.4 \mathrm{~Hz}, 8 \mathrm{H},-\mathrm{O}-\underline{\mathrm{CH}}_{2}-\right)$ ), 2.33 (q, $J=6.6,4 \mathrm{H},-\underline{-\mathrm{CH}_{2}}-\mathrm{CH}=\mathrm{CH}_{2}$ ), 2.18 (q, $J=7.3 \mathrm{~Hz}, 8 \mathrm{H},-\underline{\mathrm{CH}}_{2}-$ $\left.\mathrm{CH}=\mathrm{CH}_{2}\right), 2.02-1.70\left(\mathrm{~m}, 12 \mathrm{H},-\mathrm{O}-\mathrm{CH}_{2}-\underline{\mathrm{CH}}_{2}-\right) .{ }^{13} \mathrm{C}$ NMR $\left(50 \mathrm{MHz}, \mathrm{CDCl}_{3}\right) \delta(\mathrm{ppm}): 162.91,153.70$, 138.72, 138.26, 133.48, 130.79, 129.92, 128.28, 125.25, 123.21, 122.84, 115.03, 114.78, 107.02, 72.85, 68.55, 30.49, 30.35, 29.81, 28.78. UV/Vis $\left(\mathrm{CHCl}_{3}\right): \lambda_{\max }(\log \varepsilon)=530$ (6.47), 491 (4.13), 460 (1.55), 261 (2.35), 242 (4.18) nm. MALDI-TOF-MS: calculated for $\mathrm{C}_{66} \mathrm{H}_{66} \mathrm{~N}_{2} \mathrm{O}_{10} \mathrm{MW}=1046.47 \mathrm{~g} / \mathrm{mol}$ [M], observed $\mathrm{m} / \mathrm{z}=1046.47 . \mathrm{FT}-\mathrm{IR}(\mathrm{ATR}) v\left(\mathrm{~cm}^{-1}\right): 3075,2939,2874,1072,1666,1640,1591,1577,1501,1468,1433$, 1402, 1363, 1319, 1233, 1196, 1178, 1110, 993, 969, 908, 851, 809, 796, 745, 721, 688, 628, 535, 500. 
Figure S5. ${ }^{1} \mathrm{H} \mathrm{NMR}$ of $\mathbf{P B I}\left(\mathrm{CDCl}_{3}\right)$

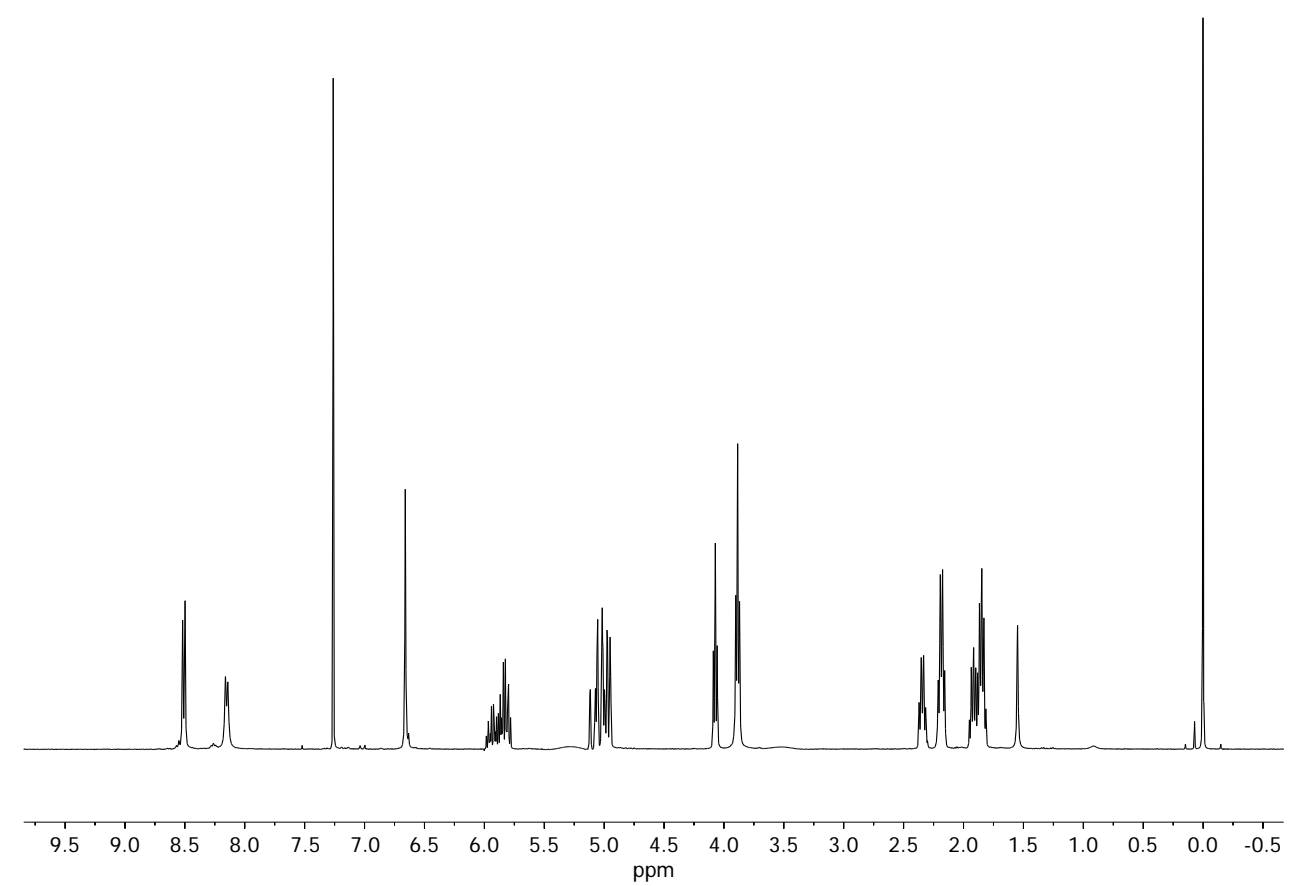

Figure S6. ${ }^{13} \mathrm{C}$ NMR of PBI $\left(\mathrm{CDCl}_{3}\right)$

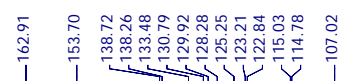

$\mid \begin{array}{ll}n & \\ \infty & 4 \\ & 0 \\ 1 & 0\end{array}$

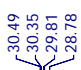

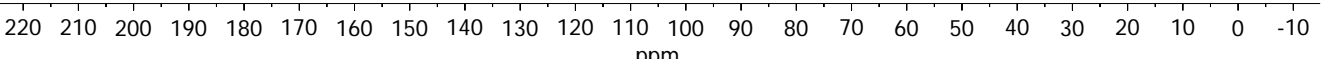


Figure S7. MALDI-TOF spectra with and isotopic distribution pattern of PBI
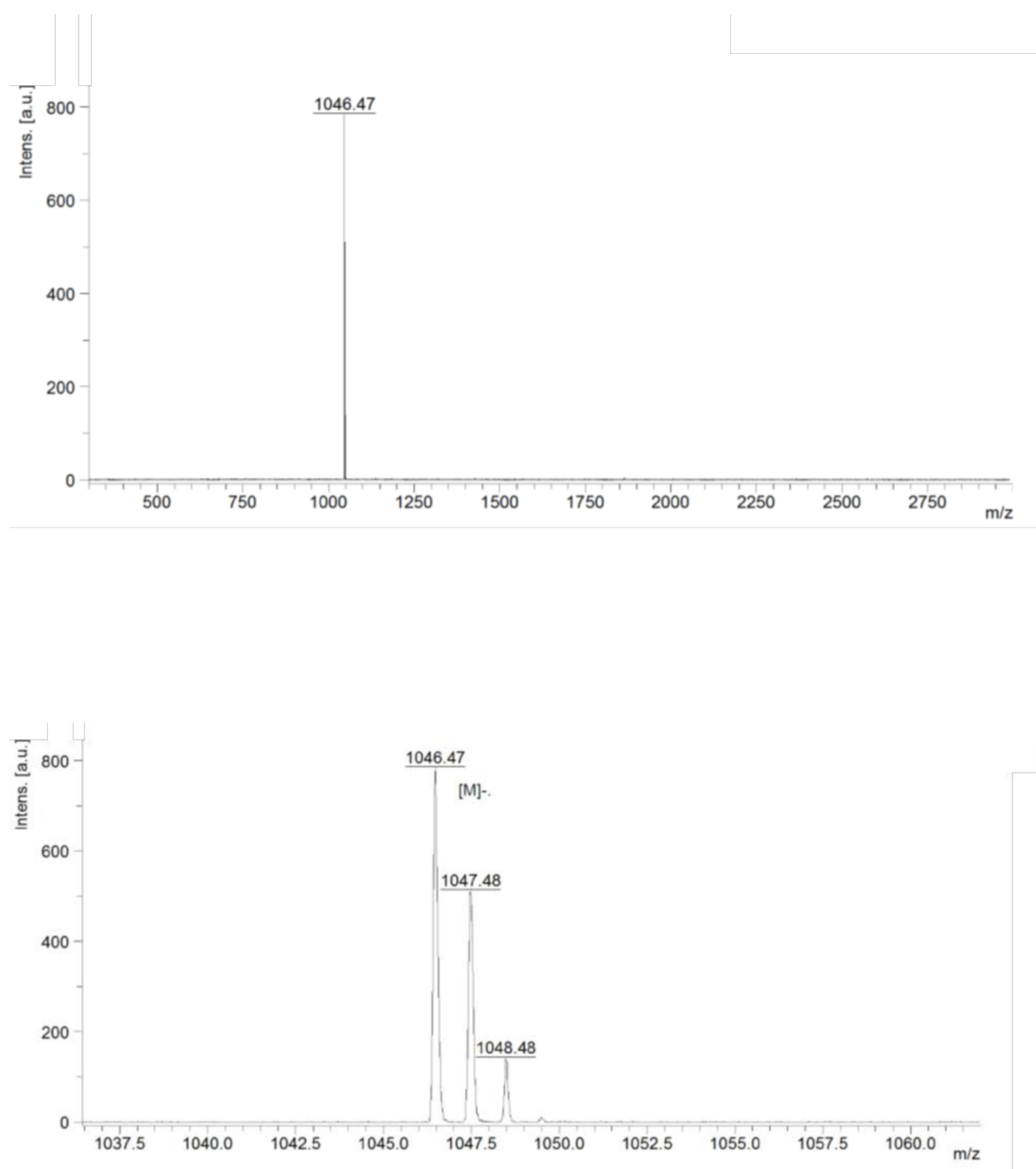


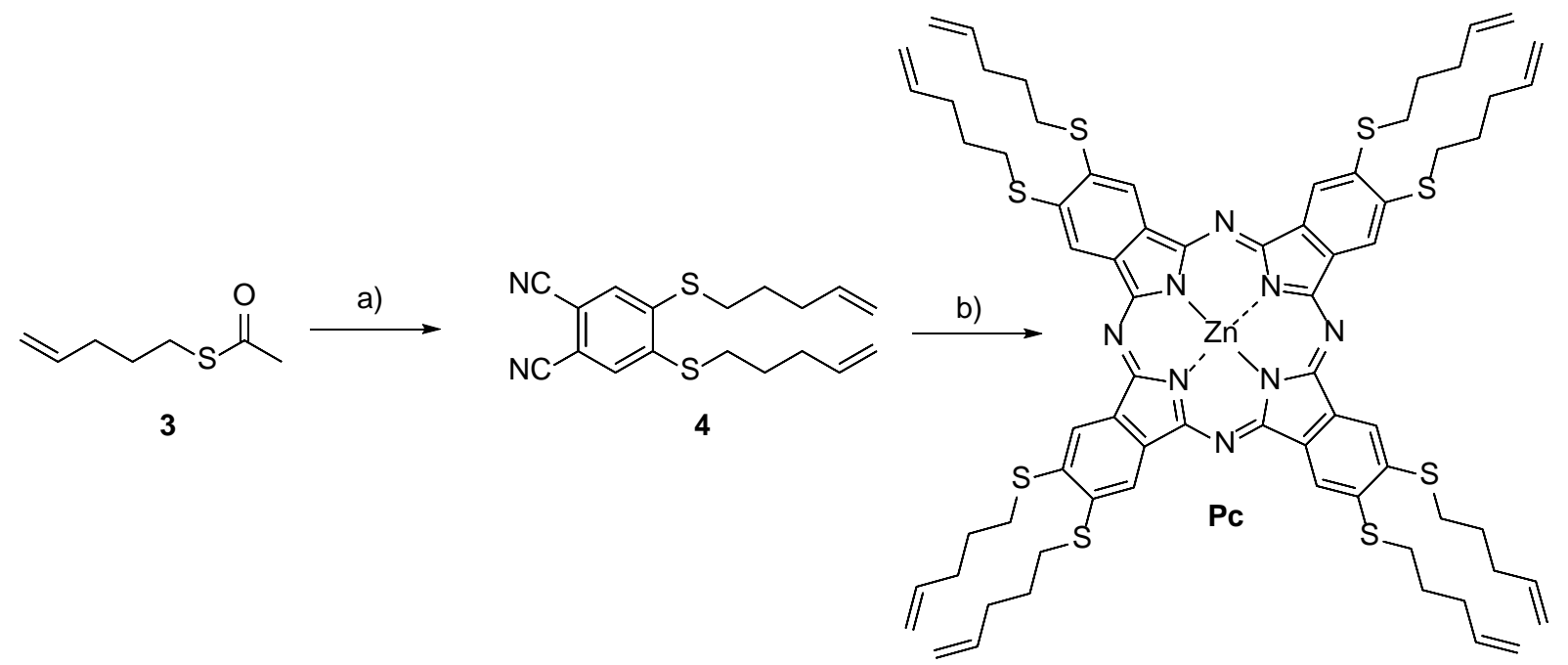

Scheme 2: a) i $\mathrm{K}_{2} \mathrm{CO}_{3}$, DMSO, R.T, 30 min. ii 3,5-Dichlorophthalonitrile, DMSO, $190{ }^{\circ} \mathrm{C}, 12 \mathrm{~h}, 51 \%$. b) $\mathrm{Zn}(\mathrm{OAc})_{2}$, DBU, pentanol, $140{ }^{\circ} \mathrm{C}, 24 \mathrm{~h}, 31 \%$.

\section{S-(Pent-4-en-1-yl) ethanethioate (3).}<smiles>C=CCCCSC(C)=O</smiles>

5-Bromo-1-pentene (3.07 g, $20.1 \mathrm{mmol}$ ) was dissolved in $10 \mathrm{~mL}$ of acetone in a two-neck round-bottom flask, and a solution of potassium thioacetate (3.49 g, $30.55 \mathrm{mmol}$ ) in $25 \mathrm{~mL}$ of acetone was added to the mixture. The reaction was kept under argon over night at room temperature. The mixture was concentrated on a rotary evaporator to dryness. The red solid was dissolved in dichloromethane $(60 \mathrm{~mL})$ and extracted with water ( 3 x $40 \mathrm{~mL}$ ). The organic phase was dried over $\mathrm{MgSO}_{4}$, filtered off and concentrated. Yield: $2.22 \mathrm{~g}$ (15.4 mmol, $77 \%)$ of a yellow oil.

${ }^{1} \mathrm{H}$ NMR (400 MHz, $\mathrm{CDCl}_{3}$ ) $\delta(\mathrm{ppm}): 5.78\left(\mathrm{ddd}, J=16.9,10.2,6.6 \mathrm{~Hz}, 1 \mathrm{H},-\underline{\mathrm{CH}}=\mathrm{CH}_{2}\right), 5.15-4.86(\mathrm{~m}$, $2 \mathrm{H},-\mathrm{CH}=\underline{\mathrm{CH}_{2}}$ ), 2.87 (t, $J=7.4 \mathrm{~Hz}, 2 \mathrm{H},-\underline{\mathrm{CH}_{2}}-\mathrm{SAc}$ ), 2.32 (s, 3H, $-\mathrm{CH}_{3}$ ), 2.12 (q, J = $7.05 \mathrm{~Hz}, 2 \mathrm{H},-\underline{\mathrm{CH}}_{2}-$ $\left.\mathrm{CH}=\mathrm{CH}_{2}\right), 1.67$ (p, $\left.J=7.4 \mathrm{~Hz}, 2 \mathrm{H},-\underline{\mathrm{CH}}_{2}-\mathrm{CH}_{2}-\mathrm{SAc}\right) .{ }^{13} \mathrm{C} \mathrm{NMR}\left(100 \mathrm{MHz}, \mathrm{CDCl}_{3}\right) \delta(\mathrm{ppm}): 195.83,137.39$, 115.39, 32.72, 30.62, 28.67, 28.48. 
Figure S8. ${ }^{1} \mathrm{H}$ NMR of $3\left(\mathrm{CDCl}_{3}\right)$

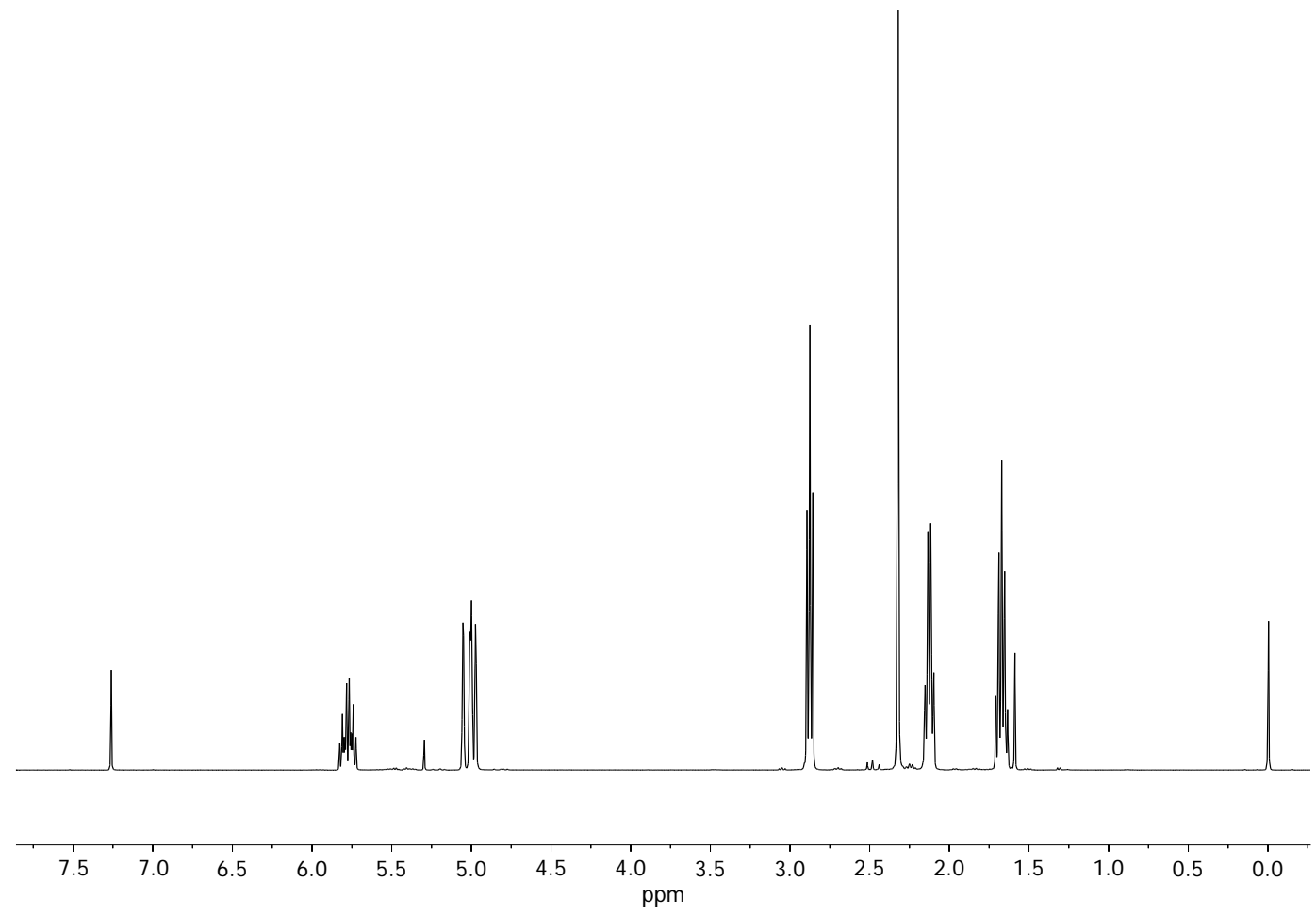

Figure S9. ${ }^{13} \mathrm{C}$ NMR of $3\left(\mathrm{CDCl}_{3}\right)$

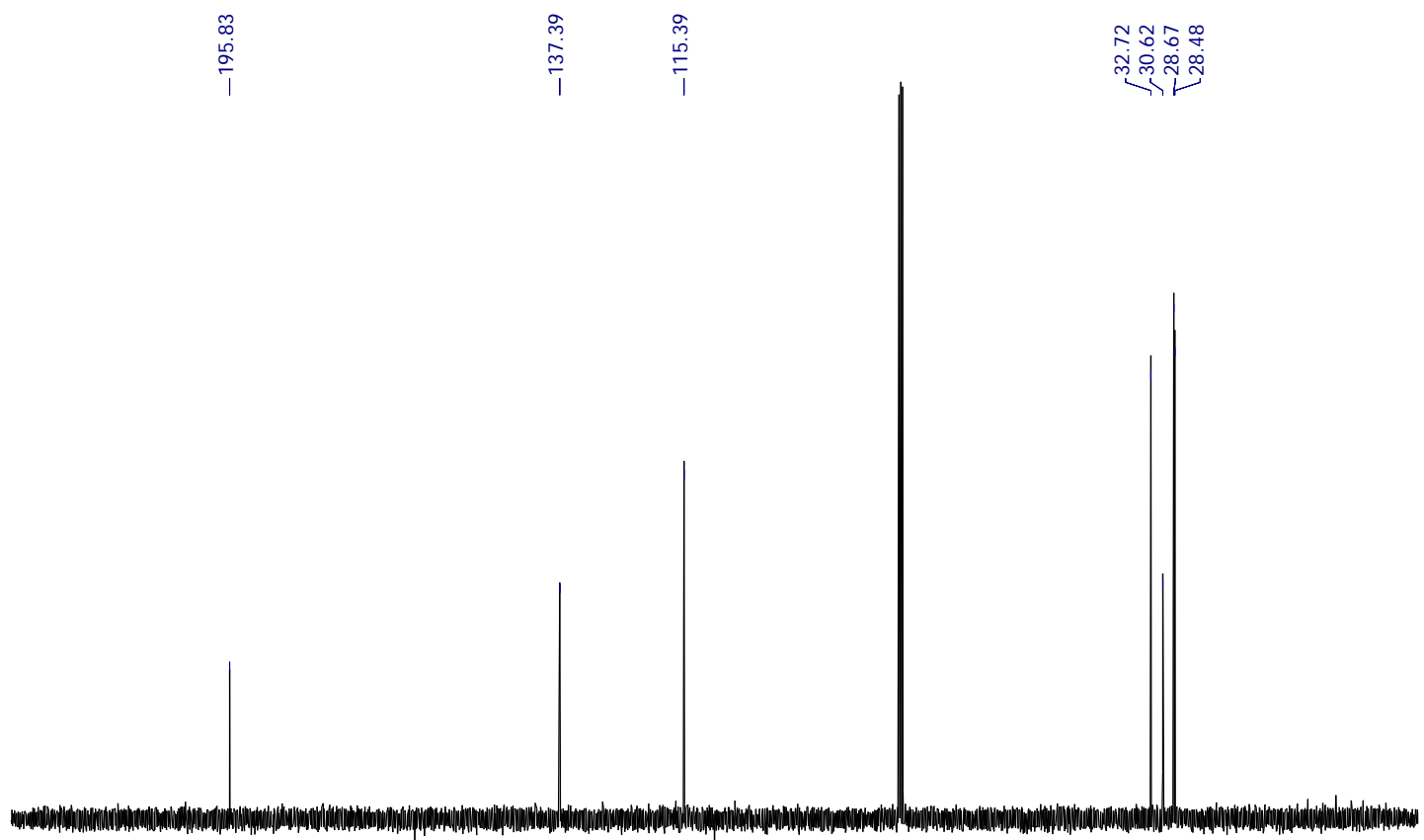

$\begin{array}{llllllllllllllllllllllllllll}230 & 220 & 210 & 200 & 190 & 180 & 170 & 160 & 150 & 140 & 130 & 120 & 110 & 100 & 90 & 80 & 70 & 60 & 50 & 40 & 30 & 20 & 10 & 0 & -10\end{array}$ 
4,5-bis(pent-4-en-1-ylthio)phthalonitrile (4).

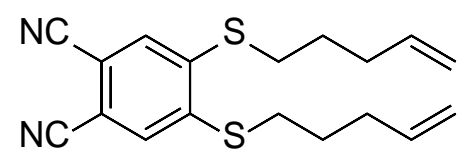

$\mathrm{K}_{2} \mathrm{CO}_{3}$ (4.89 g, $35.4 \mathrm{mmol}$ ) was dissolved in $60 \mathrm{~mL}$ of DMSO and stirred at room temperature for $20 \mathrm{~min}$. Then, $2.47 \mathrm{~g}$ (17.1 mmol) of thioacetal 3 was added dropwise to the stirring mixture. The reaction was stirred at room temperature for an additional 25 min under argon. Then, $0.65 \mathrm{~g}$ (3.32 mmol) of 3,5dichlorophthalonitrile dissolved in $15 \mathrm{~mL}$ of DMSO was added to the stirred mixture. The reaction was set to reflux overnight and subsequently it was allowed to cool to room temperature. Then the mixture was poured into $200 \mathrm{~mL}$ of brine and extracted with $3 \times 100 \mathrm{~mL}$ of diethyl ether. The combined organic layers were washed with 2 × $100 \mathrm{~mL}$ water. The organic layers were dried with $\mathrm{MgSO}_{4}$ and filtered. After evaporation of the solvent the material was purified by column chromatography using a mixture heptane: ethyl acetate. ( 9/1 v/v). Yield: $550 \mathrm{mg}(17.3 ; 51 \%$ ) of a white solid.

${ }^{1} \mathrm{H}$ NMR (400 MHz, $\mathrm{CDCl}_{3} \delta$ (ppm): 7.42 (s, 2H, Ar), 5.79 (ddt, $J=16.9,10.0,6.7 \mathrm{~Hz}, 2 \mathrm{H},-\underline{\mathrm{CH}}=\mathrm{CH}_{2}$ ), $5.17-5.00\left(\mathrm{~m}, 4 \mathrm{H},-\mathrm{CH}=\underline{\mathrm{CH}_{2}}\right), 3.02\left(\mathrm{t}, J=7.3 \mathrm{~Hz}, 4 \mathrm{H},-\mathrm{S}-\underline{\mathrm{CH}}_{2}-\right), 2.26$ (q, $\left.J=7.1 \mathrm{~Hz}, 4 \mathrm{H},-\mathrm{S}-\mathrm{CH}_{2}-\underline{\mathrm{CH}}_{2}-\right)$, 1.84 (p, $\left.J=7.3 \mathrm{~Hz}, 4 \mathrm{H},-\mathrm{S}-\mathrm{CH}_{2}-\underline{\mathrm{CH}}_{2}-\right) .{ }^{13} \mathrm{C} \mathrm{NMR}\left(100 \mathrm{MHz}, \mathrm{CDCl}_{3}\right) \delta(\mathrm{ppm}): 144.76,137.27,129.02$, 117.07, 116.29, 111.89, 33.26, 32.57, 27.85. MALDI-TOF-MS: calculated for $\mathrm{C}_{18} \mathrm{H}_{20} \mathrm{~N}_{2} \mathrm{~S}_{2} \mathrm{MW}=329.11$ $\mathrm{g} / \mathrm{mol}[\mathrm{M}+\mathrm{H}]$, observed $\mathrm{m} / \mathrm{z}=329.11$. FT-IR $($ ATR $) v\left(\mathrm{~cm}^{-1}\right):$ 3075, 2979, 2929, 2850, 2228, 1640, 1562, 1457, 1430, 1346, 1262, 1248, 1224, 1145, 1115, 1010, 988, 933, 901, 841, 777, 734, 691, 632, 531. 
Figure S10. ${ }^{1} \mathrm{H}$ NMR of $4\left(\mathrm{CDCl}_{3}\right)$
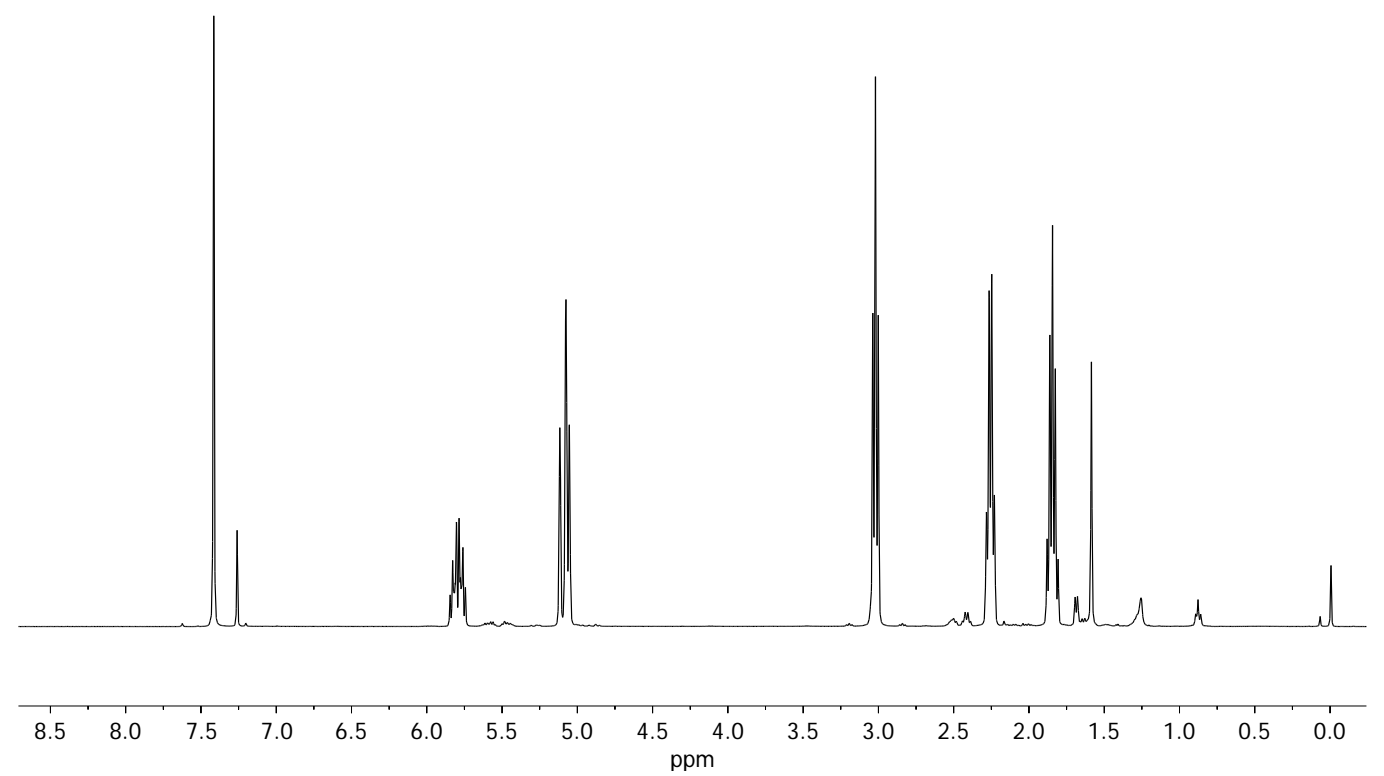

Figure S11. ${ }^{13} \mathrm{C}$ NMR of $4\left(\mathrm{CDCl}_{3}\right)$

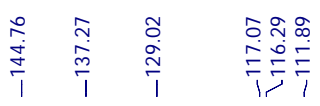
赵的品
mำก
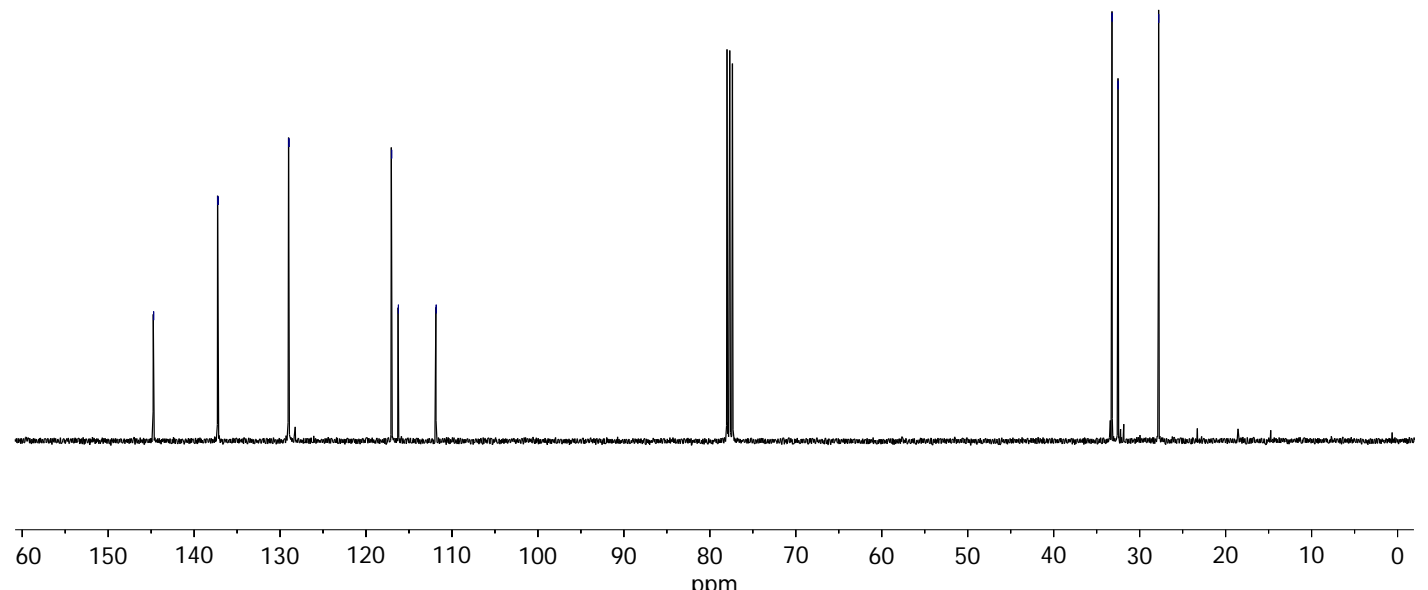


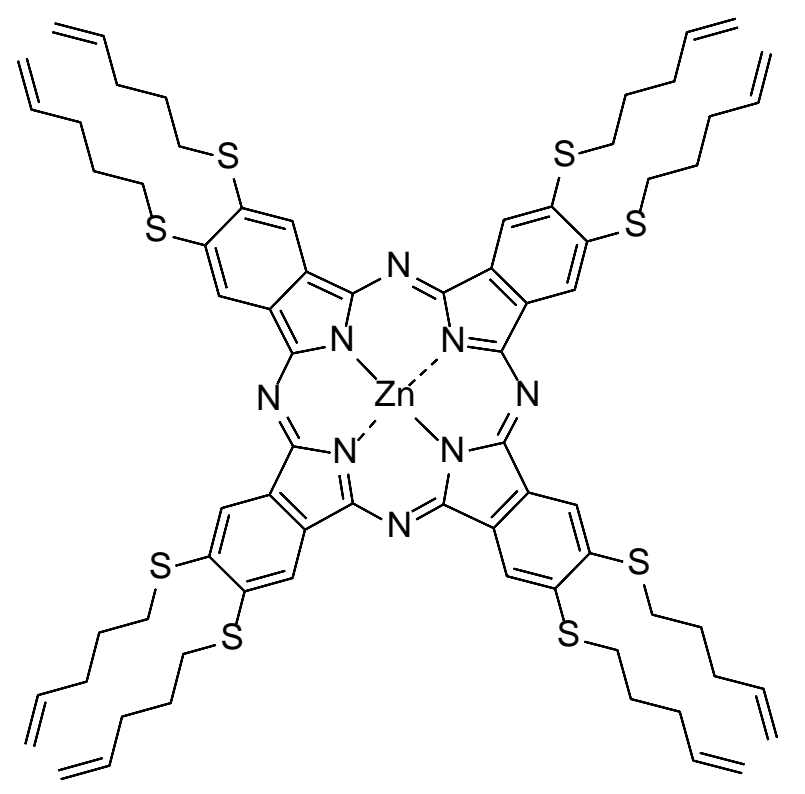

A mixture of 4 (156 mg, $0.50 \mathrm{mmol}), \quad \mathrm{Zn}(\mathrm{OAc})_{2} \quad(183 \mathrm{mg}, \quad 0.54 \mathrm{mmol})$, and 1,8diazabicyclo[5.4.0]undec-7-ene (DBU) $(25 \mu \mathrm{L}, 0,17 \mathrm{mmol})$ in pentanol (2 $\mathrm{mL})$ was heated to reflux under nitrogen for $24 \mathrm{~h}$ in a two-neck round-bottom flask. After being cooled to room temperature, the mixture was poured into $200 \mathrm{~mL}$ of $\mathrm{MeOH}$ and filtered. The residue was subjected to chromatography on a silica gel column using a mixture dichloromethane:methanol. (140/1 v/v). The solvent was removed by a rotary evaporator and the solid was triturated in methanol yielding a dark green compound after filtration. Yield: $102 \mathrm{mg}(17.3 ; 24 \%)$.

${ }^{1} \mathrm{H}$ NMR (400 MHz, $\mathrm{CDCl}_{3}$ ) $\delta(\mathrm{ppm}): 7.62$ - 6.82 (m, 8H, Pc), 5.83-5.52 (m, 8H, $-\underline{\mathrm{CH}}=\mathrm{CH}_{2}$ ), 5.01-4.63 (

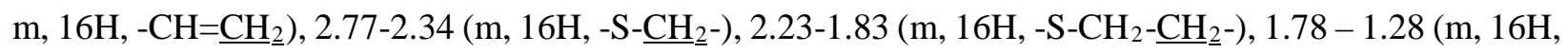
-S-CH$\left.{ }_{2} \underline{\mathrm{CH}}_{2}{ }^{-}\right)$. UV/Vis (THF): $\lambda_{\max }(\log \varepsilon)=704$ (5.4), 673 (4.4), 633 (4.5), 365 (4.8) nm. MALDI-TOFMS: calculated for $\mathrm{C}_{72} \mathrm{H}_{80} \mathrm{~N}_{8} \mathrm{~S}_{8} \mathrm{Zn} \mathrm{MW}=1376.36 \mathrm{~g} / \mathrm{mol}\left[\mathrm{M}^{+}\right]$, observed $\mathrm{m} / \mathrm{z}=1376.40$. FT-IR (ATR) $v$ $\left(\mathrm{cm}^{-1}\right):$ 3075, 2975, 2923, 2848, 1640, 1591, 1482, 1450, 1434, 1404, 1368, 1332, 1285, 1259, 1198, 1128, 1109, 1086, 1067, 988, 943, 909, 871, 841, 803, 778, 741, 699, 631, 545, 499. 
Figure S12. ${ }^{1} \mathrm{H} \mathrm{NMR}$ of $\mathbf{P c}\left(\mathrm{CDCl}_{3}\right)$

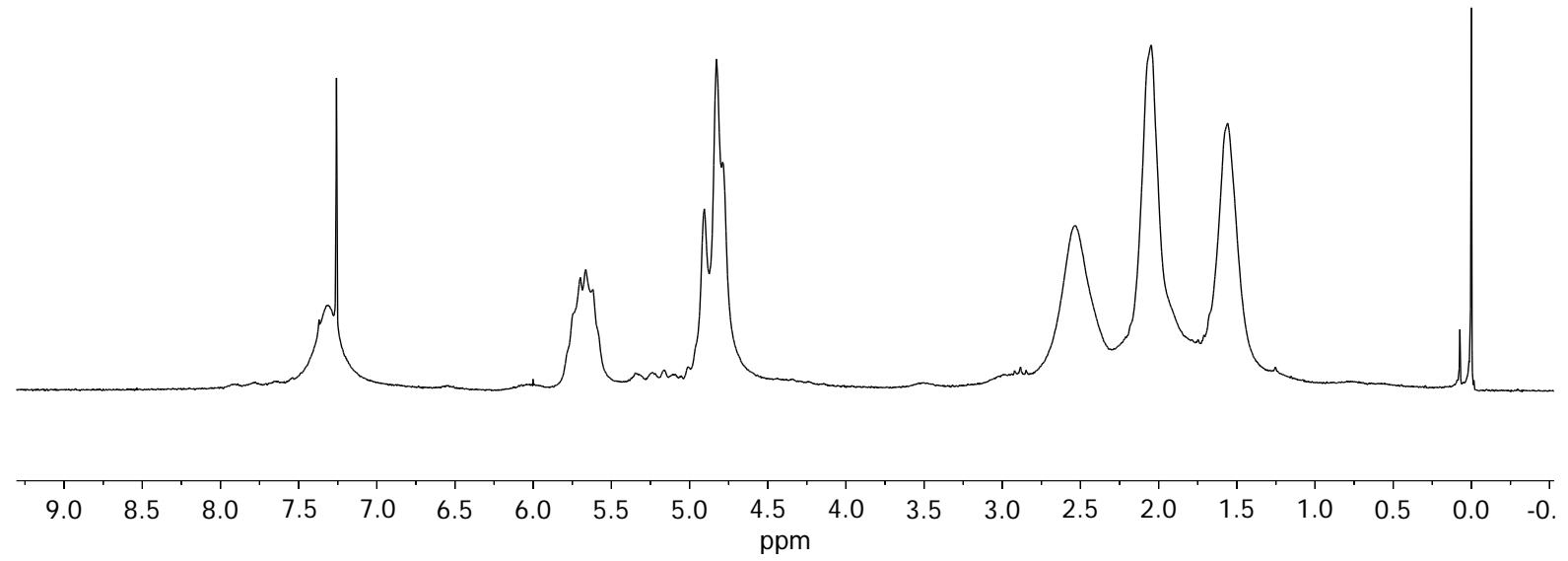


Figure S13. MALDI-TOF spectra and isotopic distribution pattern of Pc
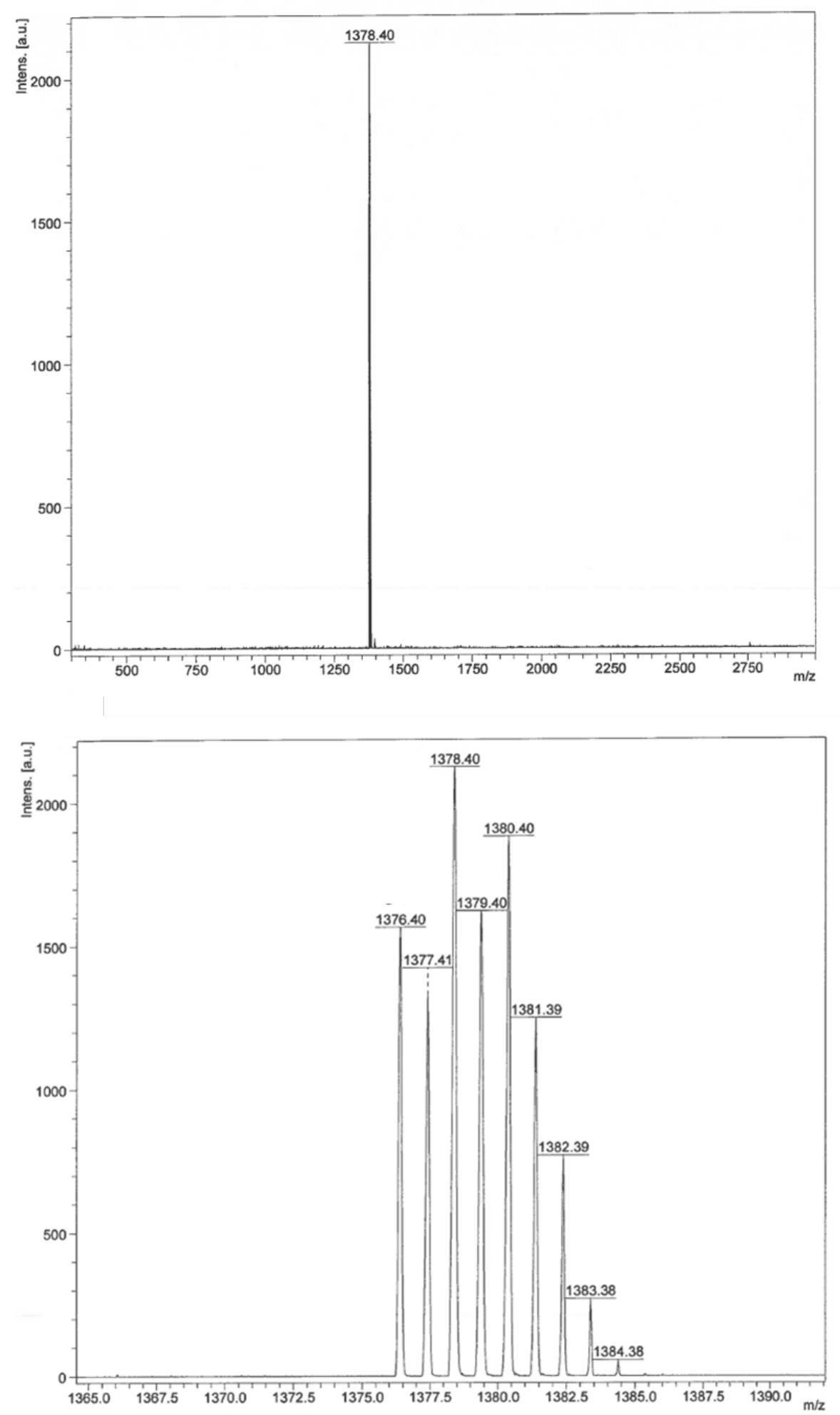


\section{I-OVDF}

$$
\begin{gathered}
\mathrm{CF}_{3-}\left(\mathrm{CH}_{2}-\mathrm{CF}_{2}\right) n\left(\mathrm{CF}_{2}-\mathrm{CH}_{2}\right) m^{-I} \\
\mathrm{~m}=0,1
\end{gathered}
$$

I-OVDF provided by Daikin Industries showed an orange color that was attributed to the presence of iodine. The presence of iodine might be detrimental for the radical reactions; therefore the product was purified using the following method:

$5.9 \mathrm{~g}$ of I-OVDF was magnetically stirred with $200 \mathrm{~mL}$ of ethylacetate in a round bottomed flask, in a nitrogen gas atmosphere for $30 \mathrm{~min}$. Then $20 \mathrm{~mL}$ of $1 \mathrm{M}$ sodium bisulfite (aq) was added, and within a minute the solution turned colourless. The contents of the flask where decanted over a paper filter into a separatory funnel. Subsequently, the solution poured into $200 \mathrm{~mL}$ of water and the mixture was extracted with 2 x $50 \mathrm{~mL}$ of ethyl acetate (phase separation takes very long) and 2x $100 \mathrm{~mL}$ of brine. The combined ethyl acetate fractions were magnetically stirred with magnesium sulfate hydrate for an hour. Finally, after filtering through a paper filter (very slow process) the solvent was removed on a rotary evaporator, followed by vacuum drying in a vacuum stove (at $30{ }^{\circ} \mathrm{C}$ ). Yield: $4.42 \mathrm{~g}(75 \%)$ of a white powder. Analysis with ${ }^{1} \mathrm{H}-$ and ${ }^{19} \mathrm{~F}-\mathrm{NMR}$ (acetone- $\boldsymbol{d}_{6}$ solution) are exactly the same as the crude product.

${ }^{1} \mathrm{H}$ NMR (400 MHz, acetone- $\left.d_{6}\right) \delta(\mathrm{ppm}): 3.96-3.76$ (m, 0.52H, - $\left.\mathrm{CH}_{2}-\mathrm{I}\right), 3.76-3.49$ (m, 1.59H, - $\mathrm{CH}_{2}$ $\left.\mathrm{CF}_{2}-\mathrm{I}\right), 3.35-3.15\left(\mathrm{~m}, 2 \mathrm{H},-\mathrm{CH}_{2}-\mathrm{CF}_{3}\right), 3.13-2.77\left(\mathrm{~m}, 8.38 \mathrm{H},-\mathrm{CH}_{2}-\right) .{ }^{19} \mathrm{~F}$ NMR (376 MHz, acetone-d6) $\delta$ (ppm): -38.93 - -41.14 (m, -CF $-\mathrm{I})$, -62.06 (p, $J=9.8 \mathrm{~Hz},-\mathrm{CF}_{3}$ ), -91.04 - -95.44 (m, -CF 2 -), -109.35 (s, $\left.\mathrm{CF}_{2}-\mathrm{CH}_{2}-\mathrm{I}\right) .-113.01\left(\mathrm{~s},-\mathrm{CF}_{2}-\mathrm{CH}_{2}-\mathrm{I}\right)$. FT-IR (ATR) $v\left(\mathrm{~cm}^{-1}\right): 1400,1269,1139,880,840$. SEC (THF, polystyrene standards): $M_{\mathrm{n}}: 522 \mathrm{~g} / \mathrm{mol}, M_{\mathrm{w}}: 718 \mathrm{~g} / \mathrm{mol}, \emptyset: 1,37$. 
Figure S14. ${ }^{1} \mathrm{H}$ NMR of I-OVDF (acetone- $d_{6}$ )

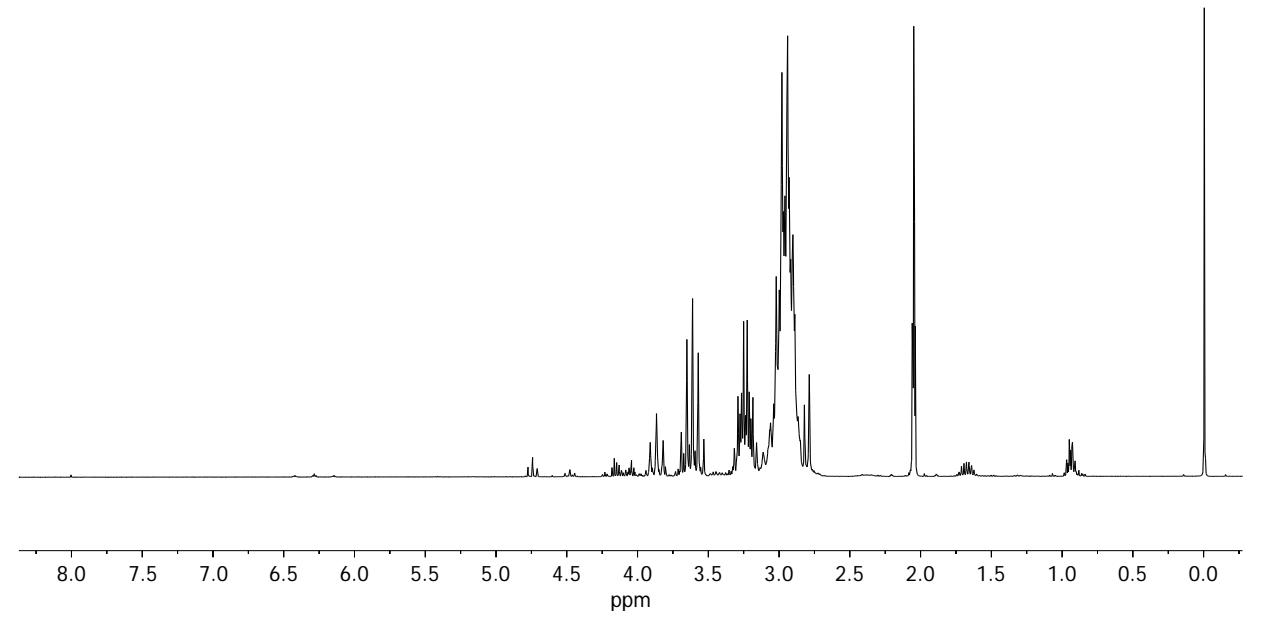

Figure S15. ${ }^{19} \mathrm{~F}$ NMR of I-OVDF (acetone- $d_{6}$ )

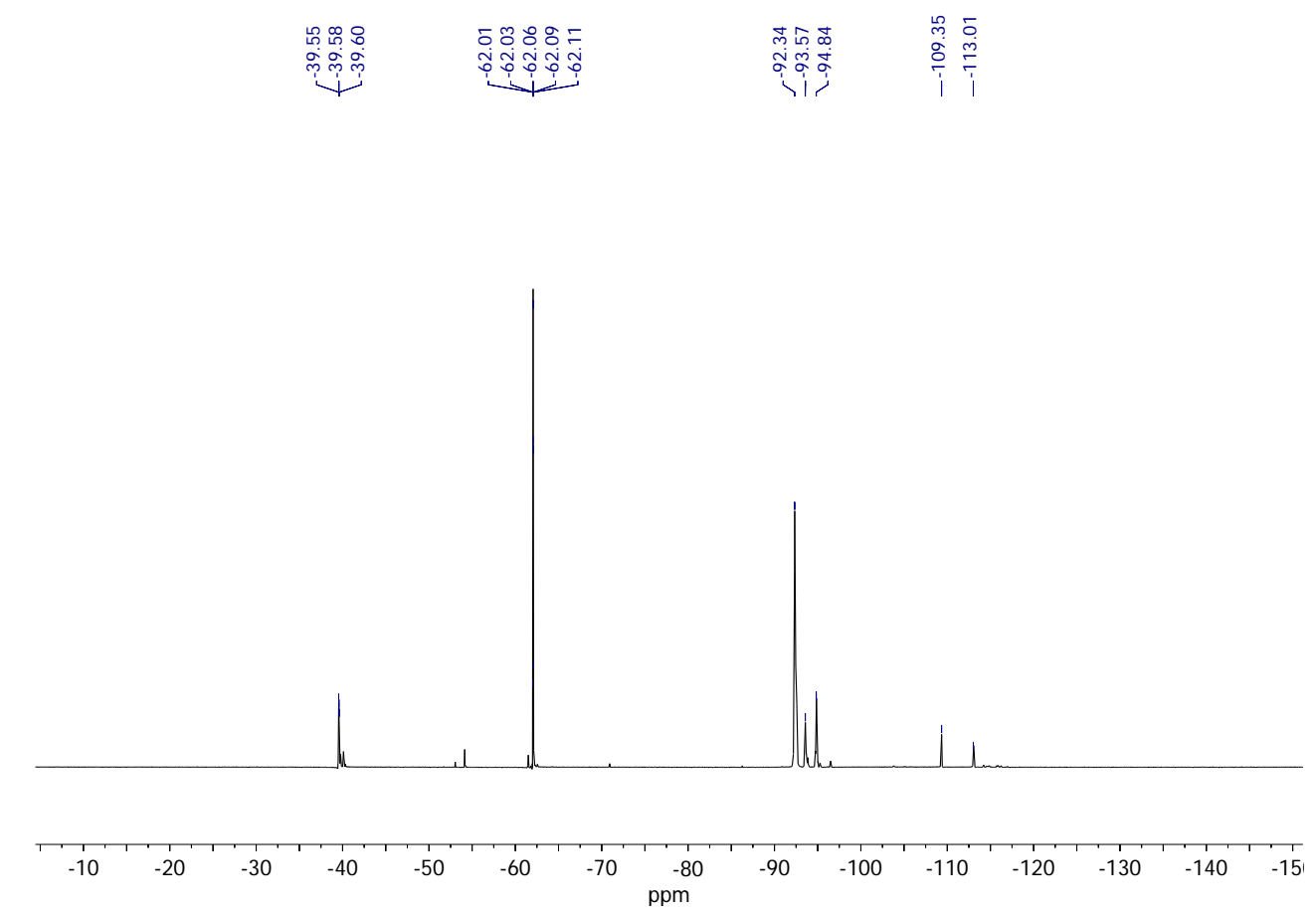


Figure S16. DSC traces of I-OVDF

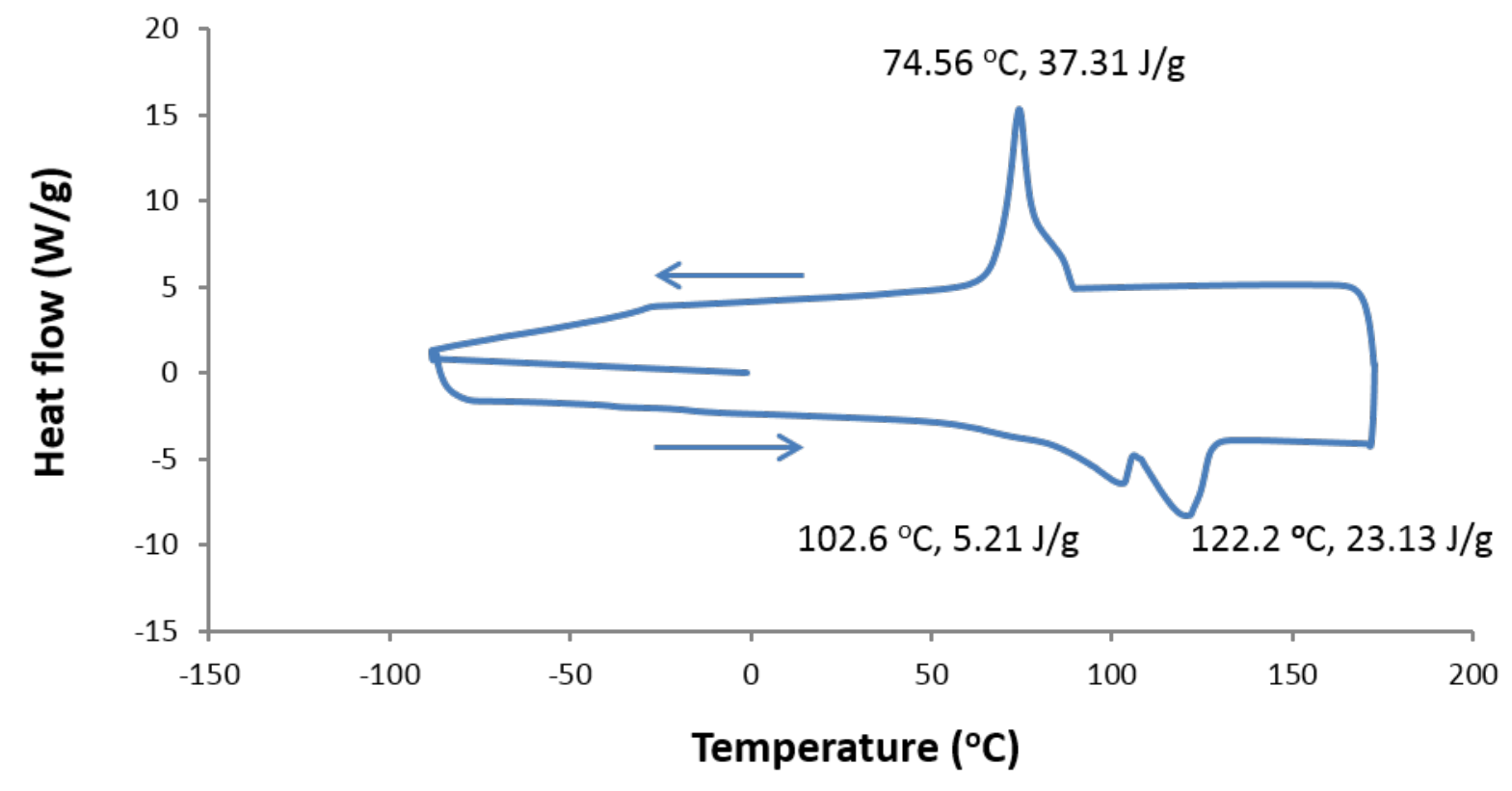




\section{Unsuccessful synthetic coupling strategies:}

A number of synthetic coupling strategies were evaluated as mentioned in the manuscript, however none of them worked except the radical coupling.

First reactions attempted were performed using the same conditions described by Vukićević, R. et $a l l,{ }^{1}$ however, starting materials and some sub-products (loss of the azide) were obtained. Therefore, authors decided to try with the conditions described by Prof. M.G. Finn, using the most powerful ligand they described. ${ }^{2}$ Unfortunately the reaction continued to fail, observing some elimination sub-products in this case (probably due to the basicity of the ligand).

The selective elimination of iodine was attempted following the zeolite assisted synthesis procedure developed by Kitagawa. ${ }^{3}$ However, unsuccessful coupling in the absence of zeolites due to the formation of elimination sub-products was achieved. Reactions were performed using one equivalent of different inorganic and organic bases (i.e Potassium carbonate, sodium hydrogen carbonate, pyridine, trimethylamine and sodium acetate) and in some occasions a defect of them respect to the oligomers. However, the selective elimination of the iodine in order to yield terminal olefins did not work, obtaining elimination sub products along the oligomer chains as Kitagawa and coauthors did.

Other reactions such as fluoroalkylations of arylboronic acids with fluoroalkyl iodides were tested ${ }^{4}$ on IOVDF but only afforded undesired products. Same conditions than the ones described for the authors in ref 4 were used, avoiding the use of bases as additives and phenylboronic acid. However, starting materials were recovered without any coupled product.

Finally, a number of synthetic radical coupling strategies were evaluated using as substrate BTA molecule. Several radical initiators were tested in order to perform the coupling such as AIBN or benzoyl peroxide, however the only one working was bis(4-(tert-butyl)cyclohexyl) peroxydicarbonate.

\section{General procedure for the radical coupling:}

To a solution of allyl derivative ( BTA ${ }^{1}$, PBI, Pc) $(0.022 \mathrm{mmol})$ and I-OVDF (105 mg for BTA, $210 \mathrm{mg}$ for PBI, $280 \mathrm{mg}$ for Pc) in ethyl acetate ( $8 \mathrm{~mL}$ ), bis(4-tert-butylcyclohexyl) peroxydicarbonate $(0.127$ mmol for BTA, $0.255 \mathrm{mmol}$ for PBI and $0.341 \mathrm{mmol}$ for Pc) was added in small portions over an hour. Subsequently the mixture was heated under argon atmosphere at $60^{\circ} \mathrm{C}$ for $6 \mathrm{~h}$. Then the mixture was poured into $100 \mathrm{~mL}$ of water and extracted with $3 \times 100 \mathrm{~mL}$ of ethyl acetate. The combined organic layers were washed with $2 \times 100 \mathrm{~mL}$ water, $100 \mathrm{~mL}$ brine and dried with $\mathrm{MgSO}_{4}$. After the evaporation of the solvent on a rotary evaporator the crude was purified in the last step on a SEC column (Biobeads@) using freshly distilled THF as the mobile phase. The main fraction (eluting first in all the cases) was recovered and concentrated in vacuum. The polymeric material was then suspended in boiling hexane, filtered and dried in vacuum, affording BTA-OVDF (33 mg, yellow solid), PBI-OVDF (71 mg, red solid) and Pc-OVDF (63 mg, blue solid). 


\section{BTA-OVDF}<smiles>[R]CC(I)[C@H](C)NC(=O)c1cc(C(=O)N[C@H](C)[C@H](I)C[R])cc(C(=O)N[C@H](C)[C@H](I)C[R])c1</smiles>

${ }^{1} \mathrm{H}$ NMR (400 MHz, acetone- $d_{6}$ ) $\delta(\mathrm{ppm}): 8.78$ - 8.26 (m, 3H, Ar), 5.06 (m, $\left.0.9 \mathrm{H},-\underline{\mathrm{CH}}-\mathrm{I}\right), 4.76$ - 4.28 (m, $2 \mathrm{H},-\underline{\mathrm{CH}}-\mathrm{I}), 4.23-3.88$ (m, 3H, CH3- $\underline{\mathrm{CH}}-)$, 3.61 (m, 2.5H, I-CH- $\left.\underline{\mathrm{CH}}_{2}-\mathrm{CF}_{2}\right), 3.41-3.15$ (m, 6H,-CH $-\mathrm{CF}_{3}$ ), $3.12-2.81\left(\mathrm{~m}, 22 \mathrm{H},-\left(\mathrm{CH}_{2}-\mathrm{CF}_{2}\right)_{\mathrm{n}}-\right), 2.57\left(\mathrm{~m}, 3 \mathrm{H}, \mathrm{I}-\mathrm{CH}-\underline{\mathrm{CH}_{2}}-\underline{-\mathrm{CH}_{2}}-\mathrm{CF}_{2}\right), 1.54-1.27\left(\mathrm{~m}, 9 \mathrm{H},-\mathrm{CH}_{3}\right) .{ }^{19} \mathrm{~F}$ NMR (376 MHz, acetone- $\left.d_{6}\right) \delta(\mathrm{ppm}):-62.00--62.11\left(\mathrm{~m},-\underline{\mathrm{CF}}_{3}\right),-92.38,-94.87--94.95\left(\mathrm{~m},-\mathrm{CF}_{2}-\right)$. FTIR (ATR) $v\left(\mathrm{~cm}^{-1}\right): 2981,2975,1658,1595,1404,1271,1153,1072,879,840$. SEC (THF, polystyrene standards): $M_{\mathrm{n}}: 2412 \mathrm{~g} / \mathrm{mol}, M_{\mathrm{w}}: 2876 \mathrm{~g} / \mathrm{mol}, \emptyset=1.19$.

Figure S17. ${ }^{1} \mathrm{H}$ NMR of BTA-OVDF (acetone- $d_{6}$ )

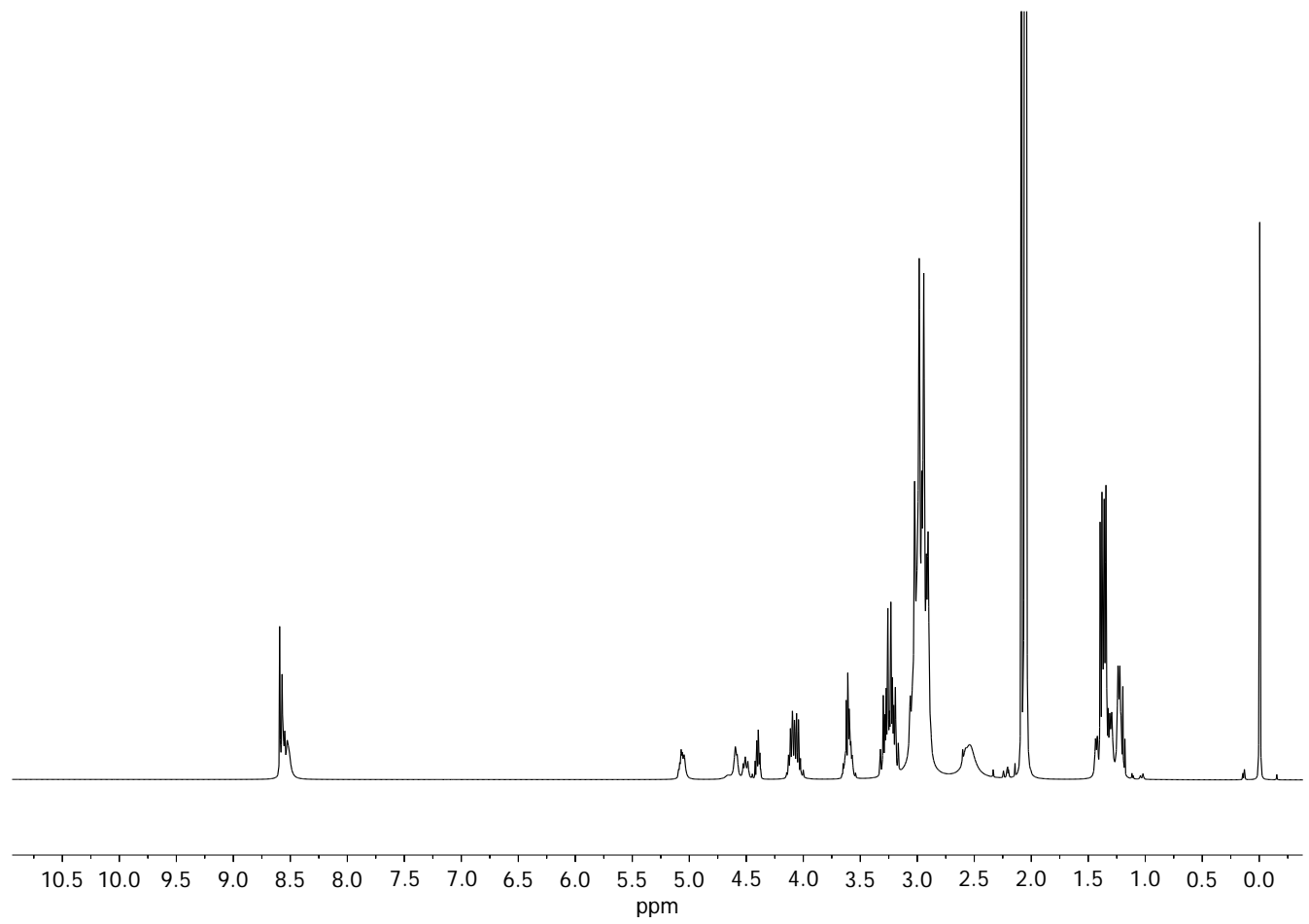


Figure S18. ${ }^{19}$ F NMR of BTA-OVDF (acetone- $d_{6}$ )

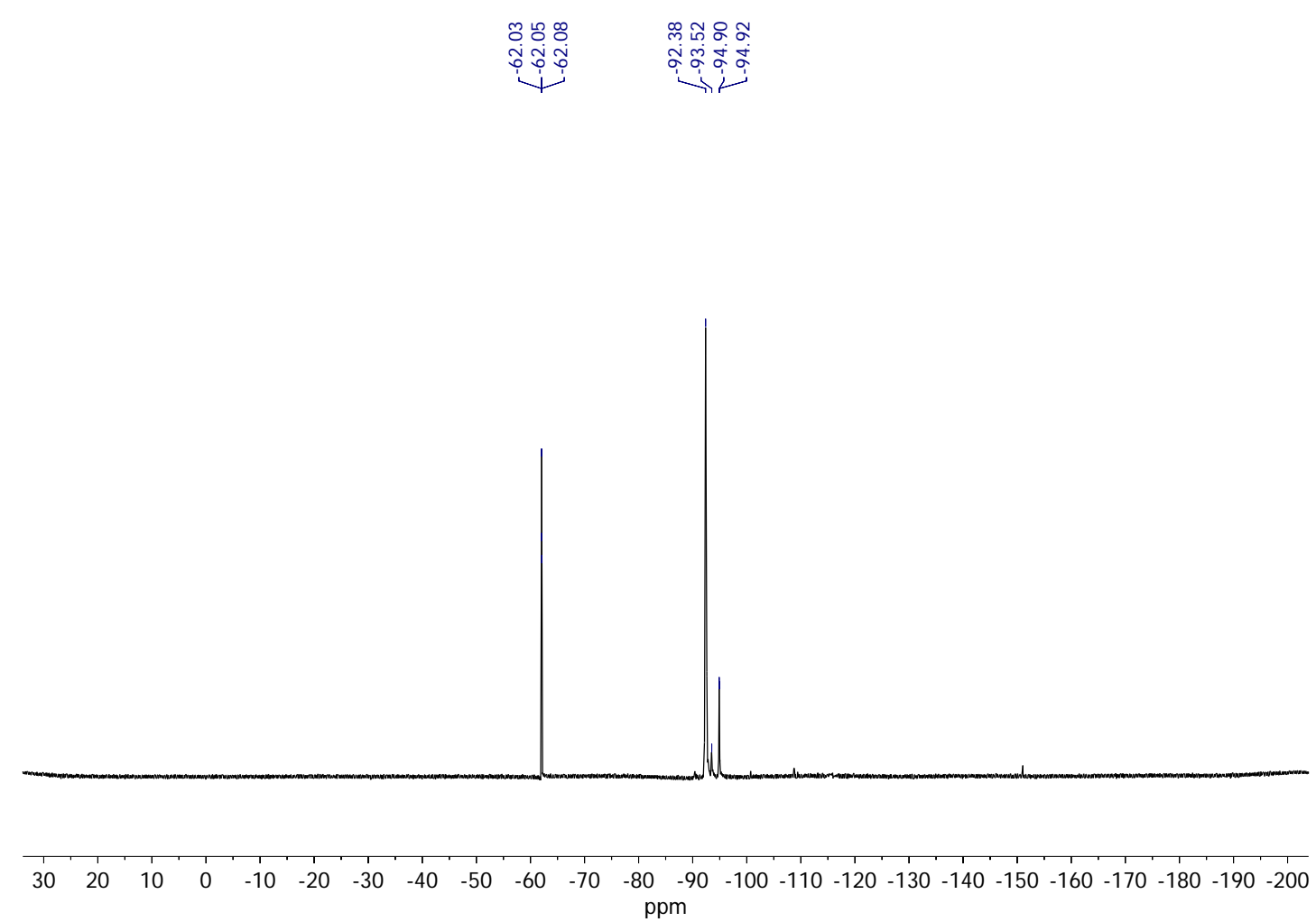

Figure S19. DSC traces of BTA-OVDF

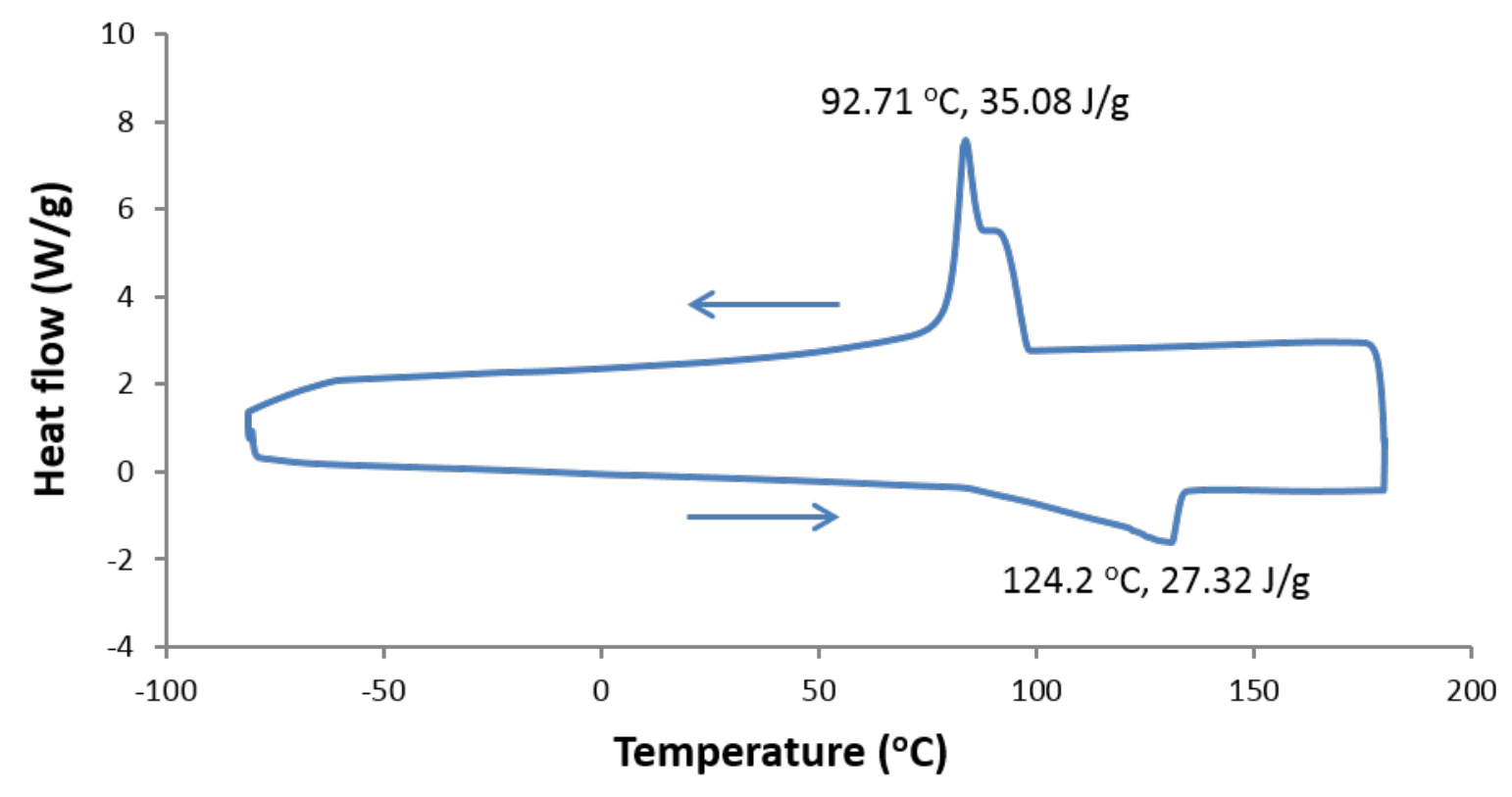




\section{PBI-OVDF}

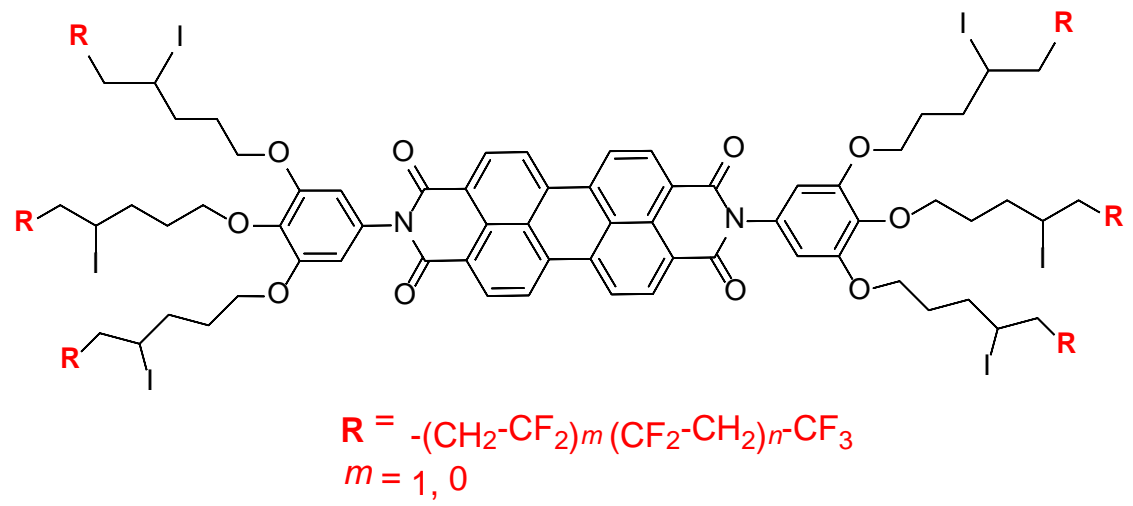

${ }^{1} \mathrm{H}$ NMR (400 MHz, acetone- $d_{6}$ ) $\delta(\mathrm{ppm}): 7.59-6.27$ (m, 16H), 5.22-4.45 (m, 6H), 4.31 - 3.85 (m, 8H), 3.64-3.59 (m, 4H), 3.30-3.22 (m, $J=15.3,6.8$ Hz, 12H), 3.12-2.81 (m, 56H), 1.47-1.46 (m, 4H), 137-1.34 (m, 6H), 0.92-0.84 ( m, 10H). ${ }^{19} \mathrm{~F}$ NMR (376 MHz, acetone- $d_{6} \delta(\mathrm{ppm}):-61.99--62.09$ (m, - $\left.\mathrm{CF}_{3}\right),-92.38$ , -94.90 (m, -CF ${ }_{2}$ ). FT-IR (ATR) v ( $\left.\mathrm{cm}^{-1}\right):$ 2941, 1670, 1595, 1398, 1191, 1112, 878, 840, 732. SEC (THF, polystyrene standards): $M_{\mathrm{n}}: 6525 \mathrm{~g} / \mathrm{mol}, M_{\mathrm{w}}: 7097 \mathrm{~g} / \mathrm{mol}, Ð=1.09$.

Figure S20. ${ }^{1} \mathrm{H}$ NMR of PBI-OVDF (acetone- $d_{6}$ )

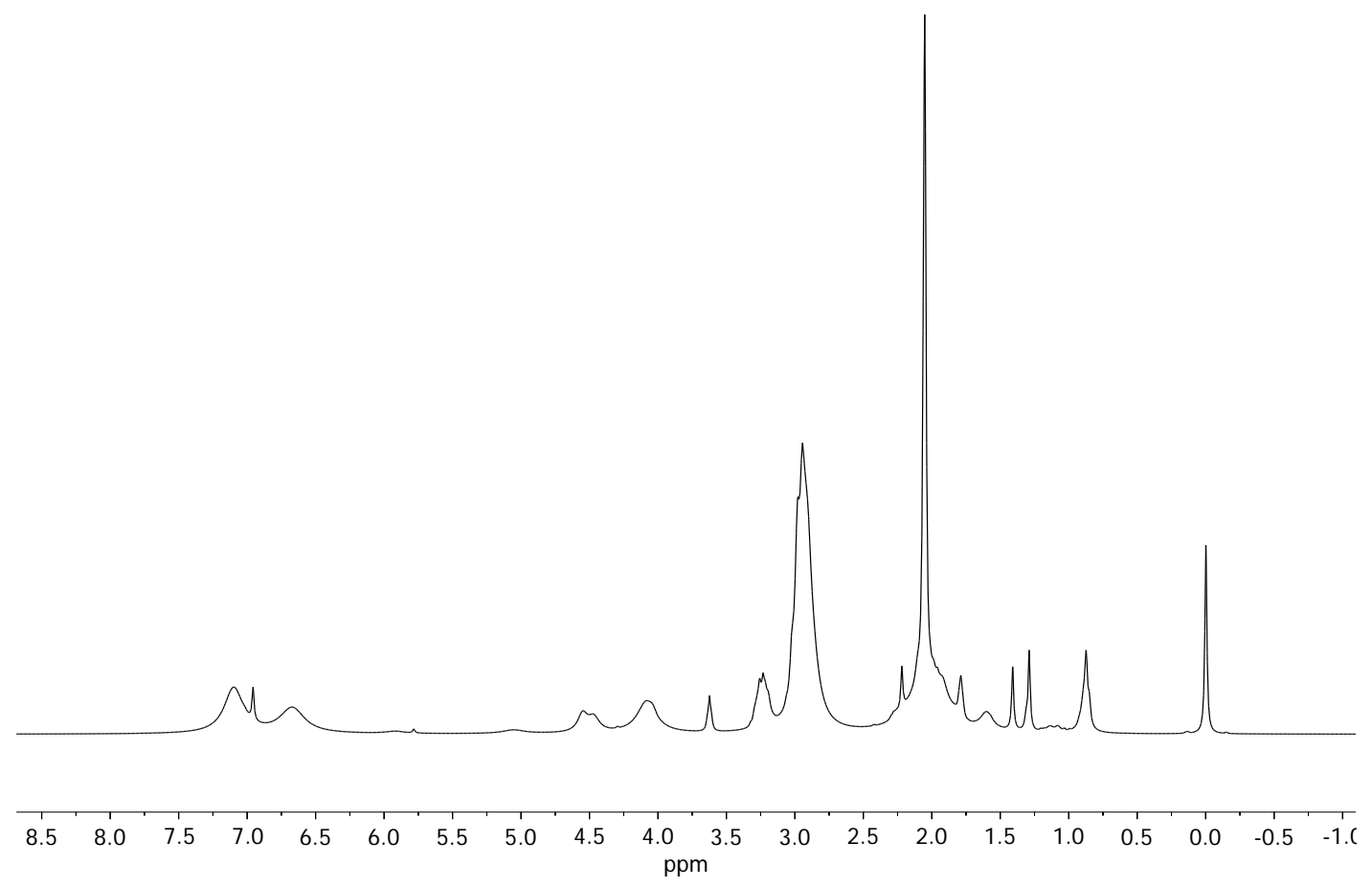


Figure S21. ${ }^{19} \mathrm{~F}$ NMR of PBI-OVDF (acetone- $d_{6}$ )

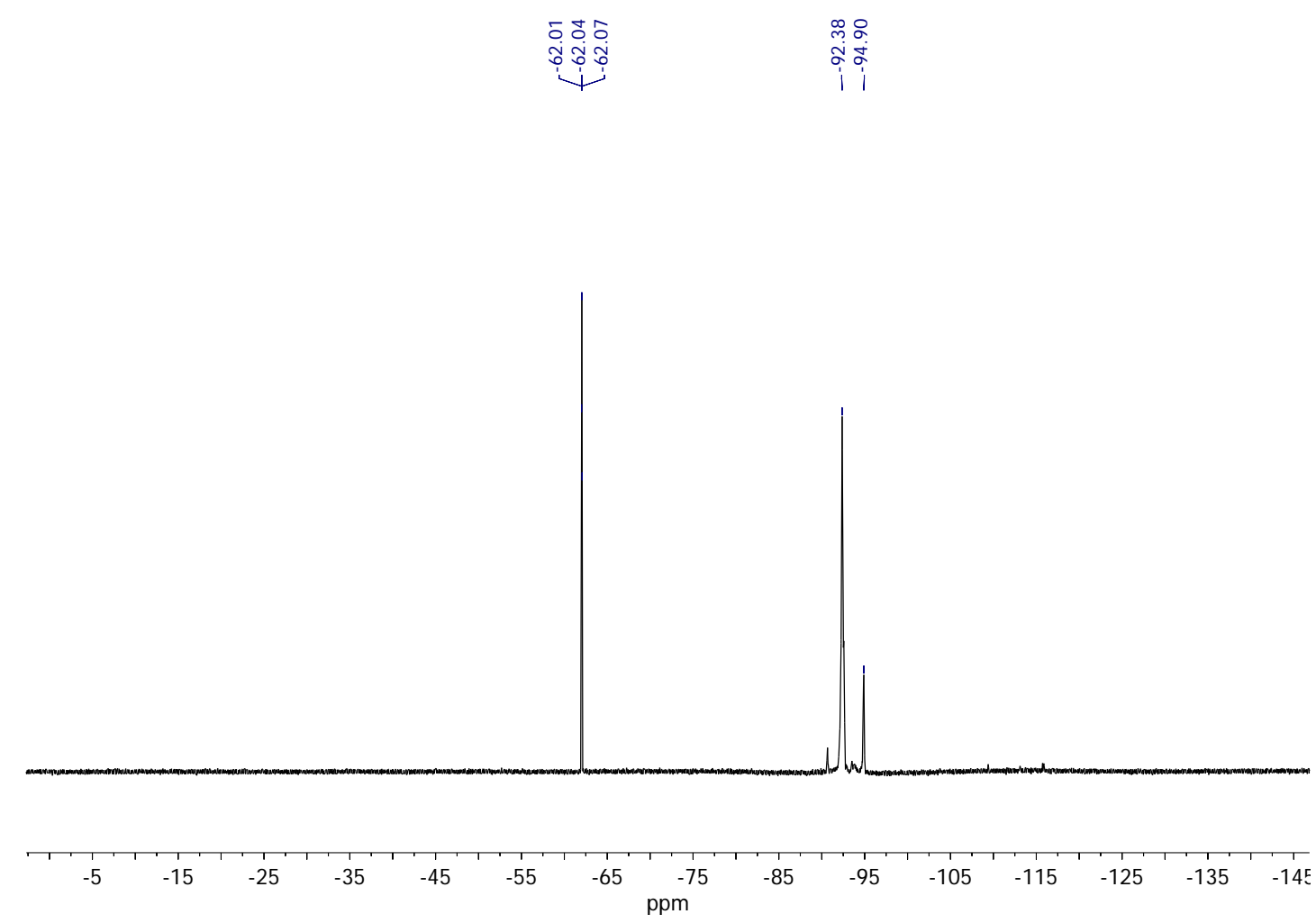

Figure S22. MALDI-TOF spectra of PBI-OVDF

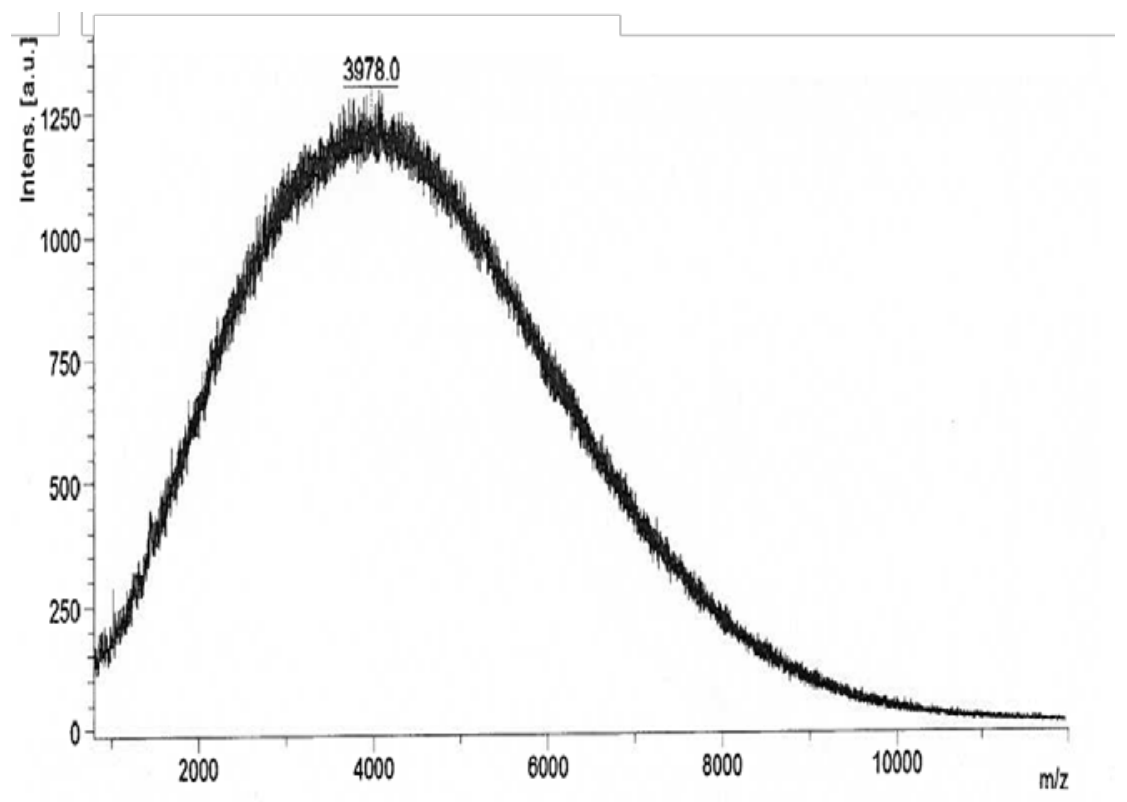


Figure S23. DSC traces of PBI-OVDF

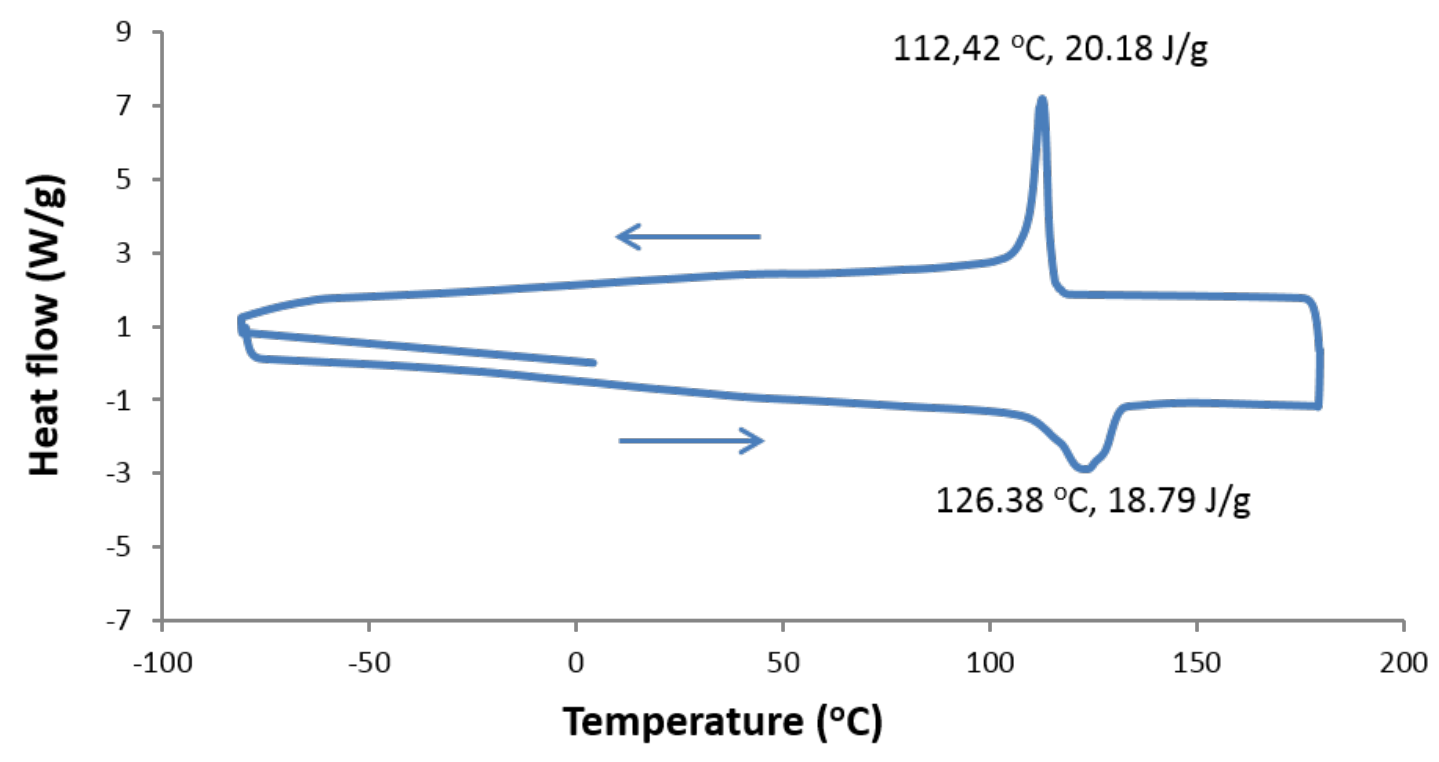

\section{Pc-OVDF}

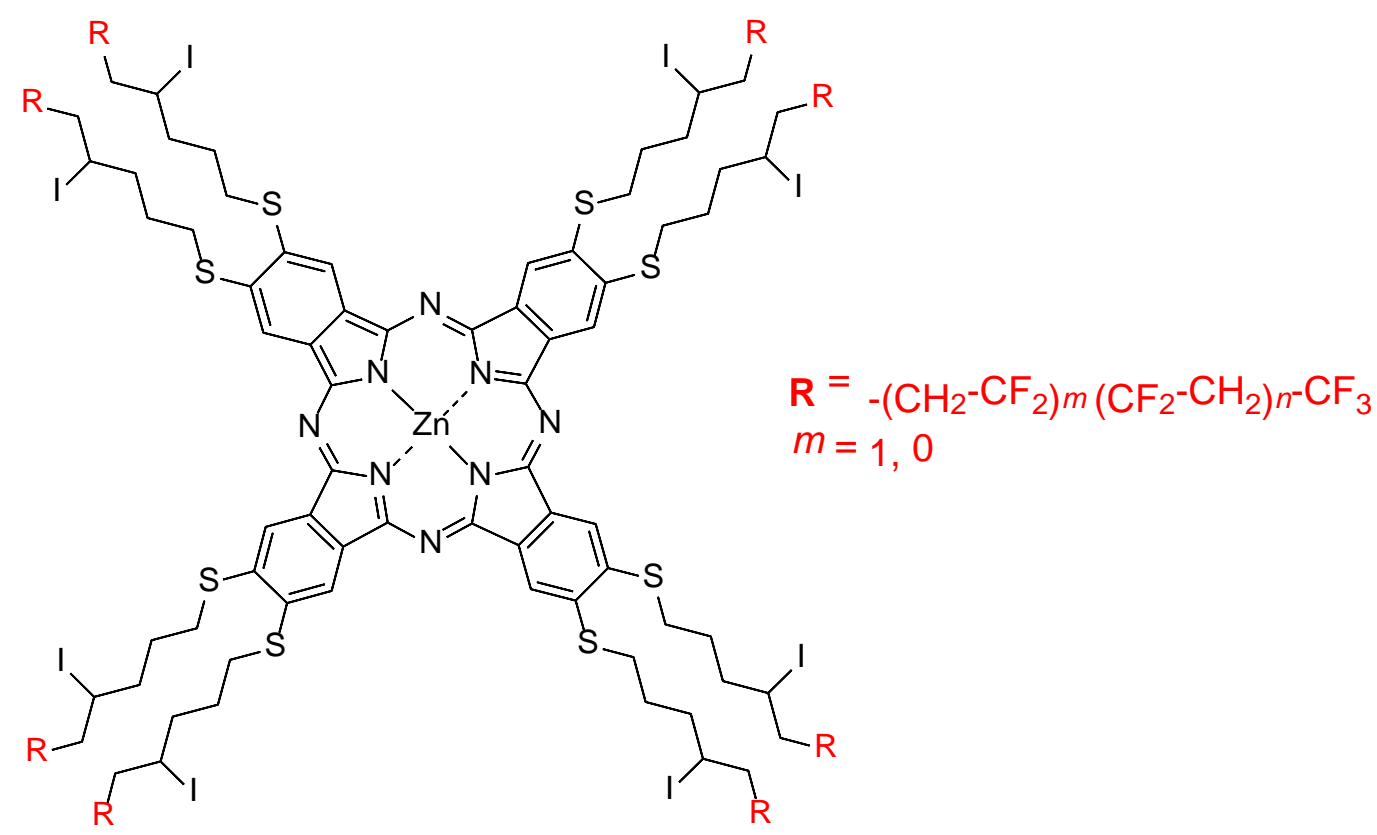

${ }^{1} \mathrm{H}$ NMR (400 MHz, acetone- $\left.d_{6}\right) \delta(\mathrm{ppm}): 8.50$ - $7.27(\mathrm{~m}), 5.02-4.3(\mathrm{~m}), 4.31$ - $3.85(\mathrm{~m}), 3.32-3.22(\mathrm{~m})$, 3.12 - $2.81(\mathrm{~m}), 2.10$ - $1.82(\mathrm{~m}), 1.71-0.84(\mathrm{~m}) .{ }^{19} \mathrm{~F}$ NMR (376 MHz, acetone- $\left.d_{6}\right) \delta(\mathrm{ppm}):-60.93--60.47$ (m, $\left.-\underline{\mathrm{CF}}_{3}\right)$, -90.08 , -92.25 (m, -CF 2 -). FT-IR (ATR) $v\left(\mathrm{~cm}^{-1}\right)$ : 2943, 2932, 1555, 1400, 1190, 1110, 880, 841, 742. SEC (THF, polystyrene standards): $M_{\mathrm{n}}: 7557, M w: 9253, Ð=1.18$. 
Figure S24. ${ }^{1} \mathrm{H}$ NMR of Pc-OVDF (acetone- $d_{6}$ )

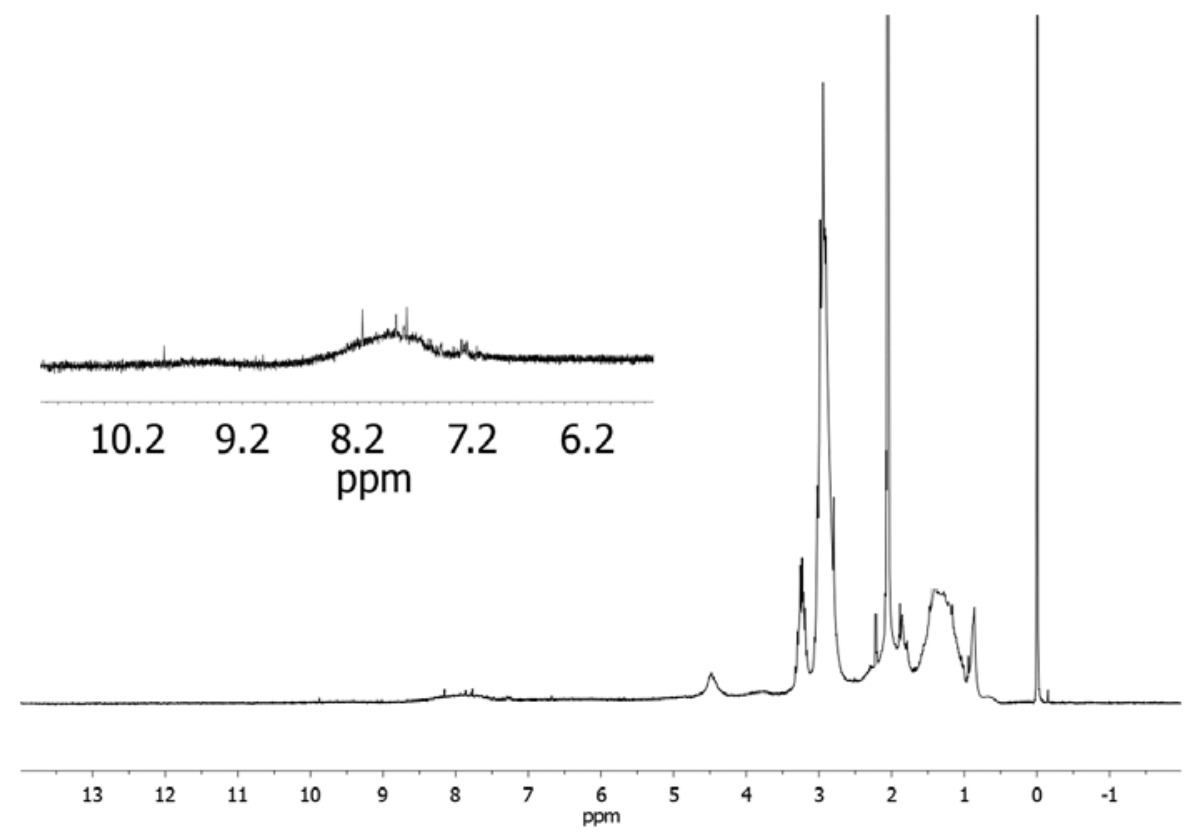

Figure S25. ${ }^{19}$ F NMR of Pc-OVDF (acetone- $d_{6}$ )

我
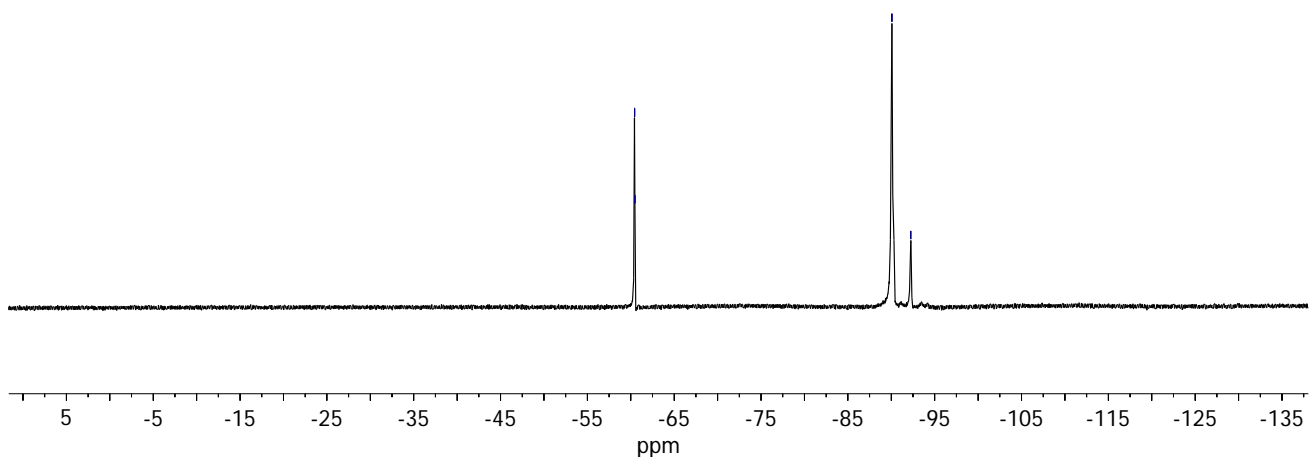
Figure S26. MALDI-TOF spectra of Pc-OVDF

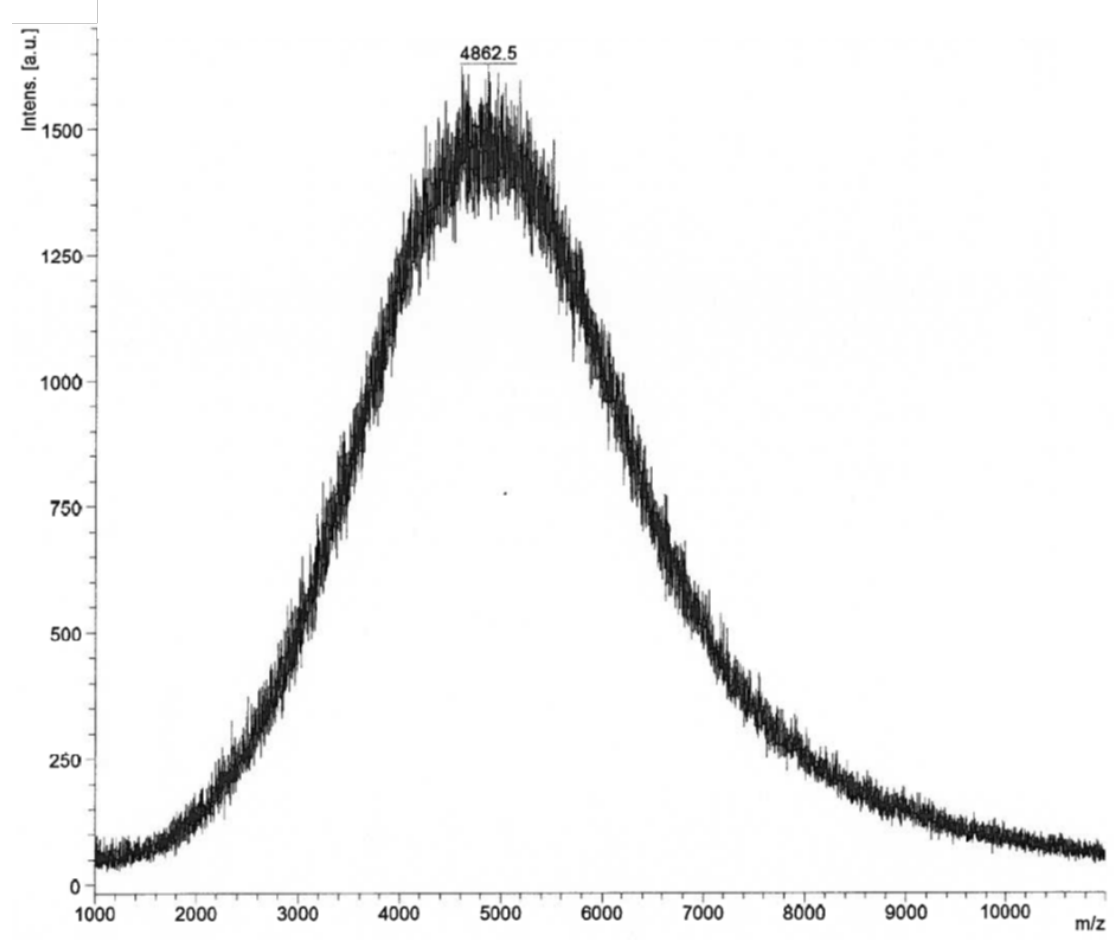

Figure S27. DSC traces of Pc-OVDF

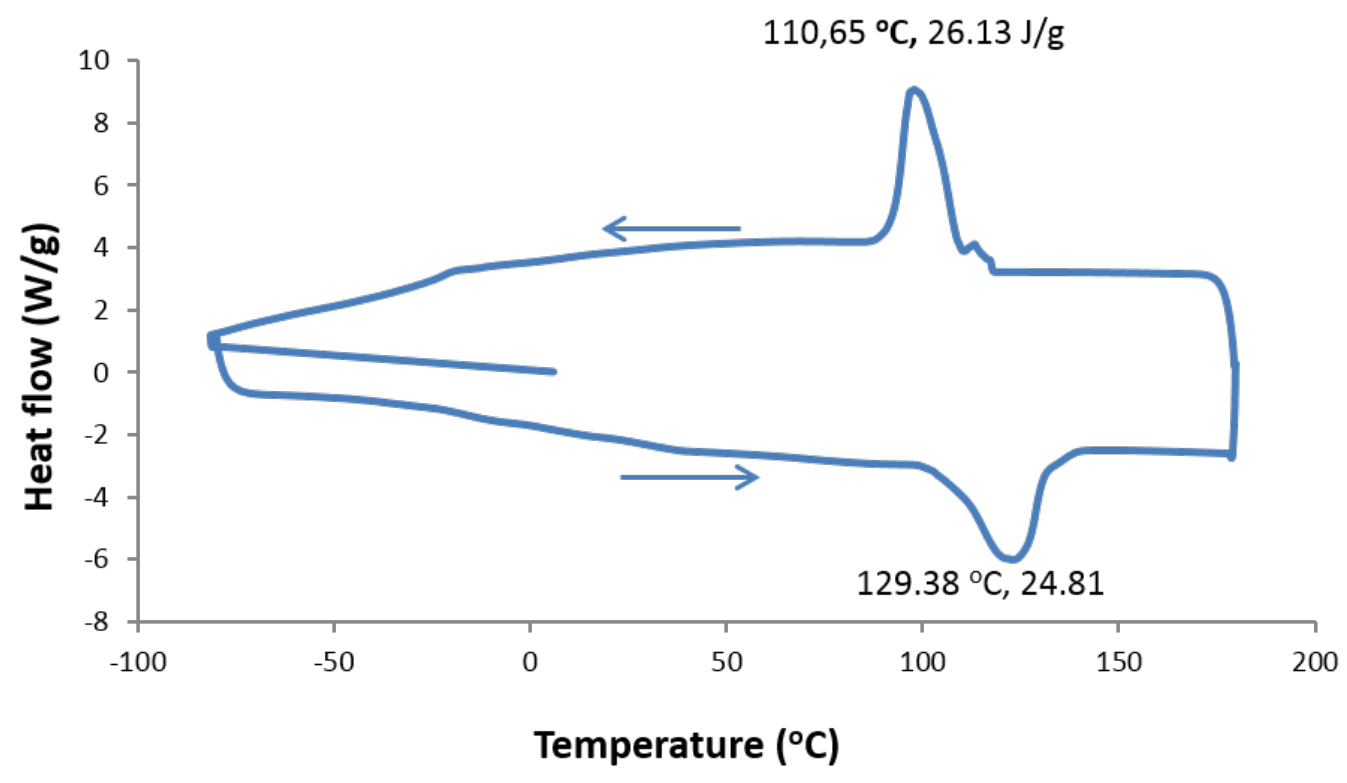




\section{Supporting data}

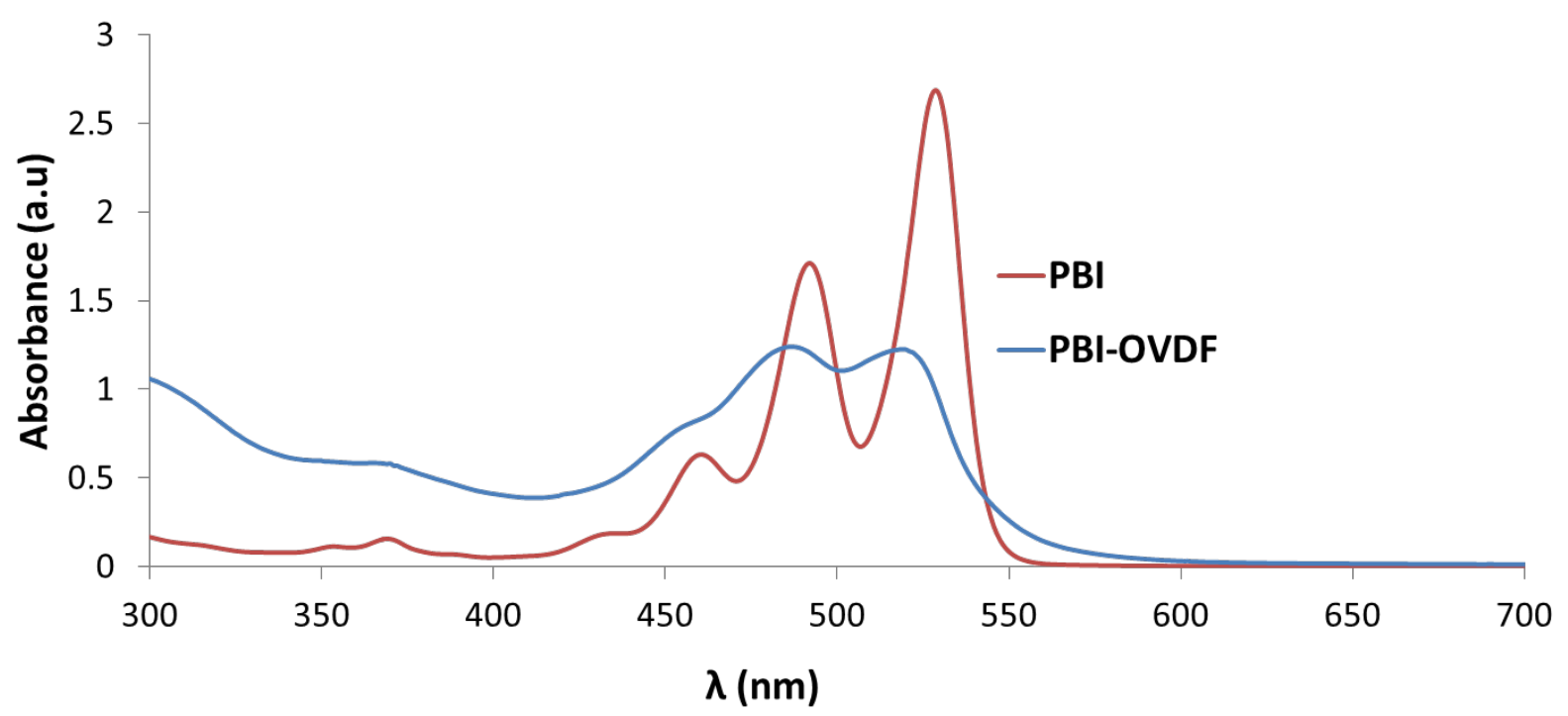

Figure S28. Normalized UV-Vis spectra of PBI and PBI-OVDF in THF at $20^{\circ} \mathrm{C}$.

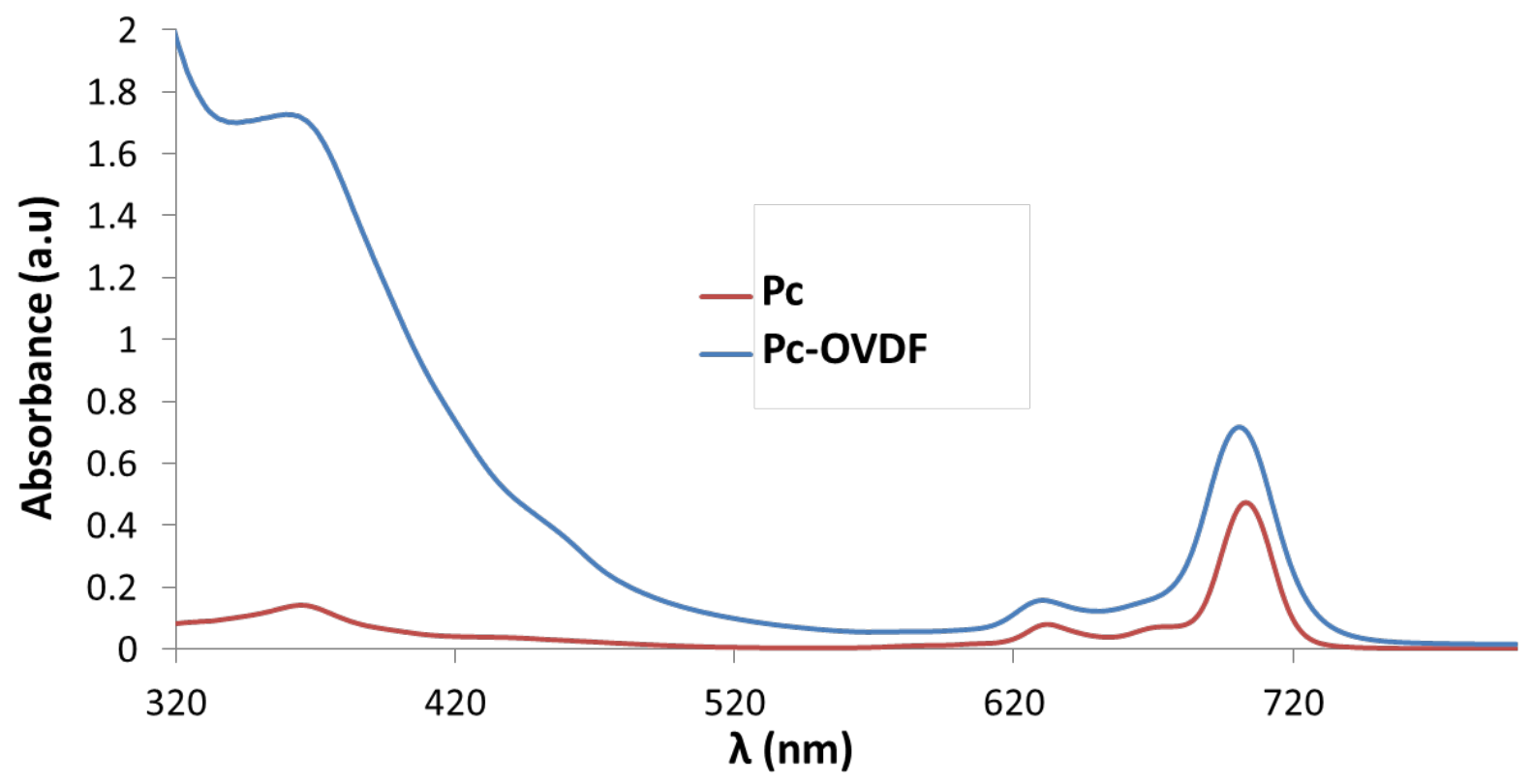

Figure S29. Normalized UV-Vis spectra of Pc and Pc-OVDF in THF at $20{ }^{\circ} \mathrm{C}$. 


\section{Polarization Optical Microscopy (POM)}

a)

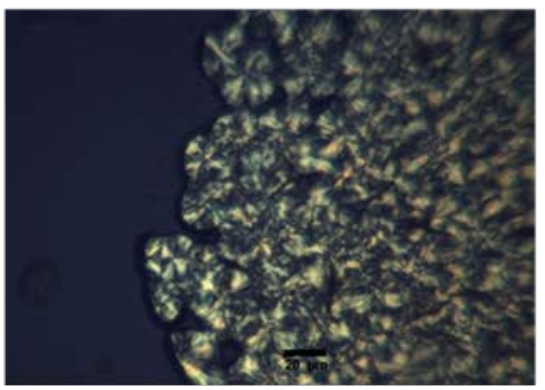

b)

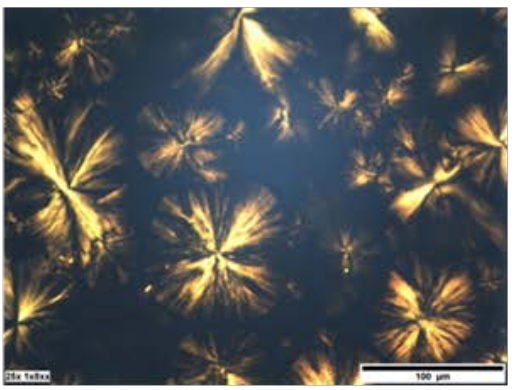

c)

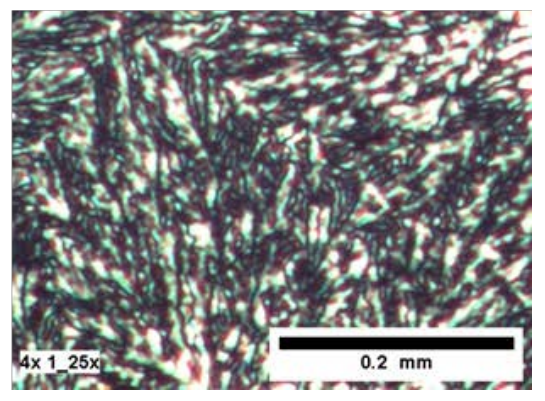

Figure S30. POM micrographs after cooling from the isotropic melt (rate $5{ }^{\circ} \mathrm{C} / \mathrm{min}$ ) of a) BTAOVDF, b) PBI-OVDF, and c) I-OVDF.

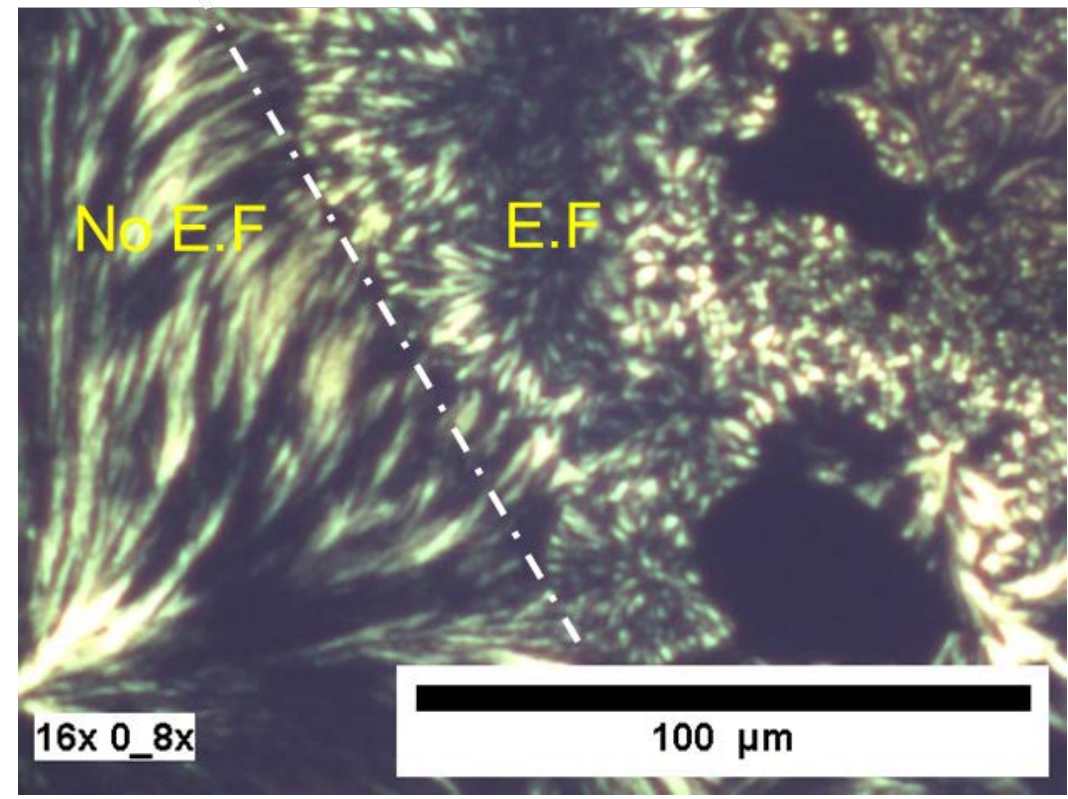

Figure S31. POM micrograph of BTA after applying an electric fied (E.F, $80 \mathrm{~V} / \mu \mathrm{m}$ ) in a liquid crystal cell. The white dashed line indicates the electrode edge. 


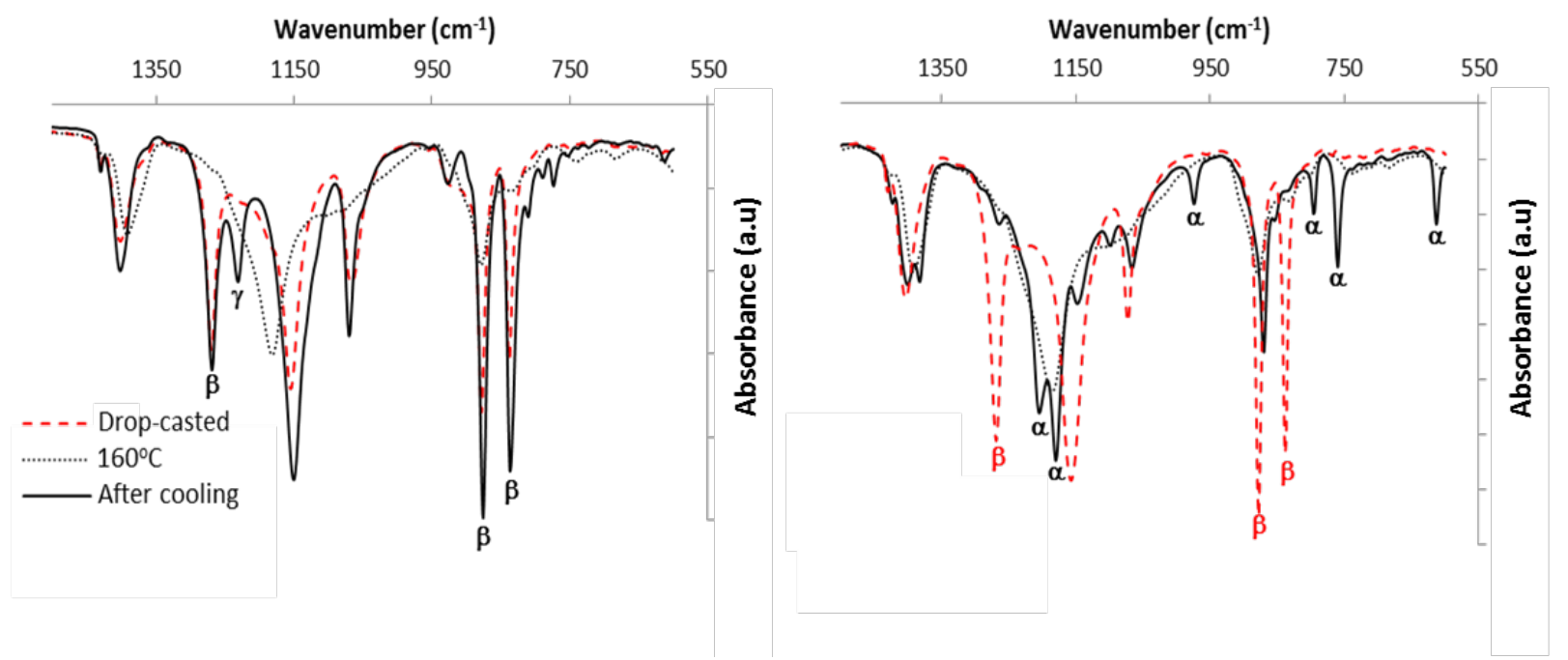

Figure S32. IR spectra I-OVDF (left) and BTA-OVDF (right) at different temperatures.

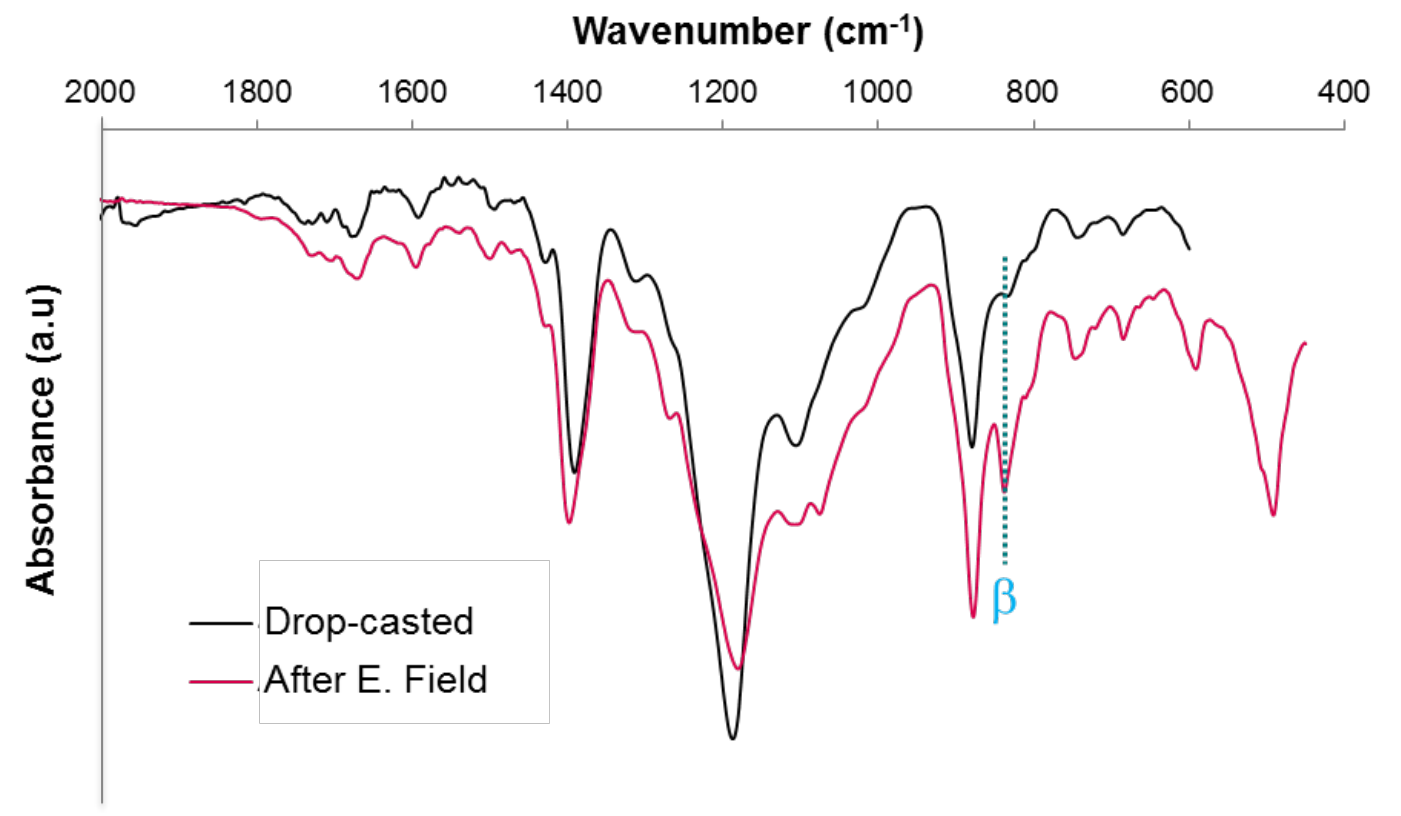

Figure S33. IR spectra of PBI-OVDF before and after applying an electrical field of ( $80 \mathrm{~V} / \mu \mathrm{m})$ in a liquid crystal cell. 


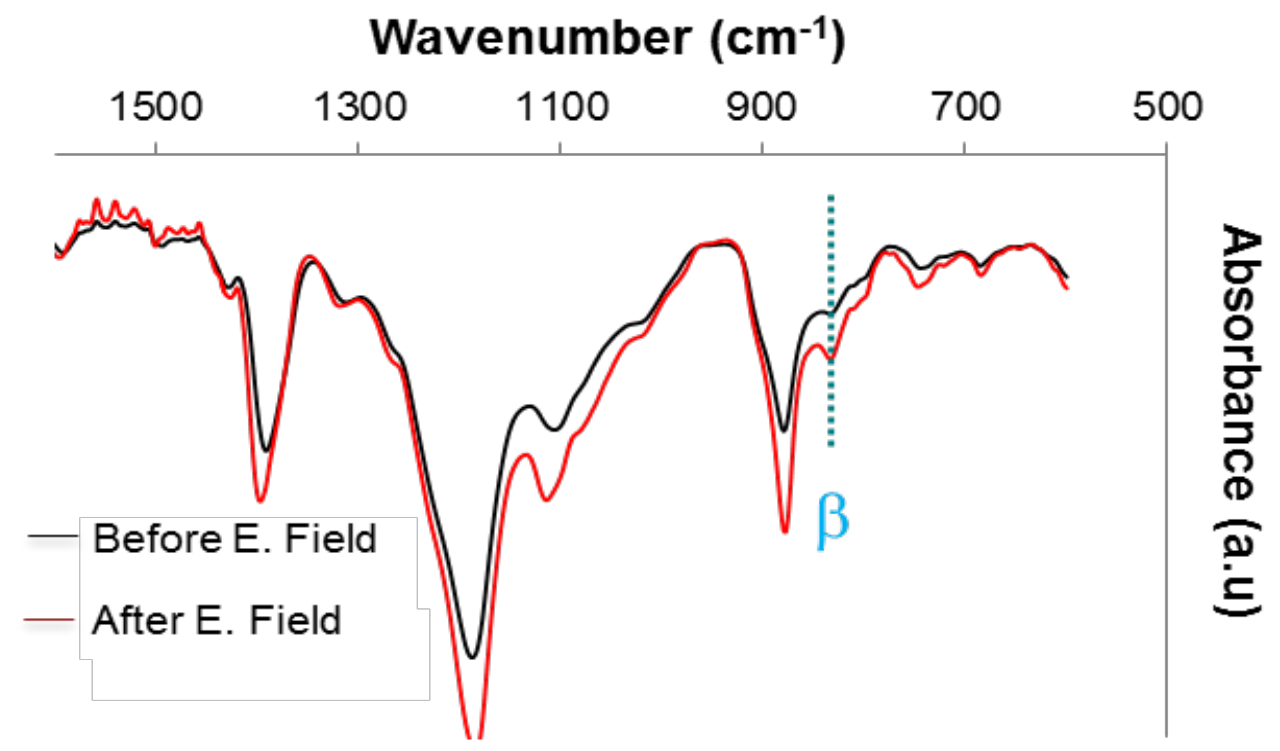

Figure S34. IR spectra of Pc-OVDF before and after applying an electrical field of $(80 \mathrm{~V} / \mu \mathrm{m})$ in a liquid crystal cell.

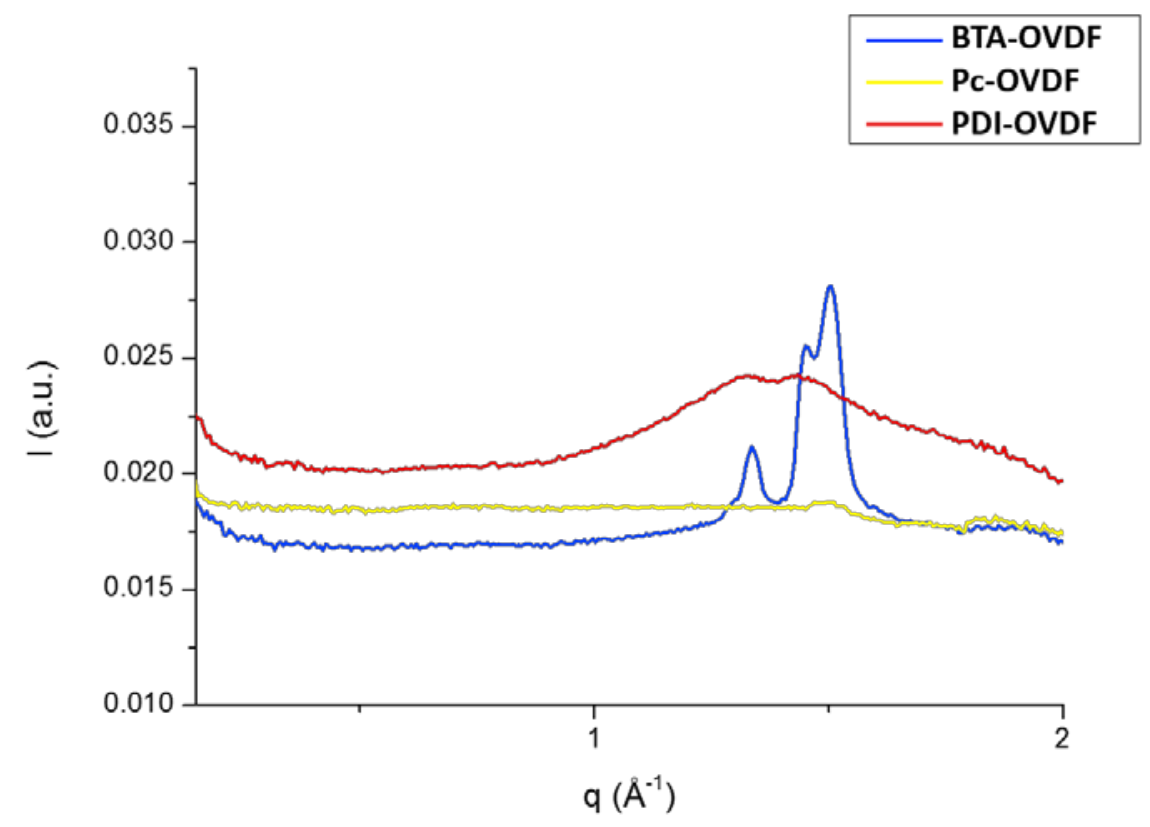

Figure S35. Radially averaged scattering patterns of BTA-OVDF, Pc-OVDF and PDI-OVDF in a capillary. 


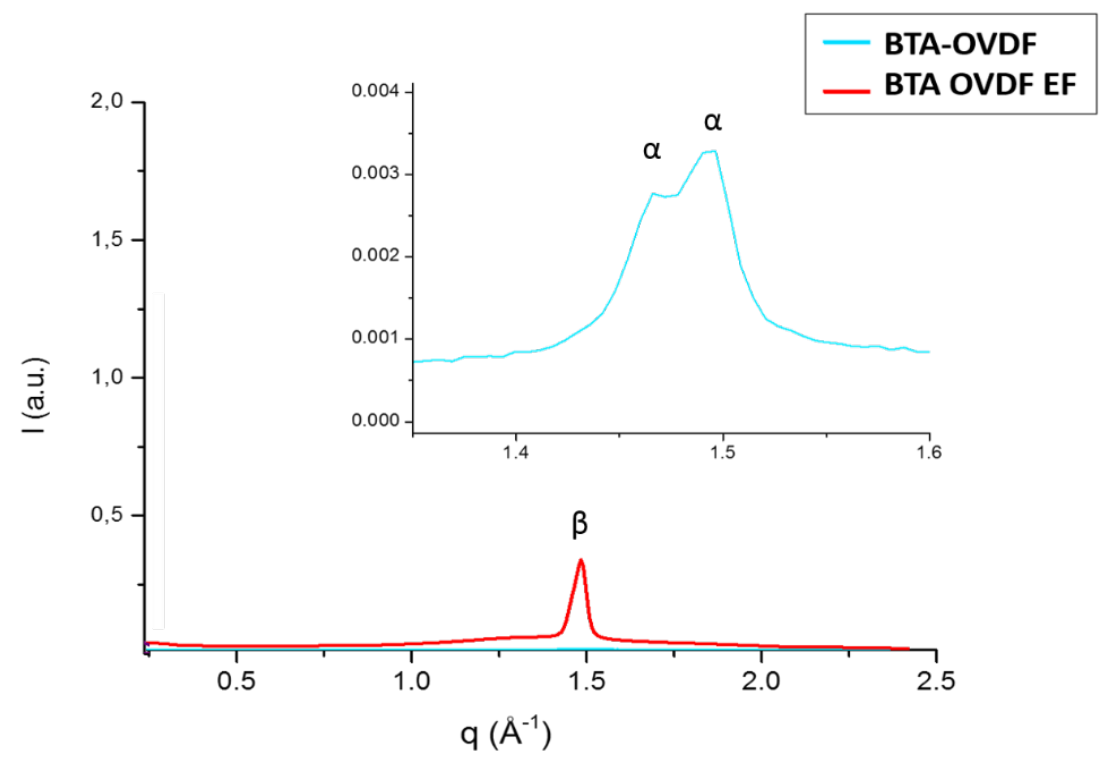

Figure S36. Radially averaged scattering patterns of BTA-OVDF before ( blue) and after applying EF ( $1 \mathrm{KV}$ for $2 \mathrm{~h}$ at $80^{\circ} \mathrm{C}$ ) by corona poling on mica (red). 


\section{References.}

(1) Vukićević, R.; Hierzenberger, P.; Hild, S.; Beuermann, S. J. Polym. Sci. Part A Polym. Chem. 2010, 48, 48474854.

(2) Presolski, S. I.; Hong, V.; Cho, S.-H.; Finn, M. G. J. Am. Chem. Soc. 2010, 132, 14570-14576.

(3) Yanai, N.; Uemura, T.; Uchida, N.; Bracco, S.; Comotti, A.; Sozzani, P.; Kodani, T.; Koh, M.; Kanemura, T.; Kitagawa, S. J. Mater. Chem. 2011, 21, 8021-8025.

(4) Qi, Q.; Shen, Q.; Lu, L. J. Am. Chem. Soc. 2012, 134, 6548-6551. 